\title{
Tama Samoa Stories: Experiences and Perceptions of Identity, Belonging and Future Aspirations at Secondary School
}

By

\section{Fuapepe Rimoni}

\begin{abstract}
A thesis submitted to the Victoria University of Wellington in fulfilment of the requirements for the degree of Doctor of Philosophy
\end{abstract}

Victoria University of Wellington 


\section{ABSTRACT}

This thesis investigates the experiences of twelve strong, articulate and thoughtful tama Samoa (Samoan boys) through their participation in secondary schools and lives outside the classroom and through the stories of others. The study looked at how the students enacted their identities as Samoans, as learners and as young men who are anticipating the future. The study is premised on the view that Pacific identities are fluid, diverse, multi-dimensional and include a range of different perspectives relating to social class, ethnicity, culture and gender. Such a view of identity as complex is not generally taken into consideration in the literature on educational success and achievement of Pacific students in New Zealand.

The study employed a phenomenological qualitative design, using focus groups and semi-structured interviews by talanoa (conversations). As the study involved a group of indigenous tama Samoa, the Samoan fa'afaletui method was used. Participants were a group of twelve tama Samoa in three Wellington secondary schools and their twelve nominated persons.

The study found that there are key aspects to making the experiences of tama Samoa positive and successful within the secondary school. These include acknowledging tama Samoa and their multiple identities while attending secondary school; supporting the development of a sense of belonging through everyday interactions with peers and teachers, and affirming the belief by tama Samoa that secondary school socialisation serves to help them make future decisions.

This study argues that the experiences of tama Samoa are deeply embedded within wider social, economic and political trends. Indeed, their "voices" are shaped in part by these broader forces that construct and represent them as being historically "disadvantaged" and socio-economically "underserved." Further, this study advocates for the diverse voices of tama Samoa, along with 
their experiences, stories, hopes, aspirations and dreams to be brought to light and placed alongside the official accounts of Pacific "disadvantage" to enable more balanced critical discourses taking place

It is hoped that this study will offer further insights into the experiences of tama Samoa in the New Zealand secondary school context, from which valuable knowledge is derived to inform and support schools in improving the New Zealand secondary school experiences of Samoan adolescent boys.

\section{KEYWORDS}

Tama Samoa (Samoan boys'), secondary school, identity, sense of belonging, future aspirations, self-efficacy, adolescent, interpretive paradigm, phenomenology, fa'afaletui framework 
This thesis is dedicated to my dad the late Lake Rimoni who passed away on the 9 December 1999.

When something is not going your way, SMILE and try again tomorrow is another day. 


\title{
ACKNOWLEDGEMENTS
}

\author{
E fa'asaga a'e ou mata i mauga, e oo mai ai lo'u fesoasoani. \\ O lo'u fesoasoani mai le Alii lea o le na faia le lagi atoa ma le lalolagi.
}

I lift my eyes to the hills, where does my help come from? My help comes from the Lord the maker of heaven and earth.

(Psalm 121:1-2)

E muamua ona ou fa'afetai i le Atua ona ole malosi ma le atamai. O le onosa'i ma le loto tele na ia foa'i mai. Ua taunu'u ai le fa'amoemoe. la tumau ia te ia le fa'afetai ma le fa'amanu i aso uma e le aunoa.

This thesis has been completed through the support of many helping hands and minds. I would like to take this opportunity to acknowledge these many hands and minds, because without your giving, I would have not been able to complete this.

To the tama Samoa and their nominated persons, I wish to thank you for accepting the invitation to be part of this thesis. Tama Samoa, you allowed me to share your experiences and perceptions of your daily experiences in secondary school, you have given me a little part of your life and have allowed me to explore your experiences with others. Your openness and humour during our talanoa sessions made the process easy. Fa'amanuia atu le Atua ia te outou uma.

To my supervisors Associate Professor Kabini Sanga and Associate Professor Anne Hynds, I have appreciated your patience, time, and opportunity to be challenged through our talanoa sessions. You have shared with me some of your knowledge and experience and have kept me going through your faith in me. Fa'afetai tele lava. 
To my wonderful colleagues and friends, Dr Joanna Kidman and Dr Cherie Chu. Thank you for being my ongoing supporters since day one. You have both given me your time and honesty every time I came knocking on your doors. Your commitments to excellence has truly inspired me.

To my Te Kura Māori colleagues and friends, $\mathrm{Dr}$ Hiria McRae, Dr Adreanne Ormand, Dr Tabitha McKenzie, and Dr Craig Rofe, Pine Southon and Belinda Cattermole, you were my little bursts of motivation. Thank you for always checking in with me and giving me words of encouragement. It was always appreciated.

I am very grateful to the Faculty of Education of Victoria University of Wellington, for financial and practical support towards completing this research. I am also grateful to the many friends across the Faculty of Education, who always took the time to stop and put a smile on my face.

To the Leadership Pacific Wellington cluster, I have missed seeing your beautiful faces, but have always appreciated our gatherings over food and talanoa. Through Leadership Pacific I have been able to build clarity and understanding of building leadership within our Pacific people, this PhD journey has been part of building and strengthening my own leadership ability. It is also through Leadership Pacific that I have meet special people who became important people in my $\mathrm{PhD}$ journey, Laura thank you for your helping hands and mind, your eye for detail and your patience, I will forever be grateful to you.

To my beautiful church family, members of the Congregational Christian Church of Samoa i Petone. E pele oe i le loto. Viia le Atua, ua tini le fa'amoemoe. Fa'afetai tatalo. Fa'afetai mo le tapuaiga. la maua pea e outou le malosi aua le Atua ma lona galuega. Ma ia iai se aoga o lenei auauna vaivai aua galuega o le Atua $\mathrm{i}$ totonu o le tatou aulotu.

Keige Kuai Kalapu, ladies you have been here since day one, thank you for the energy, thank you for the laughter and thank you for being my super heroes. Our gatherings are always a place for re-energising, revitalising and rejoicing. 
To my families, the Rimoni family and the Time family. How great it is that I have such great aunties, uncles, cousins, nieces and nephews. Family first always, thank you for always being there to support each other and for loving our parents. Thank you for your prayers and your support. I am always recruiting for Victoria University of Wellington. There are opportunities behind every door.

Over the years, there has been many family and many friends that have given me so much support through giving time, financial support, encouragement but most of all keeping me in prayer. Fa'afetai, Fa'afetai, Fa'afetai tele lava.

Finally to my aiga, my late father Lake and my mum Tuipala, brother Pena, sister Valerie, nephew Calvin and nieces L'Oreal and Elizabeth. You are my inspirations. We made it! To my dad, your physical presence on this earth is truly missed, but your spirit continues to live on within us. Thank you for always reminding me about service to others and showing me what hard work is all about. To my mum you always sat quietly and waited patiently, sometimes you worried, and sometimes you questioned, but never did you give up on me. Thank you Mum.

My siblings Val and Pena each one of you has given me something special to keep me going. To Calvin, L'Oreal and Elizabeth through the midst of chaos, you all had a way of keeping me going and have contributed in your own little ways to this thesis.

Forever thankful and grateful I have you all in my life. 


\section{In Memory of...}

My aunty who started this journey with me, but sadly did not see me complete:

Mareta Time Scrimshaw (21 June 2015).

To my darling aunties Elisapeta Rimoni Palu (9 November 2015)

and

Fanny Rimoni Young (4 February 2016)

To our dearest aunty Naomi Stanley Tiatia (29 March 2016)

“What we have once enjoyed deeply we can never lose.

All that we love deeply becomes a part of us."

-Helen Keller

To all the tama Samoa in my aiga 


\section{CONTENTS}

Abstract.

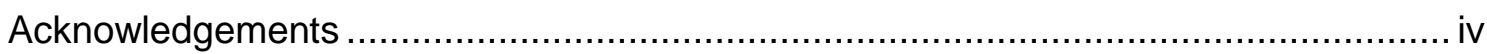

CHAPTER ONE ..........................................................................................

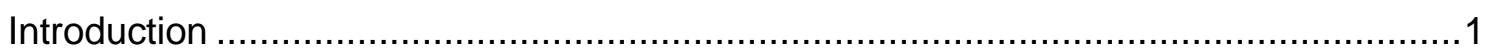

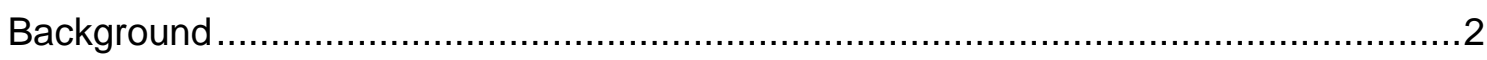

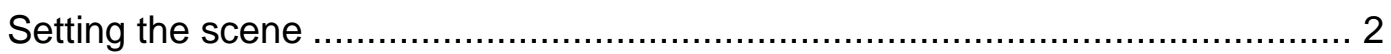

Pacific people in New Zealand .............................................................. 5

Pacific terminology .................................................................................. 7

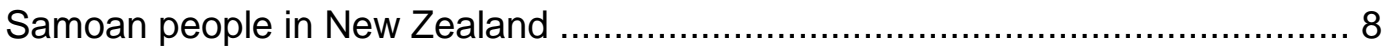

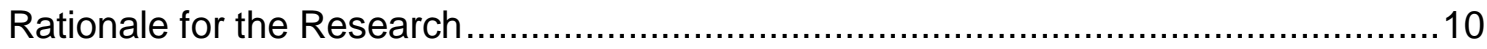

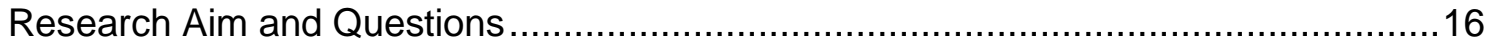

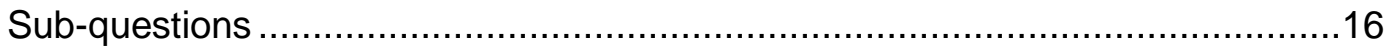

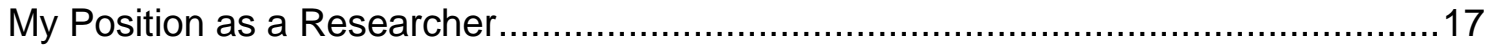

O Le 'Afa Samoa - The Samoan Sennit..................................................................19

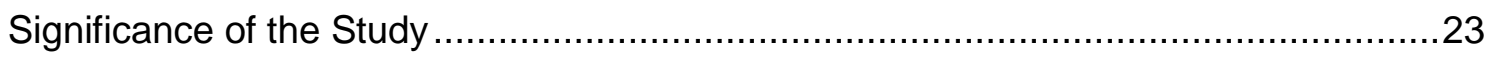

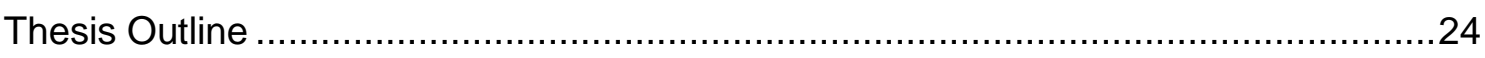

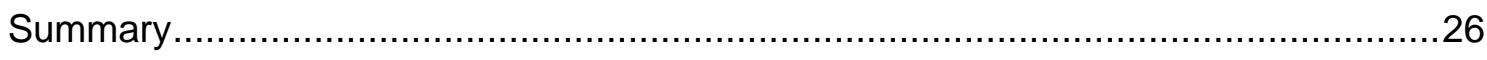

CHAPTER TWO: LITERATURE REVIEW: IDENTITY, BELONGING, AND SELF-EFFICACY .....................................................................................27

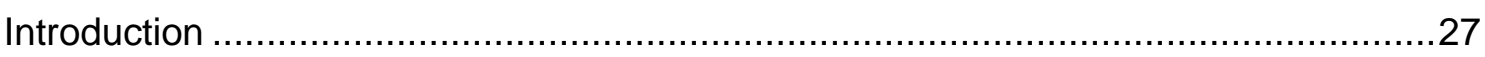

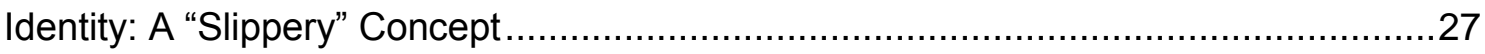

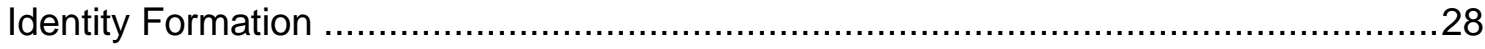

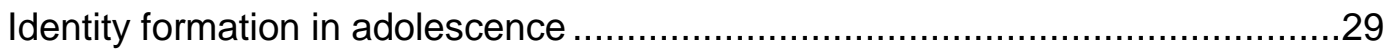

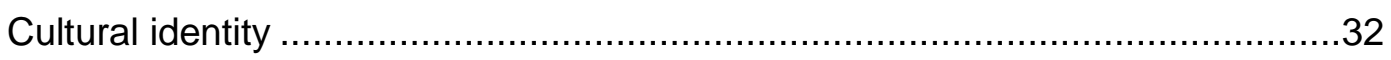

Pacific perspectives on identity formation .............................................. 35

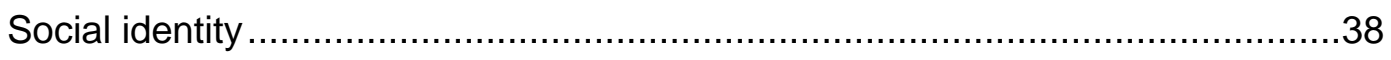

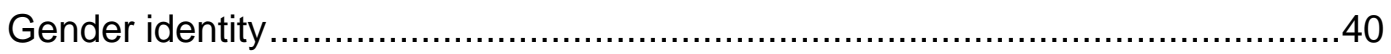

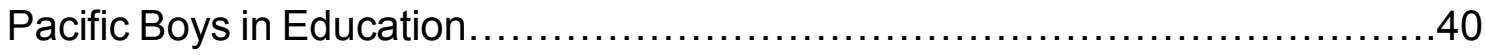

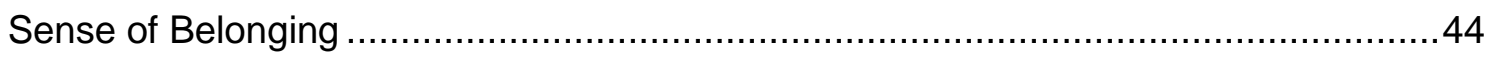

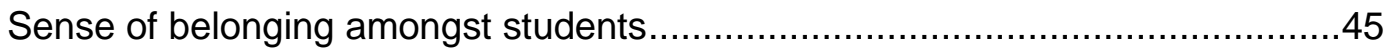

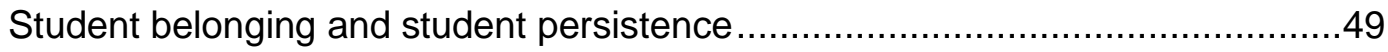

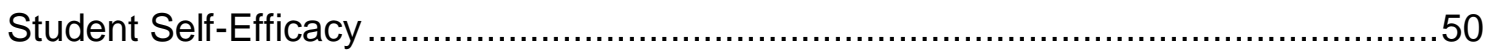

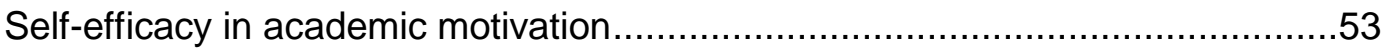


CHAPTER THREE: METHODOLOGY ........................................................55

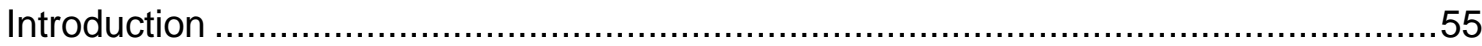

PART ONE: The Role of Theory in Educational Research .......................................56

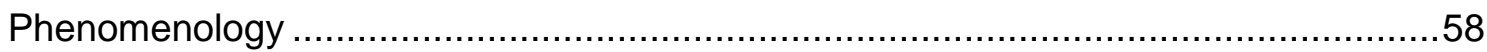

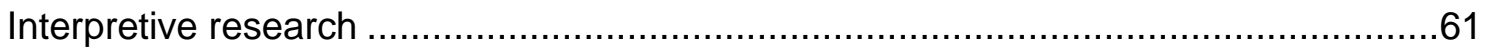

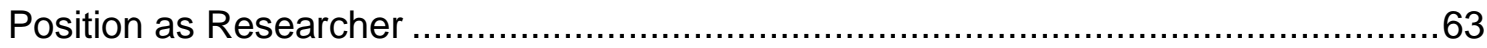

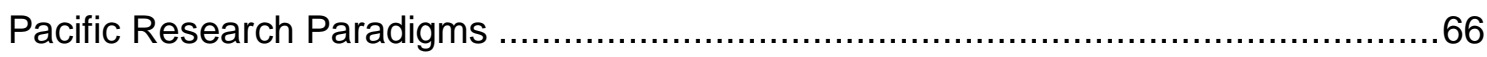

Fa'afaletui Framework ................................................................................ 71

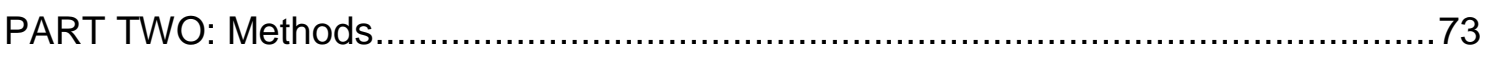

School selection and participant recruitment ...........................................73

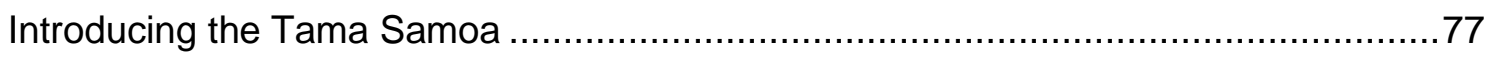

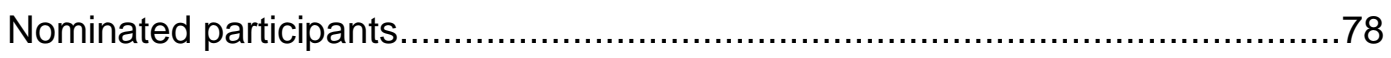

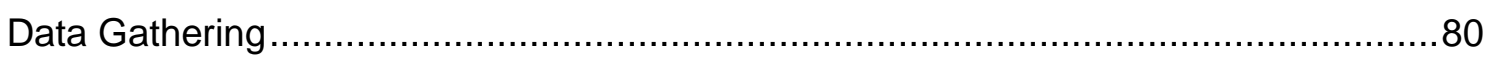

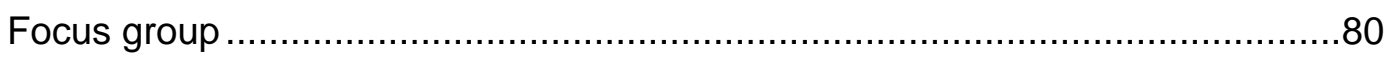

Semi-structured one on one talanoa ............................................................. 81

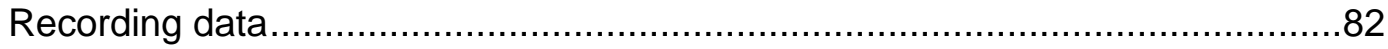

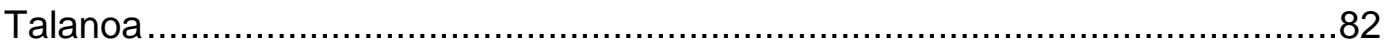

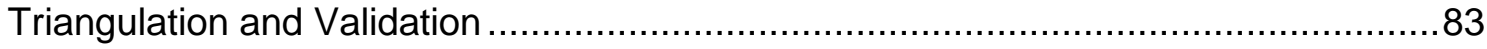

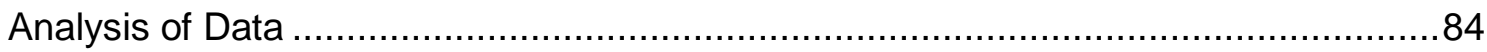

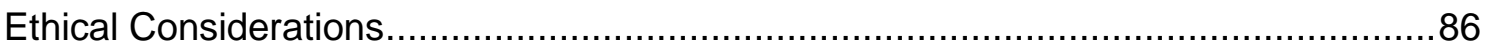

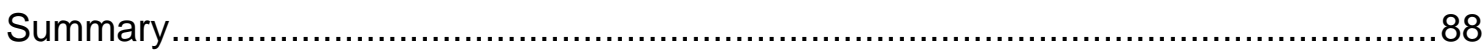

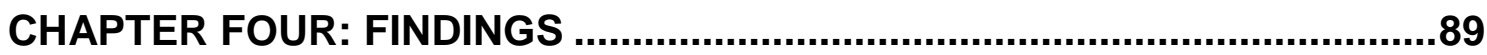

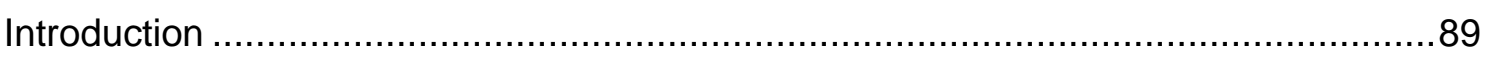

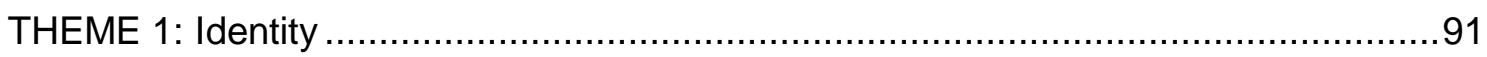

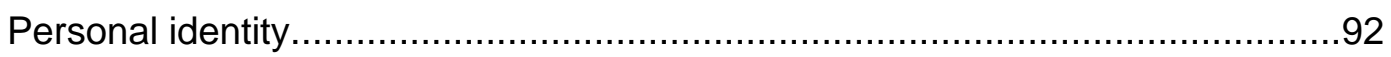

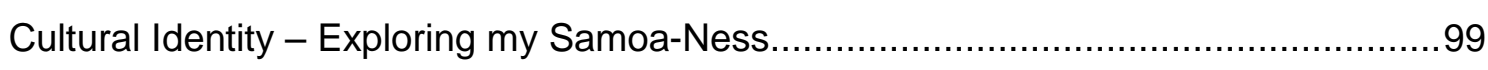

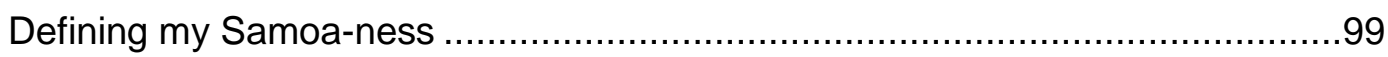

Characteristics of being Samoan ............................................................... 102

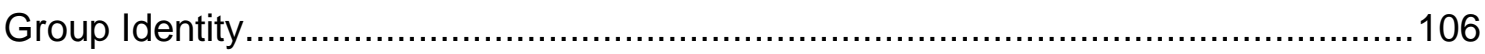

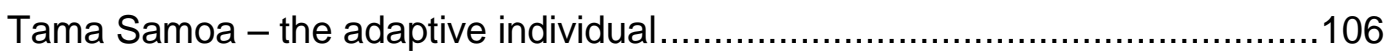

Tama Samoa - adapting roles and responsibilities .....................................109

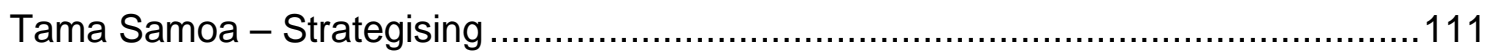

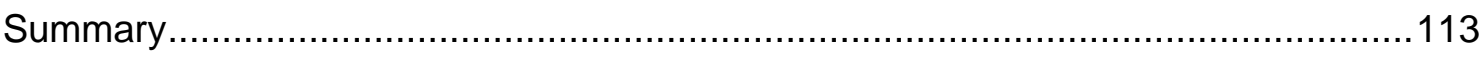




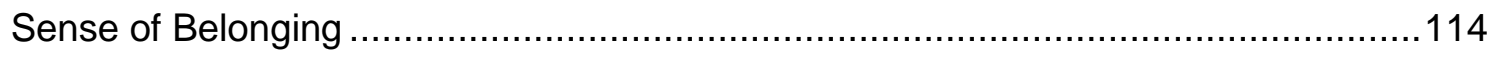

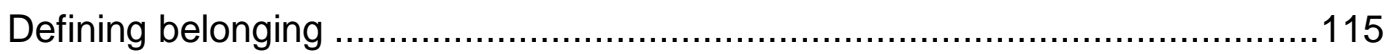

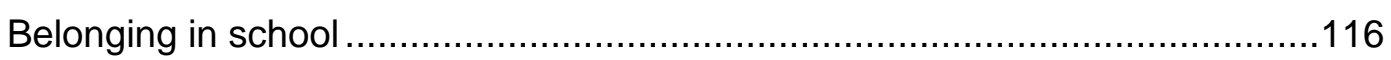

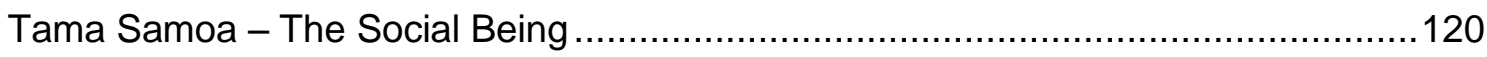

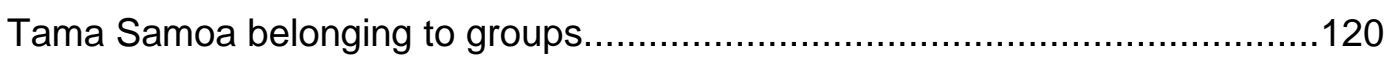

Loyalty from a tama Samoa perspective.....................................................124

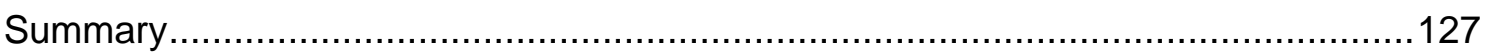

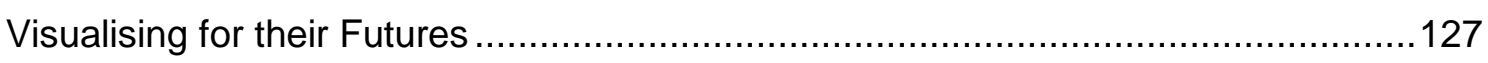

Tama Samoa expectations of their secondary schools .................................128

Perceptions on the purpose of academic learning .........................................131

Tama Samoa - Aspirations for the future ...................................................134

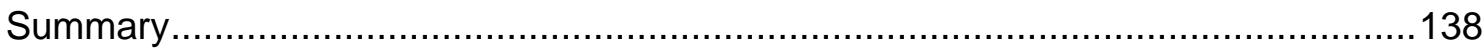

CHAPTER FIVE: DISCUSSION

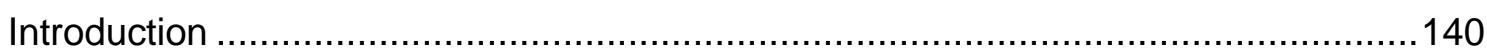

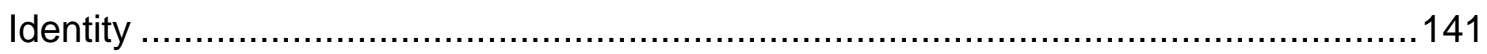

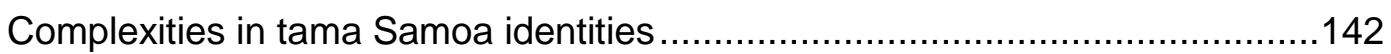

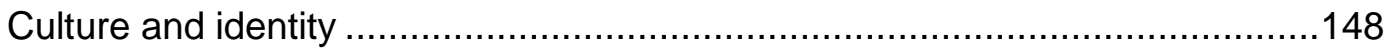

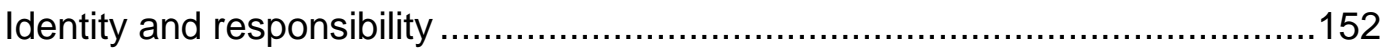

Identity as a tool for survival ...................................................................154

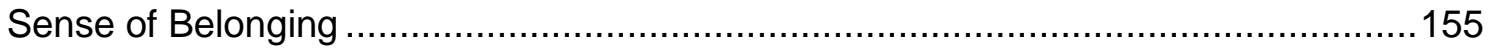

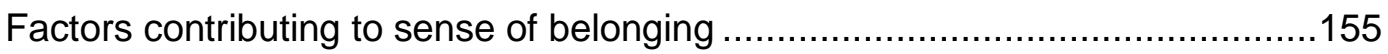

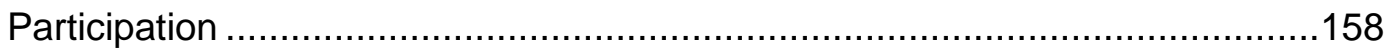

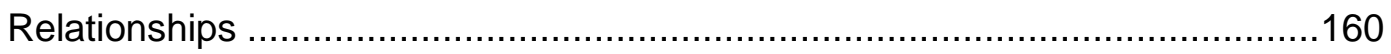

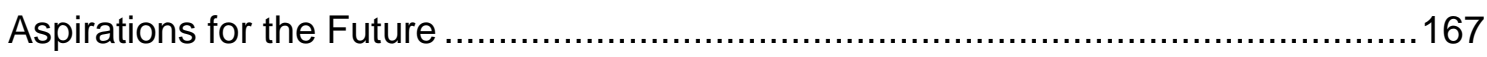

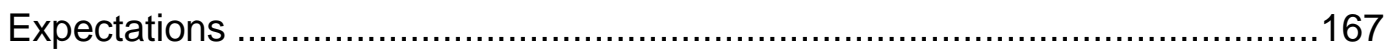

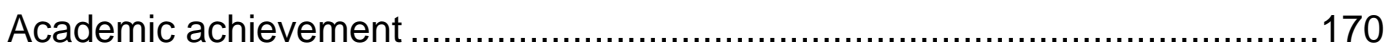

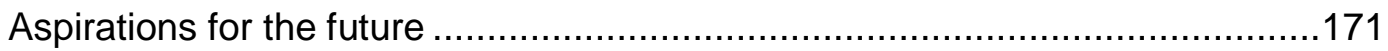

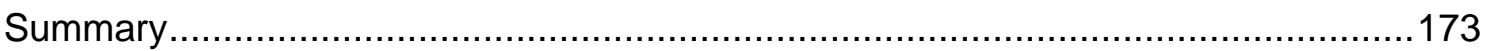

CHAPTER SIX: REVIEW OF RESEARCH QUESTION ...............................175

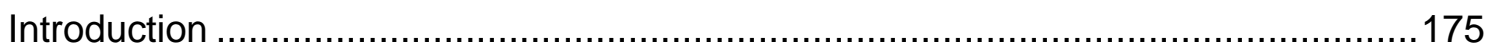

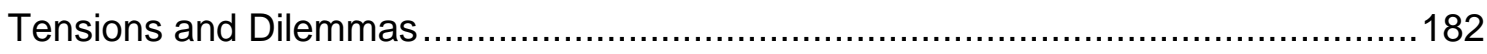

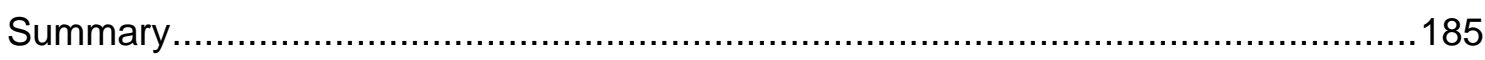




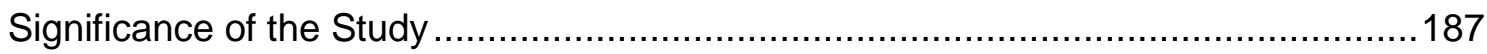

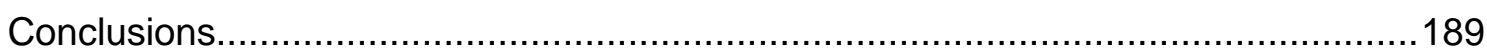

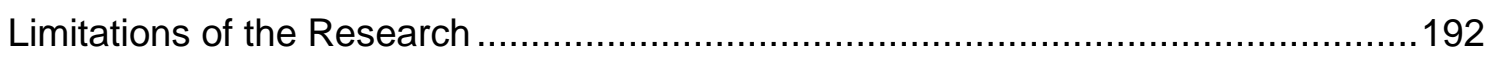

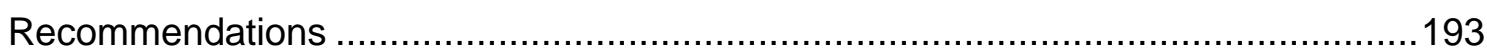

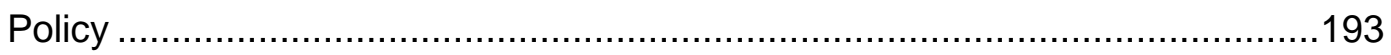

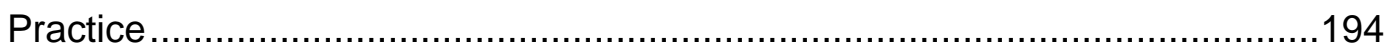

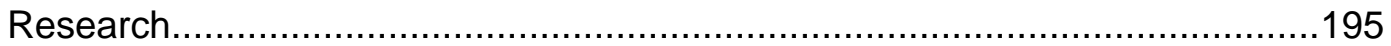

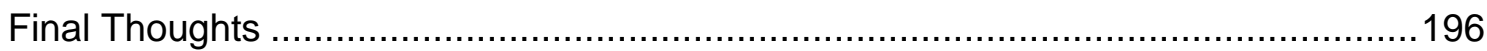

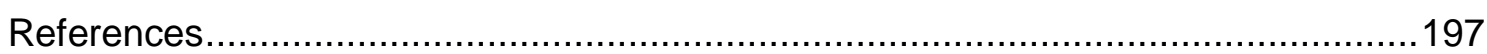

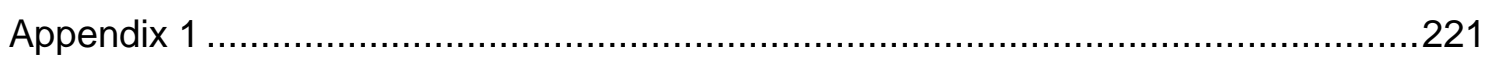

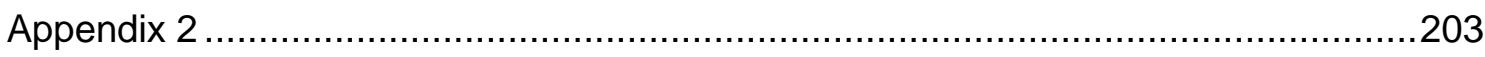

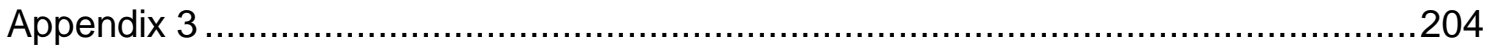

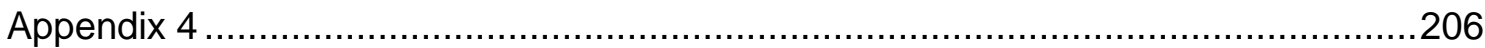

\section{LIST OF TABLES}

Table 1: The steady rises in early childhood participation between 2000 and 2013...... 4

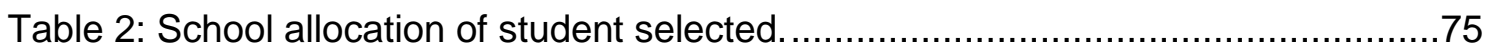

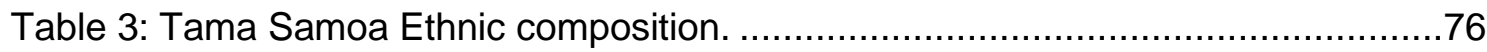

Table 4: Relationship of tama Samoa to their nominated person.................................79

Table 5: Overview of focus group and semi-structured interviews. ..............................84

Table 6: Roles taken by tama Samoa in secondary school.......................................109

Table 7: Tama Samoa sense of belonging at school. ............................................117

Table 8: Tama Samoa group/clubs involvement....................................................122

Table 9: Adapted from Furrer, Skinner and Pitzer (2014): Self system model of development. 


\title{
CHAPTER ONE
}

\author{
Saili le Niu'afa
}

(Choosing the Niu)

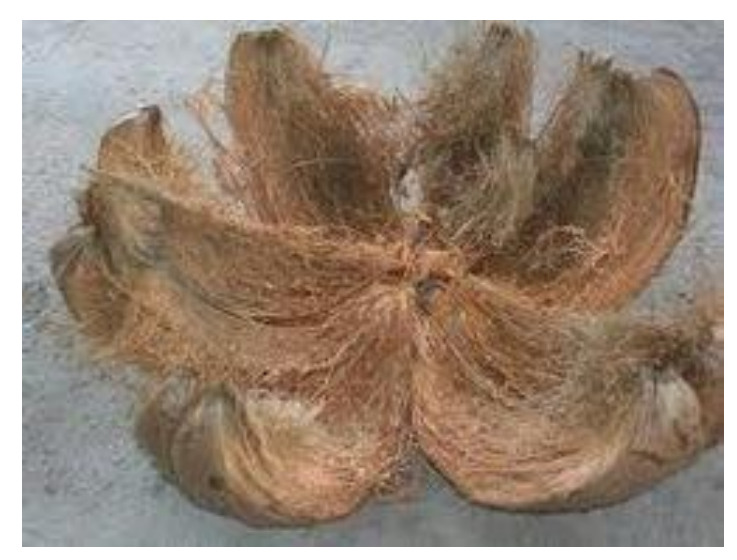

\section{INTRODUCTION}

This thesis presents the experiences of twelve strong, articulate, and thoughtful tama Samoa (Samoan boys) as they talk about secondary school. It looks at how they enact their identities as Samoans, as learners, and as young men who are looking towards their respective futures and it explores the things that matter most to them as they navigate a range of choices and possibilities in their everyday lives. The tama Samoa experiences are supplemented by the stories and narratives of the people who are closest to them, providing insights into what it is like to be a young tama Samoa growing up and going to school in New Zealand in the early twenty-first century.

In this chapter, the thesis study is introduced. I explain how I came to select the topic and the importance of this topic within the New Zealand educational context. An overview of the background for this topic is presented as following: a) the New Zealand education system structure; b) the Pacific population in New Zealand with specific focus on the Samoan population; c) the outcomes for tama Samoa in the New Zealand education system. I then provide a rationale for why I have chosen this topic for study. An outline of the research aims, research 
questions, and research context is also provided. In addition to this, I introduce myself as a researcher because if you, the reader, are to understand how this thesis came into being, you need to know something about who I am, what my background is, how I conducted this project, and why I believe that research of this nature is important.

To this end, I discuss my position as a researcher and also, importantly, I link this discussion to my own Samoan heritage using the metaphor of the 'afa (coconut sennit). The 'afa metaphor process is visible through each chapter heading. A further discussion of the 'afa metaphor will be discussed later in this chapter.

The chapter concludes with an outline of the rest of the thesis.

\section{BACKGROUND}

\section{Setting the scene}

New Zealand, Aotearoa is situated in the South Pacific. It has a current population of 4,587,510 (New Zealand, 2015). To assist the reader to understand the experiences tama Samoa have in the New Zealand education system, it is important that I discuss the nature of how the New Zealand education system works and how it works.

As identified by the New Zealand Ministry of Education:

New Zealand's education system is "world-class, modern and responsive." It combines proven, traditional principles with innovation, creativity and fresh thinking to produce leaders and citizens equipped for the 21 st century. (Ministry of Education, 2015)

Within the New Zealand education system, policy documents identify the ideal pedagogy as being student-centred; the learning and teaching that takes place within a school setting is to support and provide students with the skills to tackle problem solving, process information, and to work alongside others as well as build creative and innovative skills and ideas within their own development (Ministry of Education, 2015). 
New Zealand's education system comprises thirteen levels (Years 1 to 13) of primary and secondary schooling. It is compulsory to attend school for at least twelve years from ages five to sixteen. While it is possible for some students to opt to leave at an earlier age and attend alternative education, others will continue their education to level thirteen. Both single-sex and co-educational schooling is available through state schools (government owned and funded) and private schools, so providing families with some choice about which type of school to attend. As identified by the New Zealand Ministry of Education (2015), 85\% of school aged children attend state schools. $11 \%$ attend state-integrated schools. A state-integrated school is a former private school which has integrated into the state education system: an example of state-integrated schools are the church schools such as Catholic schools, which continue to have their own special character with funding support from the government (O'Donnell, 2001). A further $4 \%$ of students attend boarding schools. In 2014, the New Zealand education system added another type of schooling structure, Charter schools. The purpose for this school structure, according to the Ministry of Education (2015), was to provide a new type of school that integrates business sector and community groups to provide new opportunities for students to achieve educational success.

There are three main sectors in the New Zealand education system: the early childhood education (ECE) sector, the compulsory sector (primary and secondary schools), and the tertiary sector.

The early childhood sector provides education and care for children under the age of five. Although it is not compulsory for parents to put their children in an early childhood centre, most families do take the opportunity to do this.

Table 1 shows the steady rises in early childhood participation between 2000 and 2013. 
Table 1: The steady rises in early childhood participation between 2000 and 2013.

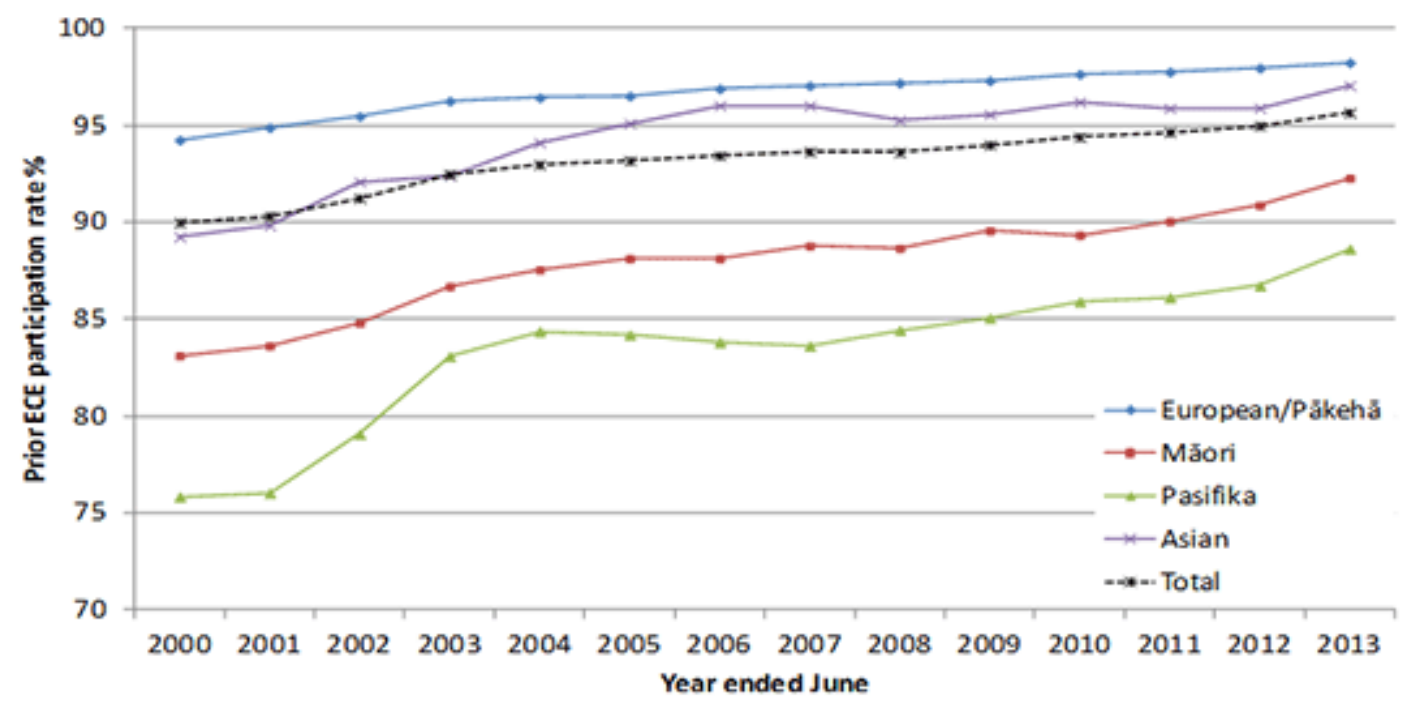

(Scott, 2014)

Under the umbrella of early childhood education, there is a range of options for families to choose from including in-home care, kindergarten, language nests and kohanga reo (Māori language centre).

Although combined into a single sector, primary and secondary schools have two different structures and systems in place. At the primary level children begin Year 1 at the age of five or sometimes six, and continue until they reach Year 8 (at twelve or thirteen years of age). They usually have a single teacher who teaches all subjects each year. Students attend secondary school - which may also be known as high school or college - from Year 9 until Year 13. The secondary school system is organised by timetable around subjects with specialist "subject area" teachers and as students get older guidance is also provided for professional career advice.

The New Zealand education system uses a National Curriculum which applies to all state primary and secondary schools. The curriculum covers Year 1 to Year 13, and identifies eight essential learning areas: English, Science, Mathematics, the Arts, Health and Physical Education, Social Sciences, Languages, and Technology. Schools can personalise or adapt their teaching to suit the learning needs of their students 
Within the secondary level, from Years 11 to 13 the focus is on students achieving the National Certificate of Educational Achievement (NCEA). The NCEA is the official secondary school qualification in New Zealand. NCEA is a recognised qualification throughout New Zealand and internationally. NCEA consists of three levels and students generally complete course modules related to these levels in their last three years of secondary school education (New Zealand Education, 2015). NCEA challenges students of all abilities in all learning areas, and shows credits and grades for separate skills and knowledge. It enables students to gain credits both from traditional school curriculum areas and from alternative programmes. (Ministry of Education, 2015).

Tertiary education is the final of the three education sectors. Education after secondary school is not limited to universities and institutes of technology or polytechnics. There is a wide range of opportunities that include tertiary study, vocational training, apprenticeships, and on-the-job training. While some tertiary programmes are "open entry", to gain entrance to enter into other institutions for example, the universities - students must have completed certain criteria, such as credits from secondary school subjects like Mathematics and English. In alignment with NCEA, students must also have a number of credits for university entrance.

This brief overview of the New Zealand education system is intended to provide the reader with an understanding of how New Zealand schools operate. The focus now moves to Pacific people and their educational journey within the New Zealand context.

\section{Pacific people in New Zealand}

There are more than 300,000 people of Pacific heritage living in New Zealand (Tukuitonga, 2013). The Pacific population in New Zealand includes people of Pacific descent who were born in New Zealand as well as people born in the Pacific Islands who migrated to New Zealand. The majority of the New Zealand Pacific population includes people of Samoan, Cook Island Māori, Tongan, 
Niuean, Fijian, and Tokelauan ethnicities. Samoa is the largest Pacific ethnicity and Tongan is the fastest growing ethnicity within New Zealand (Anae, 2010, p. 6).

There is also a small but growing number of people from other countries of the Pacific migrating to New Zealand.

The Pacific population in New Zealand grew rapidly during the 1950s through to the 1970 s as a result of work related migration. The Pacific population is currently among the fastest growing groups in New Zealand, but most of the recent growth is due to births in New Zealand, rather than due to migration (Tukuitonga, 2013). As identified by Tukuitonga (2013), two thirds of the Pacific population is now born in New Zealand and approximately one quarter of all births in Auckland claims a Pacific heritage. As identified by the Ministry of Pacific peoples, by 2026 it is projected that Pacific people will be $10 \%$ of the population compared to $7.4 \%$ in 2013. It was also noted by Anae, (2010) that the Pacific was the fourth largest major ethnic grouping in 2013, behind European, Māori, and Asian. In 2013 7.4\% of New Zealand's population identified with one or more Pacific ethnic groups (Statistics New Zealand, 2013). New Zealand's Pacific population aged 15 to 39 years is expected to reach $12 \%$ by 2026 (Anae, 2010).

The rapid growth of the Pacific population in New Zealand over the years has contributed many positive influences to building a multicultural New Zealand (Fresno-Calleja, 2016). However, it is also important to note the many challenges that have been highlighted for Pacific people within the educational setting. Fairbairn-Dunlop and Makisi (2003) point out that the educational achievement of Pacific students in New Zealand is similarly concerning. According to the Fairbairn-Dunlop and Makisi (2003);

Pacific peoples have been migrating to New Zealand for over a hundred years in search of education "for a better life" but this is not happening Pacific high rates of educational participation are not matched by robust educational outcomes. Significant numbers of Pacific students are leaving secondary school with minimal qualifications and a small number (one in three) gain university entrance standard. This is serious given that 
secondary school outcomes widen choices and set the foundation for lifelong learning, employment opportunities, and access to further study (p. 875).

According to the Pasifika Monitoring Educational Report (2013):

Pasifika people have multiple world views and diverse cultural identities. They are able to operate and negotiate successfully through spiritual, social, political, cultural and economic worlds. Success in education requires harnessing Pasifika diversity within an enabling education system that works for young people, their families and communities. This requires the education system, leadership and curricula to start with the Pasifika learner at the centre, drawing on strong cultures, identities and languages. (p. 5)

As highlighted from the above quotes, it is therefore timely that this thesis is significant in capturing tama Samoa voices, as it contributes to the strong Pacific identity that continues to grow within New Zealand context. There is also an opportunity to focus on a group of young Pacific students, who will be the face of New Zealand's future. Fairbairn-Dunlop (2013) stated that enhancing Pacific educational experiences and outcomes has urgency not only for the quality of life of Pacific families, but also in terms of New Zealand's goals of equity and aspirations as a culturally diverse nation. Adding complexity to this task is that the Pacific population is rapidly increasing ( $7 \%$ of New Zealand's total population and projected to increase to $9 \%$ by 2012), youthful (38\% under 15 years), and diverse (p. 875).

\section{Pacific terminology}

Throughout this thesis I use the term "Pacific" to describe aspects of the identities of the tama Samoa in this project. The Ministry of Education (2012, p. 12) has defined the terminology about Pacific peoples as follows:

Pasifika or Pacific (people) are collective terms used throughout this document to refer to people of Melanesian, Micronesian, and Polynesian descent or heritage or ancestry who have migrated to or have been born 
in Aotearoa New Zealand. The term Pasifika includes recent migrants or New Zealand-born Pasifika people of single or mixed heritage. While identifying themselves as Pasifika, this group may also identify with their ethnic-specific Pacific homeland. Pasifika people are not homogenous and Pasifika or Pacific does not refer to a single ethnicity, nationality, gender, language, or culture.

Furthermore, Teaiwa and Mallon (2005) note that the term Pacific people is used in New Zealand synonymously with "Pacific Nations people, tangata Pasifika, tagata Pesefika, Pasefika people and Pacific Islanders" (p. 208). In all cases this represents a "lumping together" that obscures diversity. Teaiwa and Mallon also identify a crucial point of difference between the various groups coming from the Pacific Islands to New Zealand originates from the special historical and constitutional relationships that exist between the Pacific countries and New Zealand as current administrative power over Tokelau, and as former colonial administrator for Samoa, Cook Islands and Niue (p. 208).

In New Zealand, the term Pacific is often used as a "one size fits all" label intended to represent all Pacific peoples. It is important to recognise, however, that not only does each Pacific country have its own cultural understandings, its own cultural knowledge and systems of belief, but within each Pacific Nation there is also a diverse mix of cultural practices and understandings (Wendt-Samu, 2006).

\section{Samoan people in New Zealand}

Like people from other Pacific nations, Samoan people have been migrating to New Zealand since the 1950s (Sauni, 2011), and, also like other Pacific Nations, Samoan people come to New Zealand in search of better opportunities for employment and education. However, as pointed out by Sauni (2011), education for Samoans living in New Zealand has not been easy; there continues to be a struggle to succeed in New Zealand in a competitive, multicultural, and capitalist society. 
According to the 2013 New Zealand census, Samoan New Zealanders comprised 144,138 people, or 3.6 percent of people who identified as an ethnic group living in New Zealand (Statistics New Zealand, 2013). It is predicted that by 2020 a possible $25 \%$ of the eligible workforce in New Zealand will be made up of Samoan people (Sutton, Arini, \& Panara, 2011). It is, vital that Samoan people who have established themselves in New Zealand are enabled to achieve and do well in learning environments and within the New Zealand education system.

Like other Pacific cultures, Samoa has its own central elements in the Samoan culture which includes; aiga (family), giving and receiving, tautua (service), fa'aaloalo (respect), and alofa (love). These are some of the crucial values that are highlighted in Samoan social relations, although many Samoan families have adopted both a Samoan way of life with a New Zealand way of life. Young people are still expected to serve and show respect to elders, and can expect to receive love, protection, honour, a name to be proud of, and to be defended by the family when it is needed.

However as identified by Melani Anae (1997), many younger Samoans have difficulty accepting tautua (service) and fa'aaloalo (respect), and the unquestioning obedience required of children. On the other hand, older members appreciate these concepts because they are now receiving tautua and fa'aaloalo from their children and extended family.

In recognising the diversity of peoples, ethnicities, and nations that make up "Pacific", this thesis acknowledges the importance of identifying the particular Pacific group that is focused on in this research - namely, tama Samoa. The tama Samoa involved with this study are a group of boys that identify themselves in relation to their Samoan ethnicity: the centrality and importance of their Samoan heritage is the common thread that carries across my research conversations with these tama Samoa. Throughout this research, however, their experiences and their voices are seen as uniquely theirs.

The tama Samoa who participated in this research are all New Zealand-born. This was not a decision I made consciously when selecting the tama Samoa for this research and only became evident when tama Samoa gave consent to 
participate in the research and their country of birth was noted. In reflecting back to when these initial decisions were made I realise it had not occurred to me that if the tama Samoa had different countries of birth this may have made a difference to the research. There is no doubt now in my mind that the experiences of tama Samoa born in Samoa would have provided another perspective to this research: however, this was not the case and although the twelve tama Samoa are all New Zealand-born, they are also individuals with their own distinct stories and aspirations.

Thus, while there were striking similarities in their experiences of school, each tama Samoa is represented in this research as an individual.

\section{RATIONALE FOR THE RESEARCH}

Earl (2004) argues that the marginality of minority ethnic groups often coincides with a relatively marginal economic position. He explains that in the past Pacific peoples have generally been employed in unskilled manufacturing and service work. The contraction of the manufacturing sector during the 1980s has been a major factor in contributing to the extremely high unemployment rates for Pacific peoples. After the initial inflow, Pacific migration to New Zealand declined substantially in the mid-1970s. This decrease continued in the following decade due to the economic recession and to changes and restrictions in official immigration policies which, from the late 1980s, began to priorities skilled or more affluent migrants from other countries.

As Anae (2012) highlights Pacific migrants in this period experienced "disproportionate poverty and contesting representations of diasporic Pacific identities and unemployment rates, received substandard education and health care and were exploited by unscrupulous landlords".

While the New Zealand education system is effective for large numbers of students, some groups are failing. One group that is over-represented in school underachievement statistics is Pacific students (Shortcliff, 2014). Since the late 1990's, educational research that has included a focus on Pacific learners in the compulsory sector has been dominated by large, comprehensive Ministry of 
Education and development projects. Examples of this are the Strengthening Education projects for the areas of Mangere and Otara (SEMO) in Auckland. The SEMO initiative purpose was to use resources and support networks to change the mindset of classroom teachers in low decile schools within the Auckland area. Auckland city is the home to the largest Pacific population in New Zealand. The SEMO intervention team evolved through two phases. In the first, the two communities and the schools were consulted about the causes of low student achievement. This phase resulted in the formulation of a generic project that provided the framework for each school to apply for additional funding to improve its students' literacy levels. In the second, the schools submitted individual project proposals, obtained the funding and implemented their self-identified projects Timperley, \& Robinson (2001). The Improving Achievement in Multicultural High Schools (AIMHI) (1996); has continued to be an updated project since it began in the mid-1990s. The AIMHI project involved three individual projects, which focused, in some way, on the teaching/learning processes involving Māori and Pacific lower students in different parts of North Island region in New Zealand. There were also research initiatives such as the Best Evidence Synthesis (BES), just one example of the intensity and scale of research activity funded and driven by the Ministry of Education in New Zealand (2003).

Over the years reports from the Organisation for Economic Co-operation and Development (OECD) have made reference to a "long tail" of underachievement by Pacific students as compared with majority culture New Zealanders (OECD, 2001, 2002). The research shows that Pacific students tend to be marginalised in New Zealand classrooms; for example, they have the highest stand-down and suspension rates and are over-represented in low rates of literacy and numeracy regardless of schools' decile ratings (Alton-Lee, 2003; Bishop, Berryman, Tiakiwai, Richardson, 2003; Hattie, 2003; OECD, 2001; Timperley, 2007). In particular, one group that is consistently identified as educationally underachieving is Pacific boys enrolled in mainstream secondary schools (Harkness, Murray, Parkin, \& Dalgety, 2005).

In April 2000 the New Zealand Government focused on a number of initiatives and programmes with the goal of addressing Pacific student needs. It was at this stage the New Zealand Government developed a strategy policy document, the 
"Pasifika Education Plan", for early childhood centres and schools to support the needs of Pacific students in New Zealand (Anae et al., 2001; Hunkin-Tuiletufuga, 2001; Ministry of Education, 2000). The goal of this document was to close the gap between Pacific students and non-Pacific students within 20 years (Ministry of Education, 2002).

One key goal within the current Pasifika Education plan 2013-2017, is for the compulsory schooling sector to establish stronger connections between home and school for Pacific learners. If such connections are to be effectively made, the influence of social and cultural factors on students' learning and achievement needs to be identified and valued within their school environments as well as by classroom teachers (Anae et al., 2001).

Yet what is known about these tama Samoa? What is known about the living, breathing, vibrant tama Samoa who make up the statistics on Pacific educational failure? What is known about the complex, nuanced, and finely calibrated identities that sit beneath the bleak figures and graphs about educational underachievement? (Fergusson, Gorinksi, Wendt-Samu, Mara, 2008; Gorinksi \& Fraser, 2006; Hawk \& Hill, 1998).

As highlighted by Fergusson, Gorinksi, Wendt-Samu and Mara (2008), Pacific identities are fluid, diverse, and multi-dimensional and include a range of different perspectives relating to social class, ethnicity, culture, and gender. These distinctions, however, are not generally taken into consideration in relation to the statistics on educational "success" and achievement. It is argued in this thesis that the experiences of these students are deeply embedded within wider social, economic, and political trends; indeed their "voices" are shaped in part by these broader forces that construct and represent them as being historically "disadvantaged" and "underserved" socio-economically. Throughout this study, therefore, I argue that the diverse voices of tama Samoa, along with their experiences, stories, hopes, and aspirations.

Boys' underachievement, as compared to that of girls', appears to be of national concern (Irwin, 2007). Alton-Lee and Praat (1999), published a report on boys' achievement that discusses an integration of issues that influence male student 
achievement in secondary schools. These issues include boys' participation, engagement. This report identified that boys generally tend to have a wider spread of academic scores than girls. Consequently, boys tend to be overrepresented in the lowest achieving group, and this is particularly true for Māori and Pacific male students. The report emphasises that gender differences in achievement patterns had grown over the previous ten years. For example:

Females are more likely than males to gain an NCEA qualification at all levels... and are more likely than males to leave school with University Entrance or higher qualifications and this gender difference has grown.

Males are more likely than females to leave school with little or no formal qualification but this difference has decreased over recent years.

Females are more likely than males to leave school with University Entrance or higher qualifications and this gender difference has grown. Māori and Pasifika males are least likely to leave school with University Entrance or higher qualifications.

(Alton-Lee \& Pratt, 2000, p. 4)

There is also evidence (Harkness et al., 2005) that the achievement of male Pacific students in secondary schools is a matter for concern. As a Samoan researcher and community member, I am particularly concerned about the possible effects of focusing too heavily on the problem of underachievement or failing to recognise the wider social, economic, and political forces that mitigate against educational success for Pacific students. Various academics have noted that constantly identifying ethnic student groups as "failures" contributes to stereotyping, low expectations, and deficit theorising which in turn influences these students' identities as successful school achievers (Bishop \& Glynn, 1999; Shields, Bishop, \& Mazawi, 2005). In other words, focusing on the underachievement problem and ignoring the broader social and educational forces that underpin failure at school potentially creates a harmful, destructive, self-fulfilling prophecy, which in turn impacts on students' self-efficacy or belief that they can succeed in mainstream school settings (Bishop, Berryman, Tiakiwai, \& Richards, 2003). There are, of course, Pacific students who do 
exceptionally well in New Zealand secondary schools; unfortunately, however, there is a lack of research in this area to inform policy and practice. My research addresses this and I take the opportunity to explore to provide a space for tama Samoa to share their experiences in secondary school and address the importance of tama Samoa voices to future policy, practice and research needs for Pacific students.

Harkess, Murray, Parkin and Dalgety (2005) argue that the benefits of achieving and gaining secondary school qualifications are numerous, including stronger foundations for life-long learning, easier access to tertiary education, and access to a wider range of opportunities in the job market. For that reason, when Pacific boys leave school without the range of choices that educational qualifications can provide them, there are far-reaching effects not only for themselves as individuals but also for their families and their future prospects as members of Samoan communities. Whatever the reason, as highlighted by Coxon, Anae, Mara, Wendt-Samu and Finau (2002) the voices of Pacific males are decidedly "silent" in comparison with those of Pacific females. Both the male voices, and the reasons for their relative silence, are issues for further research, particularly given the data that suggest that Pacific males do not do as well overall in education as Pasifika females.

I began my research with the assumption that many tama Samoa often do not feel a sense of belonging or ease with their schooling environments. This thesis was an opportunity to explore beyond the anecdotal and professional experience of myself and other Pacific educators in New Zealand schools. There is little research in the New Zealand context about whether a sense of belonging at school is a major concern for tama Samoa or whether their experiences of the schooling environment play a part in whether they will be successful at secondary school. I base my hypothesis about the importance of "belonging" on some of the wider literature in the field. For example, Steele (1997) states that developing a strong sense of belonging within academic learning environments is an important aspect of building an identity as a school achiever. This research then, is an opportunity to review tama Samoa experiences and identify the way that their experiences can be more closely aligned with successful educational outcomes. As noted above, there are few studies that provide information about how Pacific 
boys experience secondary school. Ferguson, Gorinski, Wendt-Samu, and Mara's (2008) report confirmed that there is limited research available on Pacific boys in general in New Zealand. In line with this, Jones' (1991) and Ward's (1998) work supports the view that research in this area could lead to greater Pacific male students' educational achievement. These studies point towards the educational disparity in New Zealand schools that exists between boys and girls, mentioned above. This disparity is further magnified when the educational outcomes of European/Palagi boys and Pacific boys are compared. FairbairnDunlop (2010) notes that more Pacific females than Pacific males leave school with some qualifications, and that provides female students with a much wider range of career choices and options. Fairbairn-Dunlop (2010) further comments that:

The realistic issue is that Pacific peoples' high rates of participation in secondary schooling have not been matched by sound educational outcomes. This is serious, given that secondary school qualifications set the foundation for life-long learning, employment opportunities, access to tertiary education, and social and economic participation. (p. 20)

The views of tama Samoa are rarely sought by New Zealand Ministry officials and researchers and little data exists about how they experience their schooling. For this reason I decided to focus on the tama Samoa voices, as this could provide future key learning for not only teachers, but also teacher educators. To that end, this research is designed around a set of guiding questions and aims as discussed in the following section.

According to Statistics New Zealand (2013), the Pacific student population in New Zealand secondary schools has continued to grow in recent years. Chu, Glasgow, Rimoni, Hodis, and Meyer (2013) note that almost one in five Pacific students will leave school without any qualification; another one in five will leave with NCEA Level 1 only; and around one in five with NCEA Level 2. One in ten will become disengaged from education, employment, or training by the age of seventeen (Ministry of Education, 2013, p. 4). Over the past twenty years, many reports and educational initiatives directed at understanding or reducing educational underachievement for both Māori and Pacific students have come 
and gone (see for example, Hawk, Cowley, Hill, \& Sutherland, 2002; Hawk \& Hill, 1998, 2000). However, while these reports and other related research are certainly worthwhile and have contributed to ways that teachers and school environments can improve the situation for Pacific students in terms of their academic achievements, this thesis aims to contribute towards redressing the lack of student voice through the use of phenomenological methods.

\section{RESEARCH AIM AND QUESTIONS}

The aim of this study was to identify tama Samoa perceptions of what factors influence their schooling experiences and the impact this has on their decisions about the future.

The overall research question is: In what ways do tama Samoa experiences within a secondary school context contribute to their identity, sense of belonging, and aspirations for the future?

\section{Sub-questions}

1. In what ways are tama Samoa's identities influenced by their secondary school experiences?

2. What is the nature of the relationship between tama Samoa sense of belonging and their daily experiences within secondary school?

3. What experiences have tama Samoa had during secondary school that have contributed to their aspirations for the future?

Understanding of the tama Samoa experience at secondary school is crucial for the purpose of developing programmes and an environment that will enhance their learning. It is anticipated that these tama Samoa experiences will contribute to knowing how and why tama Samoa and other Pacific students have multiple identities. Furthermore, the study will contribute to the understanding of the importance to tama Samoa of the sense of belonging and how secondary schools can foster this. It is also important to note that the three themes of identity, sense of belonging, and aspirations for the future were pre-set as key areas for this study to focus on. 


\section{MY POSITION AS A RESEARCHER}

I am a Samoan woman and identify as a Niu Sila Samoan (Tupuola, 2004), a New Zealand Samoan. My interest in completing a PhD was sparked when I was appointed as a lecturer of Social Studies at the Wellington College of Education. I have always had a strong commitment to Pacific Nations education and a passion to find ways of better understanding the reasons for, and ultimately improving, the negative statistics that surround educational outcomes for Pacific students in New Zealand secondary schools.

Discussions about these educational statistics that took place in the media, in schools, and in my place of work became a sensitive issue for me for a number of reasons. Firstly, because I am a Pacific educator and my teaching philosophy is based on working with Pacific young people to build a better tomorrow for them as well as for their families and their communities. Secondly, members of my own family are represented in the education statistics that place Pacific people at the lower tail of the achievement levels (OECD, 2001). Thirdly, the age structure of Pacific groups in New Zealand is very young, particularly for those born in New Zealand (Callister \& Didham, 2008). As the Pacific population in New Zealand grows, the educational experiences of young Pacific people's needs to be better understood.

It was here that I began to reflect on the experiences of Pacific students within the secondary school context, and in particular the experiences of tama Samoa and whether their experiences were acknowledged and understood by school leaders and teachers. It seemed to me that if there was a greater understanding of the world views of tama Samoa, and if their voices were heard more clearly in educational research, perhaps the situation might start to change.

While I wear many hats in my role of being an aunt, a teacher, a friend, and a Samoan researcher, my role within this research is primarily due to the relationship I have with my nephews. The significance of this role is due to how the tama Samoa of my family see me. The relationship as aunt to tama Samoa in my family is based on warmth, affection, informality, and trust. Within this 
relationship my tama Samoa are able to confide and share with me in ways that they may not with their parents, or their teachers, or other formal authority figures.

Along with being intrigued by the statistics of where Pacific students are placed in secondary school, I also have a more personal interest in this topic. As an aunty, the stories that my nephews share with me about their learning, about their friends, and about their schools are particularly compelling. They share with me the impact of these influences on their everyday lives as students. My nephews, who are also tama Samoa, have many stories of their secondary school experiences. In some cases their stories are funny, and enjoyable to listen to. However, at other times what they have told me of school has not been enjoyable to listen to, nor funny to laugh at. It is often very uncomfortable to listen to what they tell me; their experiences make me feel terribly sad because few of their experiences at secondary school are positive or affirming of who they are and what they care about. In listening to my nephews over time, I came to realise that there is much that we, as researchers and educators, have yet to learn about the schooling experiences of these young tama Samoa

In taking an interest in the study of tama Samoa, I am aware that there may be some conflict in requesting the tama Samoa in this research to openly talanoa (converse) with me about the everyday experiences they have in secondary school. Brayboy and Deyhle (2010) argue that qualitative researchers must continually be aware of how those we study view us as well as how we view them.

For the record, then, I want to make clear at the outset that the common bond that I have with the twelve tama Samoa involved with this study is that I am Samoan and I am a New Zealand-born Samoan. I am familiar with, and indeed have had some of the same kinds of, educational experiences that the tama Samoa participants report, especially in relation to learning to operate both in a Samoan world and the more Westernised world of New Zealand society and culture. In the literature on Pacific education, researchers are encouraged to take an interest and be aware of the importance of who their participants are, and of the need to have purposeful research that reflects the group of people they research (Airini, Anae, Mila-Schaaf, Coxon, Mara \& Sanga, 2010; Sauni, 2011; Vaioleti, 2006). Tuafuti's (2011) perspective on indigenous based research notes 
the importance of "teu le va" in a Samoan context and highlights the importance of not just including the sacredness and negotiation of identities between researcher and participants - that is, building relationships - but including the concept of encouragement for the researcher to respect his or her participants and therefore to keep their silence (p. 36). Thus, throughout the research process I was always mindful of the dignity of the tama Samoa participants and was careful to take the time needed to build a research relationship with them. This is particularly important as the use of the Samoa fa'afaletui framework as a methodological process requires the research participants (the tama Samoa) to co-construct the way in which the research will turn and, therefore, to give them a degree of control over the research design.

McFall-McCaffery (2010) argue that when conducting Pacific research it is important to consider Pacific knowledge systems and conceptual frameworks. These knowledge systems sit at the heart of the way that Pacific peoples understand the world and represent themselves to others. From the 1980s, Pacific scholars have continued to develop research models that represent the diversity of Pacific indigenous epistemologies, cultural worldviews, and theories of knowledge (Gegeo, 2008). It was important to me to develop and apply a Samoan methodological framework that also aligned with Western methodological paradigms so that the study could speak to both Western and Pacific worldviews and which would ultimately allow me to stand in both worlds.

\section{O LE ‘AFA SAMOA - THE SAMOAN SENNIT}

Over time, Samoans have discovered multiple uses for almost every part of the coconut tree. One of the most ingenious uses of one particular type of coconut tree, the Niu'afa, involves the processing of the coconut husk to produce 'afa (coconut sennit). The 'afa is made from the only terrestrial plant fibre resilient to salt water. 'Afa is a strong and versatile cord that has significant cultural and utilitarian value to Samoa. To understand the importance of the Samoan 'afa to Samoan life and culture, one must understand the process of making it. An explanation of this process provides a clearer visualisation of why the 'afa is important to Samoan people, and also - most importantly - how it is significant 
to this study. From the beginning, starting with the raw coconut husk, to the end product of twisted fibres and braided cords, it is the process in between that is utilised as the metaphor for this study.

As mentioned above, the 'afa holds significant cultural value to Samoan people, but it is also highly valued in other Pacific countries where the coconut tree is an important symbol of life and regeneration. Samoans often refer to the coconut tree as "the tree of life" because of its life-giving qualities: for example, it provides a nourishing drink, food, oil, and medicine; it is a fibre fuel and is used for timber, thatching, baskets, mats, brooms, and domestic utensils (Chan \& Elevitch, 2006). The corded 'afa was once widely used in Samoa for clothing and for personal adornments such as wrist and ankle bracelets and necklaces. In addition, it was also once widely used in the construction and decoration of fale (traditional Samoan houses) and meeting places. In this context, because it is the 'afa that binds the foundation posts together and anchors the fale in the surrounding earth, it becomes a key metaphor relating to the strength of a community that has its deepest roots in the land and the people. In this respect, it is a symbol of unity but it is also a symbol of endurance because the various strands of the 'afa are plaited and pulled together so that it is strong enough to bind the central poles of the fale Samoa so that the people are sheltered. Thus, this material and its uses in the constructing of the fale Samoa is also used as a guiding metaphor in this research.

The preparation of the Samoan 'afa is both a delicate and rough process but each stage of the 'afa process is needed to prepare it for its future purpose. Throughout this thesis each process of preparing the Niu'afa is also placed as a sub-heading for this thesis. For each process of preparing the Niu to the 'afa several stages must be completed before the 'afa is ready for joining strands, I will now explain how each stage links with each of the chapters of my thesis.

Saili le Niu'afa - (Choosing the right Niu), once the Niu has been picked, one must separate the interfibrous material from the fibre. In Chapter One the topic is introduced - and the significance of why tama Samoa are an important choice of topic are discussed. This is also the process reviewing background information, like the selection of $\mathrm{Niu}$, consideration of background knowledge is needed. 
Tatao le Niu'afa i le suasami) - the interfibrous material is soaked in sea water to soften. Samoa people believe the longer the fibre is soaked in sea water the better the strength and lasting qualities of the fibre. In Chapter Two the literature provides further information and so strengthens the knowledge about the key themes of this research, identity, sense of belonging and aspiration.

Sasa le pulu - after being removed from the sea the husk is beaten so that the fibre softens, widens and become strips of fibre. In Chapter Three we begin to prepare the tama Samoa for the data collecting through fa'afaletui (further explanation of fa'afaletui is provided in Chapter Three).The Niu has been stripped and prepared for the next stage.

Matofi le Niu'afa - once the Niu is soften, the fibre is ready for exposure to the sun to dry and be rid of dampness to prepare it for braiding. In Chapter Four, I begin to review data; the stories and perspectives of tama Samoa and their nominated people are prepared for analysis.

Fa'ata'a le Niu'afa - this is the braiding process which involves placing short pieces and long pieces together and rolling them into suitable strands. The discussion chapter, Chapter Five, highlights links and connections within the themes.

Fili le Niu'afa - At this stage of the Niu'afa process, the strands are now ready for plaiting to commence. The purpose of this is to allow the strands to be strong before used to join and be connected. Chapter Six reviews the themes and identifies possible tensions and dilemmas, this is important as the key ideas from the talanoa will allow for pulling together of final thoughts before tama Samoa perceptions are discussed to question 'where to from here'?

Likewise, in Chapter Seven, the findings of the thesis are considered together to highlight key points, provide new understandings, and to make recommendations about how these understandings may be put to use. Sauni le Niu'afa mo so'oga - is the final stage, the plaited sennit threads are ready for joining. Each plaited sennit, will now be used for a new purpose, it will be used to strengthen buildings, baskets, roofs and much more. The talanoa in Chapter Seven, will have new understandings to provide support in improving the experiences of tama Samoa 
during secondary school. Tama Samoa perceptions have developed new thinking.

On reflecting on my PhD journey, I am reminded of my experiences in Samoa of the making of the Samoan 'afa. As a learner I found the process was challenging. I had not participated in the earlier stages of preparing the coconut husk through the processes of drying and stripping. I had entered into the process at the stage of binding the fibre from husks to make it into an 'afa Samoa. As a learner I found myself comparing my 'afa to my uncle's. While his 'afa was near to perfection, I noticed that mine had gaps and was a weak piece of rope that was not binding together strongly. I knew from this early attempt of making a 'afa Samoa that mine was not going to be useful for any of the purposes that the 'afa Samoa is used for. However, my uncle noticed the weakness in my 'afa and found a way to pull my strands together to strengthen and bind them with other strands of husk, which at the end of the process made my 'afa strong enough to be purposeful for use.

In this thesis the process of making the 'afa process is applied as a metaphor in a non-traditional context and setting. It is used within the context of New Zealand secondary schools, literally transformed into a metaphor with the capacity to absorb the complexity and realities of both the participants and myself as a researcher. My journey as a Samoan researcher equates to the process of making a Samoan 'afa. My task as researcher is to strengthen the knowledge by pulling the individual experiences and perceptions (strands) of each tama Samoa together. This combination of knowledge will be valuable and useful for weaving new ideas and policies to support tama Samoa in secondary school contexts.

I have chosen to develop metaphorical explanations in this study because, as Sanga (2013, p. 40) explains, "metaphors are cultural constructs". The reason for integrating metaphor into research, Sanga suggests, is because metaphor can provide another layer of meaning to what is being researched. This notion is also supported by Violeti (2006), who states that the value of metaphor is that it allows for a cultural synthesis of the information, stories, emotions, and theorising which produces relevant knowledge and possibilities for addressing Pacific issues (p. 21). Gibbs (2007) discusses the idea of doing research in alternative ways 
and argues that use of metaphors is one way in which research can shed a different light on our subject; we see things in a new light. Gibbs argues that although some researchers would not necessarily be excited about the use of this it may open new visions on teaching and learning. Others explain that, purposely used, metaphor can provide expressive meanings to convey the message; it can also stimulate imagination to create action and change; metaphors can also enhance and inspire creative thinking (Bryant \& Zillmann, 1988; Elliot, 1984; Hoffman, 1983; Johansson-Fua, Ruru, Sanga, Walker, \& Ralph, 2012).

This research is a narrative, a chapter in my own educational journey, which highlights and explores the experiences of twelve tama Samoa attending secondary schools. The story is co-constructed by myself, the twelve tama Samoa, and the people they nominated to speak for and about them. Throughout the thesis, you, the reader, will note the need to prepare the use of the Samoan 'afa. As I begin to process my 'afa, throughout my journey, the weaving of the connecting threads in the tama Samoa's stories will be brought together in ways that are intended to represent their experiences of identity, belonging, and preparation for the future.

\section{SIGNIFICANCE OF THE STUDY}

This study set out to investigate the perceptions of tama Samoa experiences in the secondary school context. Studies on tama Samoa in secondary schools had mainly involved them as part of a collective Samoan students group (Goldring, 2006; Lipine, 2010; Silipa, 2004) exploring their experiences in the classroom, or as part of a collective group of Pacific students, and the barriers that prevented them achieving in secondary school (Atkinson, 2013; Siope, 2010). In 2009, there was a population of 73,018 Pacific students in New Zealand secondary schools. In 2014 there was an increase to 75,198 (Scott, 2014) Pacific students enrolled in New Zealand secondary schools. Samoan students make up

$47 \%$ of the Pacific population in secondary schools. It is therefore imperative that this research be undertaken to better understand the situation for tama Samoa within the secondary school environment. This research was an opportunity to explore the element of schooling experiences of tama Samoa. 
Finally, while there have been some positive initiatives regarding Pacific students in some secondary schools, there has been a lack of significant improvement. Therefore taking the direct perspectives from tama Samoa voices could increase the knowledge and awareness about what enhances tama Samoa's everyday experiences in secondary school to support their learning. It is anticipated that this study will offer further insights into the context of the experiences made by the tama Samoa in a New Zealand secondary school context, and will, therefore, create valued knowledge that can support and inform school management as to the best way forward to guide and support Samoan adolescents in New Zealand secondary schools.

\section{THESIS OUTLINE}

In this chapter - (Saili se Niu'afa - Choosing the Niu'afa) I have explained how I came to select the topic, and the importance of this topic within the New Zealand educational context. An overview of the background for this topic was presented as following: a) the New Zealand education system structure; b) the Pacific population in New Zealand with specific focus on the Samoan population; c) the outcomes for tama Samoa in the New Zealand education system. I have also provided a rationale for why this topic was chosen. An outline of the research aims, research questions, and research context is also provided. In addition to this, I have introduced myself as a researcher; I have discussed my position as a researcher, and also, importantly, I have linked this discussion to my own Samoan heritage using the metaphor of the 'afa (coconut sennit) and explained how it will be applied in this thesis.

In Chapter Two - (Tatao le Niu'afa i le suasami - Soak the Niu'afa in sea water to soften), the review of the literature is provided. In particular, ideas relating to identity formation and other related concepts are examined, and studies about the role of sense of belonging in young people's sense of self and their educational biographies are introduced. Relevant literature on student selfefficacy and how this can support tama Samoa and their preparation for the future is also reviewed. 
Chapter Three - (Sasa le Niu'afa I le pulu - Beating the husk of the Niu'afa), is divided into two parts. Part one, is a discussion on the methodology and theoretical framework appropriate for this study. I then discuss the interpretive paradigm and how this paradigm was deemed to be the most appropriate for this study. I then discuss my position as a researcher within this study. I also discuss Pacific research frameworks and identify the value of using Pacific research frameworks when working with Pacific participants. Following this I introduce the fa'afaletui framework and justify its use as both a methodology and method for this study. In part two I present the methods selected for this study and identify the selection process for the tama Samoa participants. The procedures for collecting and analysing the data are also described. The ethical and cultural issues related to this study are taken into consideration and discussed. Issues surrounding credibility and validity are also discussed. The chapter concludes with an overview.

Chapter Four - (Matofi le Niu'afa i le la - Expose the Niu'afa to the sun) presents the findings and is organised into in three themes. Theme one presents identity. This is followed by theme two, belonging; and, finally, theme three aspirations for the future. Chapter Four portrays the findings through use of the voices of tama Samoa about their journey through their educational experiences at secondary school.

In Chapter Five - (Fa'ata'a le Niu'afa - Braiding the Niu'afa), I discuss the findings through the process of fa'afaletui, and identify the key ideas that have been highlighted in the findings. Chapter Five is divided into three parts corresponding to the three themes presented in Chapter Four: identify formation, sense of belonging, and aspirations for the future.

In Chapter Six - (Fili le Niu'afa - Plaiting the Niu'afa), I provide a review of the research questions and align them with the key findings. It will also provide an analysis of tensions and dilemmas that I have identified though the findings chapter. 
The final chapter - (Sooga le Niu'afa - joining the strands of the Niu'afa), Chapter Seven, is an opportunity for the researcher to reflect on the overall aim of this thesis. Chapter Seven reflects on the use of the 'afa Samoa in terms of how tama Samoa experiences in secondary school have prepared them for the next stage of experiences. It also presents a series of recommendations based on the findings. These recommendations are geared towards supporting tama Samoa in secondary schools, as well as Pacific students more generally. The chapter will also include further research suggestions that could be further developed. I conclude this chapter with my final words.

\section{SUMMARY}

In this chapter, the background and rationale of this study has been presented. It is argued that providing an opportunity to explore tama Samoa experiences in secondary school has the potential to enhance the learning experiences of Samoan youth. It is hoped that documenting their experiences may have an influence on improving the way that secondary schools support tama Samoa as well as other groups, such as Pacific students and male students, within the secondary school system.

The term tama Samoa refers to Samoan boys who self-identify with the Samoan ethnicity through ancestry or heritage. The Samoan student population is steadily increasing in the secondary school sector and has, been chosen for this research for two reasons: first, their Samoan ethnicity represents the largest Pacific group in New Zealand, and second, because the researcher is also of Samoan heritage. Given the continued outcomes, it is important that the needs of this group of students are addressed and that this be done more robustly than has been the case in the past. This study was influenced by the premise that understanding and exploring the experiences of tama Samoa may enhance their learning experiences. 


\title{
CHAPTER TWO:
}

\section{LITERATURE REVIEW: IDENTITY, BELONGING, AND SELF-EFFICACY}

\author{
Tatao le Niu'afa i le suasami
}

(Soak the Niu'afa in sea water)

\section{INTRODUCTION}

The purpose of this chapter is to examine the literature that contributes to an understanding of the social and cultural experiences of tama Samoa in New Zealand secondary schools. In this chapter, three related areas of inquiry are explored. First, the concept of identity and identity formation is discussed. Reflecting the complexity of this topic, identity is discussed from a number of angles: identity formation in adolescence, cultural identity, Pacific perspectives on identity formation, social identity, and gender identity. Second, concepts of belonging are examined. Within the secondary school context young people manage their identities in different ways often depending on the degree of belonging or alienation they experience as learners and as students. This aspect of adolescents' lives closely informs my analysis of the data and is introduced here as a key concept. Third, ideas relating to student-efficacy are evaluated in the context of students' experiences of secondary school.

\section{IDENTITY: A “SLIPPERY” CONCEPT}

In order to understand identity formation, it is worth considering how identity has been defined over time. That said, identity is a complex concept, and it is one that is woven through many aspects and stages of a person's life experiences (Peterson, 1989; Phinney, 1990). Abdelal, Herrera, Johnston and McDermott (2006) note that the literature has considerably expanded since the 1950s when one of the key identity formation theorists, Erik Erikson, began his work in the field of psychology. However, despite this, Abdelal et al. (2006, p. 685) contend that identity continues to be a concept that is "elusive, slippery and amorphous". 
This "slipperiness" has also been commented on by Fearon (1999), who compiled fifteen explanations of identity drawn from various disciplinary perspectives. These explanations range from portraying identity as "people's concepts of who they are, of what sort of people they are, and how they relate to others" (Hogg \& Abrams, 1988, p. 2) to framing it as "the ways in which individuals and collectivities are distinguished in their social relations with other individuals and collectivities". Fearon (1999) concludes his analysis with the comment:

The range, complexity, and differences among these various formulations are remarkable. In part, the differences reflect the multiple lineages that "identity" has within the academy. Different research traditions - influenced variously by symbolic interactionism, role theory, Eriksonian psychology, social identity theory, and postmodernism, to name a few. (pp. 5-6)

At its most basic level identity formation refers to a sense of self and the ideas that people have about who they are and how other people view them. Para (2008) suggests that adolescence is a critical point where individuals explore who they are, what they personally value and believe in, as well as the directions they will follow in life (see also Bosma \& Kunnen, 2001). In the following sections, I discuss elements of identity formation and explain how I have used the literature to frame an understanding of this slippery concept in this thesis.

\section{IDENTITY FORMATION}

In this literature review I am particularly concerned with key writings about identity formation that focus specifically on adolescence. For the purposes of this study I am interested in the way that cultural identity influences young people's experiences and engagement with school. For this reason, I introduce literature that extends beyond explanations about the ways that individuals carve out unique personal identities and focus more closely on the formation of social identities that are based on membership of various groups, such as family, ethnic communities, and work (Harris, Blue, \& Griffith, 1995). 
Research on identity formation has revealed a clear link between family practices and identity development (Taylor \& Oskay, 1995). Most contemporary theorists contend that human identities are not fixed but rather that they are multi -faceted and change significantly over time (see for example, Babad, Birnbaun \& Benne, 1983; Harris, et al., 1995; Peterson, 1989; Willmott, 1989). In the early years of life, identity is shaped through a child's interactions with key people, such as parents, family, and peers (Peterson, 1989). These interactions are, in turn heavily influenced by the kinds of ethnic, social class, and environmental contexts in which children grow up (Harris et al., 1995; Willmott, 1989). In this thesis, I focus much of my attention on the contexts that surround tama Samoa and explore how these contexts influence their experiences of the world around them.

\section{Identity formation in adolescence}

One of the most influential identity formation theorists was the developmental psychologist, Erik Erikson. Born in an era when one's parentage was considered an important aspect of who one is, Erikson never knew his biological father. Born out of wedlock and feeling different from his peers, Erikson's life's work centred on seeking an understanding of how human beings develop a sense of selfhood within the social and cultural milieu of their families and communities. Erikson viewed identity as an integral part of the "architecture" of the self (Friedman, 2000) and believed that one's identity encompasses a sense of one's uniqueness, a sense of wholeness or harmony with oneself and a sense that one's ideas and values are significant to others. Identity develops throughout life as the individual interacts with the social environment that surrounds him or her (Erickson, 1970). Erickson held a strong conviction that a secure identity is reflected in a sense of personal well-being. He argues that, "it's most obvious attributes are a feeling of being at home in one's body, a sense of "knowing where one is going" and an inner assuredness of anticipation recognition from those who count" (Erickson, 1968, p. 165).

Throughout the 1950s and with his own personal history as a motivation for his work in psychology, Erikson evolved a theory about developmental stages in the human life cycle. He was also the first to argue that identity formation is the major task of adolescence (Para, 2008, p. 97). According to Erikson (1959), identity 
formation, while beginning in childhood, gains prominence during adolescence. Faced with physical growth, sexual maturation, and impending career choices, adolescents must accomplish the task of integrating their prior experiences and characteristics into a stable identity. Erikson coined the phrase "identity crisis" to describe the temporary instability and confusion adolescents experience as they struggle with alternatives and choices. Alongside establishing new theoretical understandings of identity, Erikson developed a range of related psychological terms such as self-concept, self-efficacy, and self-esteem. These psychological terms have been highly influential in discussions about the ways in which individual human beings formulate a sense of self (Erikson, 1959; 1963; 1968; Marcia, 1993).

Self-concept relates to the idea of what one makes of the expectations, descriptions that one holds about one's self (Hattie, 1992). Combs (1962) argues that self-concept is "in essence what an individual believes he/she is" (p. 62). Bandura (1977) suggests that self-efficacy is based on the influence of choices people make and the courses of action they pursue. Self-esteem is used to describe a person's overall sense of self-worth or personal value. Self-esteem can involve a variety of beliefs about the self, such as the appraisal of one's own appearance, beliefs, emotions, and behaviours. Erikson develops each one of psychological terms in his theories based on his psychosocial stage theory. These ideas have informed the development of my research questions.

One of the significant elements of Erikson's (1968) psychosocial stage theory is the development of ego identity. Ego identity is the conscious sense of self developed through social interactions. According to Erikson, ego identity is constantly changing due to new experiences and information adolescences acquire in their daily interactions with others. As adolescents face each new stage of development, they face a new challenge that can help further develop or hinder the development of identity. The use of the ego identity development for tama Samoa reflects the constant changes that they go through due to the experiences and influences that each one gains from their everyday interactions with others. 
Erikson's (1968) ideas have drawn some criticism over the years. For example, that his idea of identity formation suggests that people complete the process of psychological development at a much earlier age, (Marcia, 1980; Waterman, 1985). Other critics of Erikson's (1968) theory provide evidence suggesting a lack of discrete stages of personality development (McCrae \& Costa, 1997). Theorists such as Marcia (1980) have critically analysed Erickson's (1968) ideas and suggested some common criticisms of Erikson's theory are that it does not say much about the underlying causes of each development crisis. Marci continues to suggest that it also tends to be somewhat vague about the experiences and events that mark the difference between success and failure at each stage. Also, the theory lacks any objective way to determine if a person has "passed" or "failed" a particular stage of development. However, to gain an understanding of Western philosophy it is important that Erickson's work is discussed and how this may or may not align with understanding identify formation from a Pacific perspective.

Many Western theorists such as Erikson (1970) have highlighted the different components that influence identity formation; however, as identified by Ann-Marie Tupuola's (1993) critique of Erikson's work, these ideas of how individuals develop a sense of self may not necessary be congruent with Pacific perspectives about the development and influences of a Pacific adolescent.

In many Western nations and cultures, human development has, until recently, been represented as a coherent, linear, and more or less uniform pathway that leads individuals out of childhood and into adulthood. Adolescence was viewed as a transitional stage of development occurring prior to adulthood and heralding a period of social, intellectual, and emotional change. Weber (1998) argues that as youth develop, they create increasingly sophisticated understandings of the world around them and this prefaces the construction of adult identity and a sense of selfhood that draws on a variety of sources, including social beliefs about ethnicity, race, gender, and social class.

Fine (2004) suggests that adolescents shape and reconstruct their personal and public identities through interactions in multiple social and cultural environments, including institutions, family, and peer groups. Lerner (2002) views the 
adolescent as a dynamic entity; the centre of a network of influences involving himself or herself, arguing that "developmental focuses on the interaction between the growing, that is, the continuously changing individual, and the ecological context within which that person lives" (Lerner, 2002, p. 339). Lerner's work recognises the changing, developing inner self of an adolescence in the context of a life span. This point of view suggests that to understand adolescents, one must consider the multiple influences which weigh on their choices and experiences and I have taken this perspective on board in this study.

During adolescence, young people not only undergo physical changes, but, as Spano (2004) argues, they also experience cognitive, social/emotional, and interpersonal changes. In addition, outside factors such as families, peers, and community, culture, religion, and world events including media start to become more important. Fine (2004) suggests that adolescents shape and reconstruct their personal and public identities through a range of interactions that take place in many social and cultural environments, including institutions such as school, family, and peer groups.

Several key factors contributed to the idea of identity being a slippery concept. Questions are asked about what identity means? How does identity relate to adolescent development? Within this study tama Samoa explore their own identity formations and discuss through talanoa the influential contributions of mates, peers, teachers, and family. Erikson's (1968) ego theory explains the development of adolescents is influenced through the everyday changes that surround them. In this study, tama Samoa explore their experiences through interaction with people as well as the environment.

\section{Cultural identity}

Similar to identity, cultural identity is also defined differently by different theorists. Brownlee, Boulton-Lewis, and Berthelsen (2008) argue that culture is passed on from one generation to the next through teachings and observation, through a process of interaction and socialising with others within the family or cultural group. Others believe culture is a system of beliefs and values within a society. For example, Shah (2003) suggests that culture includes shared features which 
encapsulate people together in a community. One of the simplest explanations of cultural identity is that it gives people a sense of belonging, a shared sense of companionship that involves a level of agreement about core beliefs, interests, values, and basic principles of living. In this respect, cultural identity allows people to identify with others who fundamentally have the same traditions and basic belief systems.

Hall (1990) claims that a person's cultural identity is the foundation or groundwork on which every other aspect of their being is built. It is the cornerstone of what makes them who they are. Embracing one's culture often means practicing a specific religion or wearing a certain type or style of clothing. Such practices create an outward, visible means of identifying a person as part of a particular culture or nationality.

Hall (1990) summarises notions of identity and culture as:

instead of thinking of identity as an already accomplished fact, which the new cultural practices then represent, we should think, instead, of identity as a 'production', which is never complete, always in process, and always constituted within, not outside, representation. (p. 222)

Like Brownlee et al. (2008) and Shah's (2003) definitions of cultural identity, Hall (1990) provides two definitions of cultural identity: one, involving shared understandings of culture, a sort of collective "one true self, hiding inside the many other, more superficial or artificially imposed selves", which people with a shared history and ancestry hold in common; two, recognising that, as well as the many points of similarity, there are also critical points of deep and significant difference which constitute "'what we really are'; or rather since history has intervened what we have become" (p. 223).

One part of this study, provides the tama Samoa with an opportunity to talanoa about their Samoan heritage and their perceptions of what it means to be a Samoan and to provide examples of what they do that represents their Samoan heritage, their shared understanding of the Samoan culture, and how they interpret being Samoan according to their own experiences and understandings. 
In line with Hall, Clark (2008) discusses cultural identity as being characterised by a number of factors such as race, ethnicity, gender, and class. Clark argues that:

in one way the analysis of cultural identity brings quite a dark cloud over the question of identity in general. This is because it obviously focuses on difference and the negative connotations that stem from these perceptions... Defining your own self by another often leads to a strong sense of who we are not, or more likely who we don't want to be. (p. 527)

Clark (2008), therefore, provides another angle to the understanding of cultural identity - the negative connotation that the identity principle of individual cultures is in fact established through the principle of otherness. As with any sort of individuality, cultural identity is a meeting point of several cross-cultural implications. Cultural identity, then, is of complex character, open to making its own changes in order to preserve its being in a new context of interests.

Phinney (1989) has developed a multi-dimensional model that focuses on the identity issues of ethnic minority young people, particularly in Australia and the United States of America. Phinney's (1989) central argument is that there is a time in young people's lives where they try to understand their own abilities in cognition to contemplate ethnic identity through one's social life. She also identifies the need for minority groups to consider identity issues in the light of racism and a dominant culture that may not reflect the values of their own homes. Much has been written about cultural identity and for some people an understanding of cultural identity revolves around the concept of ethnicity. However, a cultural identity can encapsulate more than ethnicity (see, for example Clark, 2008; Hall, 1990; and, Phinney, 1998). It is not simply a matter of shared artistic culture, highbrow or low, but of shared language, customs, habits, values, and practices, and of shared identifiers, icons, and symbols. These things are not necessarily superior to those of other cultures, or even unique; the point is that they are shared within the group and thought to be distinctive. 
Reviewing the literature on cultural identity, then, it appears that each individual makes decisions about who they identify with and connect to, including who they don't want to be. In respect of this I continue to investigate Pacific perspectives on identity formation as this provides a cultural perspective through a Pacific lens.

\section{Pacific perspectives on identity formation}

There continues to be a growing literature on the ideas of identify formation through Pacific lenses. Pacific researchers, whose works have provided insights to the personal, social, and political issues that surround identity, provide valuable discussions in the identity forum.

Mila-Schaaf (2010) questions Pacific identities in terms of their relationship with important "others" around them. In a New Zealand context, this has not only meant the relationship Pacific youth hold with their cultural upbringing but also their mainstream Westernized upbringing. Mila-Schaaf's participants' narratives show that, for the second generation, acceptance within Pacific social spaces is not always easy to gain. They might identify as Pasifika, but to be identified back was never a given. Mila concludes:

The second-gen identity narratives of relational space with first generation or island-born Pasifika peoples shows how these dynamics were patterned by power relations, hierarchies, politics of inclusion and exclusion. These spaces privileged Pasifika forms of capital which often disadvantaged young NZ-born Pasifika peoples. Language, age, cultural knowledge, gender, genealogy, family, service, these were all forms of capital in Pasifika social spaces. Participants had some of these forms of capital, in varying volume and degrees. Speaking your own Pasifika language was an influential form of cultural capital in Pasifika social spaces. It was associated with Pasifika identities. The second generation without the ability to speak their own Pasifika languages in some situations struggled for recognition, identification and inclusion. (p. 42)

As highlighted by Mila-Schaaf (2010), the challenges for second generation Pacific youth are quite severe in deciding how to go about strengthening their self-identity as Pacific individuals. What seems to be clear in Mila's particular 
study is the question of how to go about maintaining Pacific cultural values and the passing of these traditional cultural values to second and third and future Pacific generations in order to maintain Pacific identity. Here lies the opportunity to explore the ideas discussed by Mila-Schaaf and the use of tama Samoa and their stories of building identity within the secondary school setting on what the tama Samoa perceive to be influences and experiences that support and develop their identity as tama Samoa.

According to Anae, secured identities can be reached by Pacific youth going through a pathway, or as Anae suggests, a series of rites of passage. These rituals give the Pacific individual to be challenged through the right to be a New Zealander or be challenged to have the right to be "a Samoan" (Anae 1997, p. 128). Anae suggests that once a Pacific individual is successful in negotiating his or her identity, this will eventually lead to a secured identity; that for young Samoan individuals to go through this process they must thoroughly understand and be involved with Samoan customs and culture.

Anae's research $(1998,2001)$ into the identity journey of New Zealand-born Samoans highlights a series of stages that the New Zealand-born Samoans experienced. She suggests that many may experience a period of "Identity Confusion" followed by a "Time Out" period where individuals act out their confusion, explore other lifestyles, leave their church, and in some cases adopt a more general Pacific identity. Anae (1998) also speaks of a "Secured Identity" which is marked by a persistent Samoan self-concept where one finds resolution between internal and external conflicts in what it means personally to be a New Zealand-born Samoan.

Tiatia (1998) examines the tensions in the relationship between Pacific youth and "the church", and uses the voices of youthful participants themselves to describe these tensions. Tiatia's "Caught between two cultures" explores the dilemma of being Pacific people in a European society which does not understand their cultural uniqueness, and of being "the silenced Western educated voice", ignored within Pacific cultures due to being regarded as a threat to cultural traditions. 
A further researcher in this area is Anne Marie Tupuola who conducted an analysis of cultural identity and its relationship to school performance (Tupuola, 1993). Tupuola's background is in human development, adolescent development, adolescent psychology, youth studies, and youth cultures. Her research interests include adolescent ethnic, personal, and sexual identity formation processes across diverse cultures as well as in designing indigenous, cross-cultural and trans-national participatory qualitative research methods for hard to reach youth populations. In subsequent works Tupuola (2000) has examined the issues related to what can be argued to be a more specific aspect of identity development; the development of sexuality for young Samoan women. Although each one of these Pacific academics provides some examination of identity formation, their approaches for this examination vary.

Tupuola (1998) points out that using theoretical development stages such as Maslow's (1954) "self-actualising person" can be problematic for the reason that "the notion of a personal identity is a social-cultural construct, not a development" (p. 150). She makes an argument for "the notion of identity achievement being limited and somewhat unrealistic because it makes the assumption that this stage, as defined by Western theorists, is attainable universally" (Tupuola, 1998, p. 58). Tupuola explicitly questions the idea of an "achieved identity" born of response to crisis. In her article "Pasifika Edgewalkers: complicating the achieved identity status in youth research" (2004) Tupuola explicitly questions the idea of an "achieved identity" born of response to crisis.

Building on her doctoral research, Tupuola's interest in diasporic and transnational youth identity privileged a model of continued negotiations, as opposed to Anae's quest for an "arrival" in the identity journey via the practice of fa'aSamoa (Samoan way). What this meant was instead of identities having to resolve the disconnect between two disparate cultures, which leads to feelings of entrapment and hopelessness, identities were instead conceived as skirting the borders of both worlds. This idea, described as "edgewalking", privileges the idea of shifting and active negotiation between the borders of the world's Pacific young people are connected with; a conceptualisation that hooks into wider global discussions of postmodern and "borderland" identities (see, for example Hall, 1991). Tupuola, also noted that the importance of providing adolescents with a 
sense of space to develop their own sense of identity within various environments was needed; this idea can be beneficial for tama Samoa as their identity formation may differ depending on the situation and environment. This also includes their cultural identity and social identity.

Increasingly used as a health model for Pacific people, Pulotu-Endemann's (2001) Fonofale model is represented metaphorically as a fale (traditional Samoan house). The structures that comprise the fale represent different factors that are important for the overall health of a Pacific individual. The foundation represents family, the foundation for all Pacific cultures. The roof represents beliefs and cultural values considered to be the shelter for life. Four posts between the foundation and roof represent the spiritual, physical, mental, and other aspects of life that form the connections between family and culture. Surrounding the fale is a cocoon that represents the environment, time, and context, all of which can have direct or indirect influence on an individual (Pulotu-Endemann, Cowley, \& Stanely-Findley 1995).

Anae (1998), Tiatia (1998), and Tupuola (1993) and, more recently, Mila-Schaff (2010) each identify crucial elements important in the identity formation of Pacific youth including tama Samoa. What is clear from the studies of Anae, Tiatia, Tupuola, and Mila-Schaff is that to provide a clear description of identify formation for Pacific adolescents - including tama Samoa - a Pacific lens and theoretical framework must be considered, as Westernised ways of theorising may not be sufficient.

Pulotu-Endemann's Fonofale model provides an example of what needs to be considered when trying to understand Pacific adolescents. The use of Pacific metaphor to explain or describe identity formation from a Pacific perspective highlights the Pacific element within research on Pacific people.

\section{Social identity}

Social identity is a person's sense of who they are based on their group membership. Phinney (1993) states that the development of all youth is influenced by their identification with social groups. For adolescents, the choices involving group identities are constrained by the norms and values of a particular 
group; certain behaviour and interactions seen by adolescents by their peers and social groups reflect on their individual development.

Tajfel (1974) developed the original social identity theory. As explained by Tajfel, social identity can be understood as a person having not one "personal self", but rather several selves that correspond to widening circles of group membership. Different social contexts may trigger an individual to think, feel, and act on the basis of his personal, family, or national level of self. Tajfel and Turner (1979) propose that the groups (for example, social class, family, football team etc.) which people belong to are an important source of pride and self-esteem. Groups give us a sense of social identity, a sense of belonging to the social world. Peer group identity becomes a central factor in the process of development for adolescents. Tajfel and Turner's later work (1986) continues their discussion of the individual having multiple social identities: it is an individual-based perception of what defines the "us" associated with any internalized group membership. This can be distinguished from the notion of personal identity which refers to selfknowledge that derives from the individual's unique attributes. Although Tajfel (1974) developed the social identity theory through different approaches of scientific origins, the one that resonates well with this research is the idea that social identity theory connects to "a critique of social comparison research, arguing that in intergroup contexts, people make comparisons that maximise differences between selves as in (in-group) and other as in (out-group)" (Tajfel, 1974, p. 68). According to DuBois, Burk-Braxton, Swenson, Tevedale, and Hardesty (2002), it is often during this time of development for adolescents that social relationships form as a result of favourable adjustments. As noted by Hogg (2006), social identity theory addresses phenomena such as "prejudice, discrimination, ethnocentrism, stereotyping, intergroup conflict, conformity, normative behaviour, leadership and much more" (p. 111).

Theorists also highlight how peer identity groups have played an important role in the need for young individuals to belong, have companionship, identity, and comfort. According to Hartnett (2007), peers possibly play an increasingly critical role in forming identity as family dynamics change, society changes, and young peoples' futures seem more unpredictable than ever. Harris' (1996) asserts that peers have more influence on each other than their parents do in shaping values. 


\section{Gender identity}

As indicated previously, recent years there has been comprehensive reporting of local and international concern about the performance of boys in education. Theories of masculinity have become extended as educators and social scientists have sought to explain the over-representation of boys in negative social and health outcomes, and theorise the links between these and some forms of masculinity (Alton-Lee \& Pratt, 2000). However, it has also been identified that there is a significant gap in the research in terms of reports that specifically focus on issues for Pacific males - the boys and young men in our schools (Fergusson, et al., 2008).

Various meanings associated with the term gender can provide a link between the types of male identities that may or may not exist in schools. According to Alton-Lee and Pratt (2000), gender is not a neutral concept and the definitions of gender imply a set of assumptions or theories of what it means to be masculine and feminine. Alton-Lee and Pratt (2000) contend that gender is:

more than biological differences between men and women. It includes the way those differences, whether real or perceived, have been valued, used and relied upon to classify women and men, and to assign roles and expectations to them. (Ministry of Women's Affairs, 1996)

Alton-Lee and Pratt's (2000) definition acknowledges that, while there are obviously biological differences between males and females, gender and social processes also influence ways of being masculine and feminine. These influences provide meanings and understandings that individuals subscribe to as being male or female. According to Alton-Lee and Pratt, gender identity is defined as a personal conception of oneself as male or female (or less commonly, both or neither). This concept, gender identity, is intimately related to the concept of gender role, which Alton-Lee and Pratt define as the outward manifestations of personality that reflect the gender identity. Furthermore, the authors Alton-Lee and Pratt claim that gender identity, in nearly all instances, is self-identified, as a result of a combination of inherent and extrinsic or environmental factors. On the 
other hand, however, gender role is manifested within society by observable factors such as behaviour and appearance.

James (2007) claims that the gender role is "male" only if the individual demonstrates typically male characteristics in behaviour, dress, and/or mannerisms. Thus, gender role is often an outward expression of gender identity, but not necessarily so. Furthermore, James claims that in most individuals, gender identity and gender role are congruous. Assessing the acquisition of this congruity, or recognising incongruity (resulting in gender-variant behaviour), is important in the developing child.

The gendered construction of the social world has historically been so culturally pervasive, even within different forms, that work, leisure, language, knowledge and representation in our societies have been deeply gendered. Even colours and shapes carry gendered associations. For each of us, irrespective of our ethnicity, social class, work, geographic location, disabilities, and sexuality, our gender is an essential part of our identity within the cultural practices that frame our everyday lives (Alton-Lee \& Pratt, 2000).

Our gender deeply influences the ways we experience, negotiate, and participate in social life. For students and teachers in our society, negotiating gender identity and the gendered influences on educational practices is a task that inescapably shapes the constraints upon and possibilities within our lives.

It is important also to note that cultural differences abound in the expression of one's gender role, and, in certain societies, such nuances in accepted gender norms can also play some part in the definition of gender identity. According to James (2007), in order to understand gender identity development and related issues, definitions must be emphasised for clarity. Gender identity is often discussed merely in terms of dysfunction, and the diagnosis of gender identity disorder is a known phenomenon in both children and adults.

Alton-Lee and Pratt (2000) and James (2007), suggest that specific factors such as stereotyping, peer pressure, and social expectations associated with gender could have an intense influence on boys' learning in a coeducational environment. Irwin (2009) identifies a number of factors that contribute to boys' 
underachievement in schools. Irwin's (2007), PhD thesis "Hear our boys' voices: what hinders and enhances their academic success" focused on identifying how too many young males do not reach their full potential or achieve academic success. His interest includes ways in exploring why and how we can engage boys and adolescent males in education. Among these is the notion of "masculine bravado and a boys' code that places restrictions on how boys express themselves and behave" (p. 30).

Irwin summarises boys' codes as:

never cry, never show emotion, don't show weakness, don't care, don't do anything girly or nerdy, be tough, respect power and strength, it's cool to be a fool, talk as little as possible, Stand on your own two feet, have good mates that will stand by you and enjoy sports. (Irwin, 2009, p. 33)

\section{Pacific Boys in Education}

Within the secondary school context young people manage their identities in different ways often depending on the degree of belonging or alienation they experience as learners and as students.

Ferguson, Gorinski, Wendt-Samu, and Mara, (2008) note that there is limited research available on Pacific boys in general, and Jones' (1991) and Tupuola's (1998) work supports the view that research in this area could lead to Pacific male students' greater educational achievement. The data from Ferguson et al.'s work points towards a disparity currently existing between boys and girls and this is magnified again when Pakeha and Pacific boys are compared.

Ferguson et al. (2008), cautioned that it is important that future research does not generalise female perspectives on issues for Pacific learners across to male learners.

The New Zealand Ministry of Education (2015a) data showed that, in terms of achievement, ethnicity differences are more marked than gender differences. For example, of the students who failed to achieve a qualification at school, Māori males formed the highest percentage, followed by Māori females, Pacific males, 
and then Pacific females through to Asian females who had the lowest percentage of non-qualification.

Lashlie's (2005) work on how boys think, interact, and identification of what are some of the crucial elements to their success in life, applies to all male students. The role of the teacher in education is also important. Carpenter (2001), for example, notes the power of the teacher and their integral role in delivering curriculum. Evans (2011) points out that teachers who understand the significance of this role and can provide pedagogical practices that reflect the cultural diversity of their students are more likely to succeed in raising student's achievement.

McMillan's (2012) study provides an example of the importance of the nature of the relationships between Pacific boys and teachers within a secondary school, such as suggested by Carpenter (2001). McMillan (2012) explored the effectiveness of interventions aimed at improving the engagement and achievement of the boys at the school where he was teaching. This particular intervention identified the need for the teachers as facilitators to commit to handing over ownership of the learning to students. Both of the facilitator respondents spoke of the bond that had developed within the group as a consequence of this sharing of roles (p. 105). According to McMillan the programme, which improved the engagement of Māori and Pacific boys, was one of constant evolution, incorporating activities and values that embrace the cultures of the participants. He explains that the results are evidence of a genuine attempt to engage the boys; to identify the students as located within their culture, and then to develop skills which have relevance in a real world situation.

McMillan's research contributes to the debate around the engagement of Māori and Pacific boys in schools in New Zealand. He also acknowledges the need for more research to be carried out to improve the life chances of boys, arguing that educators and schools have to play their part in shaping a society that gives equal opportunities and expectations to all regardless of background, gender, and ethnicity (p. 116). 
In the next section of this literature review, I review the concept of sense of belonging, and how this is interpreted within a secondary context and amongst students within a secondary school setting.

\section{Sense of Belonging}

As the literature shows, the idea that people desire social bonds and connections with others has a long history in psychological research. This desire has been referred to as the need for affection between people (Murray, 1938), the need for positive regard from others (Rogers, 1951), the need for belongingness (Baumeister \& Leary, 1995; Goodenow, 1993a; Maslow, 1954), the need for affiliation motivation (McClelland, 1987), and the need for relatedness (Deci \& Ryan, 1991; Ryan, 1993; Vallerand, 1997). The need for social bonds and connections has also been defined in a number of ways. For example, Deci and Ryan (1991) suggest that the need for relatedness "encompasses a person's striving to relate to and care for others, to feel that those others are relating authentically to one's self, and to feel a satisfying and coherent involvement with the social world more generally" (p. 243). Vallerand (1997, p. 300) suggests that the need for relatedness "involves feeling connected (or feeling that one belongs in a social milieu)".

Goodenow (1993b), proposes that a sense of belonging at school reflects "the extent to which students feel personally accepted, respected, included, and supported by others in the school social environment" (p. 80). Baumeister and Leary (1995) suggest that the need to belong is characterised by a need for regular contact and the perception that the interpersonal relationship has stability, affective concern, and is ongoing. In their seminal article on the importance of the sense of belonging to wellbeing, Baumeister and Leary (1995) propose the "belongingness hypothesis", suggesting that "human beings have a pervasive drive to form and maintain at least a minimum quantity of lasting, positive, and significant interpersonal relationships" (p. 497).

According to Maslow (1954), failure to have belongingness needs met may lead to feelings of social isolation, alienation, and loneliness. Thus, a sense of belonging can be seen as a precursor to social connectedness. In their detailed 
analysis of the relevant research, Baumeister and Leary (1995) argue that the need for belongingness is more than the need for social contact. It is the need for positive and pleasant social contacts within the context of desired relationships with people other than strangers. That is, the need for belongingness is satisfied by an interpersonal bond marked by "stability, affective concern, and continuation into the foreseeable future" (p. 500). According to Baumeister and Leary, there is an important connection of interactions with other people that is essential for satisfying the need to belong. As their need for belonging has been met, and is no longer such a significant drive, individuals do not express or display the need for belonging as strongly as those for whom this need has not been met. Importantly, however, individuals differ in the strength of their need to belong. As Kelly (2001) points out, people with a lower need to belong may be satisfied by few contacts, while others with a greater need to belong may need many such contacts. Kelly suggests that it is the lack of satisfaction with personal relationships relative to their need to belong that puts the individual at risk of loneliness. Maslow (1968) indicates that beneath most emotional breakdowns lies a need for belongingness, and being loved and respected.

\section{Sense of belonging amongst students}

Proper, adequate, and timely satisfaction of the need for belongingness leads to physical, emotional, behavioural, and mental well-being (Maslow, 1968).

Reviewing the literature of defining "belonging", it is clear that the concept of feeling or sense of belonging within a school context has been an ongoing topic for academic discussion (Goodenow, 1993b; Osterman, 2000).

Good and Weinstein (1986), state that in the early 1980s research on education focused on the academic aspects of schooling with an emphasis on intraindividual processes regarding learning and teaching, at the expense of the social context where these processes took place. Only recently have researchers begun incorporating the social aspects of schools into their research when studying the effects of schooling on various psychological and behavioural outcomes (Osterman, 2000). In this growing literature students' sense of belonging emerges as a frequently researched construct (Deci \& Ryan 1991; Goodenow, 
1993b). Sense of belonging at school - also referred to as school attachment, sense of relatedness, sense of school community, or school membership - is defined as an individual's being part of a social group in the school that $s / h e$ values and feeling accepted and valued by the members of that group (Goodenow, 1992). Research has confirmed a positive association between students' attitudes and affect towards their schools and various academic outcomes, and academic self-efficacy in all levels of schooling, ranging from primary school to secondary years (Osterman, 2000, Pajares \& Urdan, 2006).

Goodenow (1993b) describes the sense of belonging in educational environments as:

Students' sense of being accepted, valued, included, and encouraged by others (teacher and peers) in the academic classroom setting and of feeling oneself to be an important part of the life and activity of the class. More than simple perceived liking or warmth, it also involves support and respect for personal autonomy and for the student as an individual. (p. 25)

Many educational researchers agree that the need for belonging is one of the most important needs of all students to function well in all types of learning environments (Connell \& Wellborn, 1991; Deci \& Ryan, 1991; Finn, 1989; Osterman, 2000). The feeling of belonging may have a direct and powerful influence on students' motivation (Goodenow, 1993b). For example, perceived support and the sense of belonging are expected to increase students' belief in their success and accordingly to increase their academic motivation. Making an argument based on an American system, Goodenow (1993b) states that one of the reasons that there is a poor fit between the opportunities provided by middle school environments and the developmental needs of adolescents is that middle school environments do not respond adequately to students' need for belonging and support, which leads to a decrease in student academic motivation. Although the American middle school level ranges from the ages of eleven to fifteen, there are similar arguments that could align with the New Zealand context. 
Further to this, Goodenow (1992) suggests that belonging and support may be especially important for academic motivation, engagement, and performance of adolescents coming from ethnic minorities and economically less advantaged families. In a review, Becker and Luthar (2002) support Goodenow's assertion, arguing that one of the key factors that affects economically disadvantaged minority students' academic motivation and classroom engagement in middle schools is the lack of a sense of belonging in the classroom or in the school.

In fact, many studies show reveal that students who experience a sense of belonging in educational environments are more motivated, more engaged in school and classroom activities, and more dedicated to school (Osterman, 2000). Moreover, much contemporary research suggests that students who feel that they belong in learning environments report higher enjoyment, enthusiasm, happiness, interest, and more confidence in engaging in learning activities, whereas those who feel isolated report greater anxiety, boredom, frustration, and sadness during the academic engagement that directly affects academic performance (Furrer \& Skinner, 2003). Satisfying the need for a sense of belonging in educational environments takes on a greater importance during early adolescence. Students within that developmental period begin to look towards peers and adults outside their family for guidance (Roeser, Eccles, \& Sameroff, 1998) and their "sense of personal 'place' is still largely adaptable and liable to influence in both positive and negative directions" (Goodenow, 1993b, p. 81). If the need for belongingness is not adequately satisfied in educational environments, students will look for other ways and people to get that satisfaction. For example, a link has been found between a lack of sense of belonging and delinquency (Baumeister \& Leary, 1995).

Furthermore, a sense of belonging decreases the experience of stress and school-related anxiety as well as the experience of self-consciousness, especially in early adolescent years (Boekaerts, 1993; Goodenow, 1993b; Roeser, Midgley, \& Urdan, 1996).

According to Goodenow (1992), increased self-consciousness in adolescence may negatively affect students' classroom engagement due to a heightened feeling of public exposure, which stimulates the experience of negative emotions, 
such as embarrassment and shame. On the other hand, a sense of belonging in the learning environment may balance students' increased sense of public exposure (Goodenow, 1993a). Additionally, research supports that sense of belonging mediates the relationship between contextual variables of the I earning environment (for example, teacher-student relationships and classroom goal structures) and self-efficacy beliefs of adolescents (Roeser, Eccles, \& Sameroff, 1996; Roeser, et al., 1998). Studies also report positive associations between adolescents' feelings of belonging and academic achievement, academic helpseeking behaviour, and avoidance of self-handicapping behaviours (Dorman \& Ferguson, 2004; Newman, 2003).

The sense of classroom belonging leads to the formation of sense of school community, which increases students' positive behavioural, psychological, and social outcomes such as achievement motivation, self-esteem, self-efficacy, academic, and social intrinsic motivation and competence and decreases negative outcomes such as delinquency and drug use (Battistich, Solomon, Watson, \& Schaps, 1997). Osterman (2000) argues that satisfaction of the need for belonging in educational environments is closely associated with students' academic engagement and involvement in school and classroom activities, academic and social behaviours, motives and attitudes, expectancies, values and goals, emotional functioning, and the development of fundamental psychological processes (for example, intrinsic motivation, self-regulation, internalisation, and autonomy), and psychological outcomes like self-concept, self-esteem, and selfefficacy.

Finn (1989) suggests that perceived feelings of belonging may decrease at-risk students' alienation from school and their decision to drop out of high school. The participation-identification paradigm, explained by Finn, emphasises that the lack of sense of belonging leads to adolescents' physical withdrawal from schoolbased activities and results in academic failure, which provokes non-identification with the school (emotional withdrawal) and alienation.

In several related studies, Goodenow (1993b) examined the association between adolescents' sense of belonging and their expectancies, values, motivation, effort, and achievement. In the first study, involving the development of The 
Psychological Sense of School Membership (PSSM) Scale, Goodenow investigated the relationship between a sense of school membership, expectancy of success, and value. The findings for this study in America revealed that the sense of school membership is significantly associated with expectancies for school success and educational value but not statistically significantly related to academic effort or behaviour. Goodenow suggests that motivation might be mediating the relationship between the sense of school membership and academic effort and achievement. Goodenow goes on to suggest that classroom belonging and support emerge as the most powerful and significant predictor of adolescents' educational values and expectations of success. Although this study focuses on a large number of students in America, the argument by Goodenow can also apply to tama Samoa in the New Zealand context, the aspect of motivation plays a role in how tama Samoa also relate and build their sense of belonging within the secondary schools they attend. According to Goodenow, the most powerful single factor associated with students' effort and achievement is students' perceptions of teachers in terms of teacher interest, support, and respect for students.

Roeser et al.'s (1996) study on the relationship between the contextual factors of school environment and students' motivational, emotional, and academic outcomes had two hundred and ninety-six eighth-grade students participating. Students' responses to self-report questionnaires revealed that students' perceived sense of school belonging was one of the most powerful predictors of their perceived academic self-efficacy. The sense of school belonging showed a small but significant positive relationship to the academic outcomes. Students who reported a high sense of belonging in the school environment reported less self-consciousness (e.g., nervousness and embarrassment) in their task-related engagements in the class and school than those who reported a lower sense of belonging to the school. The feeling of school belonging was also significantly associated with positive school affect (e.g., good mood and happiness).

\section{Student belonging and student persistence}

Being able to establish a sense of belonging within an academic environment has a powerful effect on students' emotional, motivational, and level of engagement. 
The concept of belonging is often used interchangeably with social integration. However, Hurtado and Carter (1997) argue for sense of belonging as a measure empirically distinct from integration. Sense of belonging is a psychological factor focusing on students' subjective feelings of connectedness or cohesion to the institution. In a longitudinal study, Hurtado and Carter explored a set of factors associated with sense of belonging, concluding that these were essential contributors to student persistence to feel a sense of belonging while at school. By including a separate measure of sense of belonging, researchers are able to examine both the participation in particular activities and what that participation means to the student. Following this, it can be argued that sense of belonging taps into feelings or perceptions of association or group membership (Maestas, Vaquera, \& Munoz Zehr, 2007).

A sense of belonging within a school environment is about having a connectedness, relatedness, and identification within a school. The literature indicates that when a student feels a personal connection to a school and perceives that their contribution is valued, this plays a significant part in developing a sense of belonging within the school environment. However, although identity formation and belonging are widely recognised as key to student motivation, there is a significant gap in the research literature; that is, there is none that investigates tama Samoa and their experiences and perceptions of belonging in New Zealand mainstream secondary schools. This study begins to address that gap.

\section{STUDENT SELF-EFFICACY}

Self-efficacy is a person's judgment about being able to perform a particular activity. It is a student's "I can", or "I cannot" belief. Unlike self-esteem, which reflects how students feel about their worth or value, self-efficacy reflects how confident students are about performing specific tasks. High self-efficacy in one area may not coincide with high self-efficacy in another. Self-efficacy is specific to the task being attempted. However, having high self-efficacy does not necessarily mean that students believe they will be successful. While self-efficacy 
indicates how strongly students believe they have the skills to do well, they may believe other factors will keep them from succeeding (Zimmerman, 2000).

A growing body of research reveals that there is a positive, significant relationship between students' self-efficacy beliefs and positive experiences within the school setting. Zimmerman (2000) notes the emergence of self-efficacy as a highly effective predictor of students' motivation and learning. As a performance-based measure of perceived capability, self-efficacy differs conceptually and psychometrically from related motivational constructs, such as outcome expectations, self-concept, or locus of control.

Bandura (1986) defined self-efficacy as:

People's judgments of their capabilities to organize and execute courses of action required to attain designated types of performances. It is concerned not with the skills one has but with judgments of what one can do with whatever skills one possesses. (p. 391)

Zimmerman (2000) stated by the time students are in college or university their self-efficacy beliefs are more strongly related to their achievement than any measure of their ability. If we wish to develop high educational achievement among students, it is essential that we begin building stronger self-efficacy as early as possible (Zimmerman, 2000).

Bonne's (2012) thesis on students' perceptions of self-efficacy within a New Zealand context states that self-efficacy judgments relate to a person's perceptions of what they can do - their task-specific capabilities - rather than a person's overall affective evaluation of their self-worth and the degree to which their behaviour matches their personal standards, otherwise known as selfesteem.

Schunk and Pajares (2006) note that, in 1986, when Bandura put forth a social cognitive theory of human functioning, he painted a portrait of human behaviour and motivation in which individuals' self-beliefs are critical elements. Continuing their argument, Schunk and Pajares state that of all the beliefs that people hold about themselves and that affect their day-today functioning, and standing at the 
core of social cognitive theory, are self-efficacy beliefs, which can be defined as the judgments that individuals hold about their capabilities to learn or to perform courses of action at designated levels. Furthermore Schunk and Pajares claim that, in essence, self-efficacy beliefs are the self-perceptions that individuals hold about their capabilities.

According to Bandura's (1977) social cognitive theory, self-efficacy beliefs provide the foundation for human motivation, well-being, and personal accomplishment. Unless people believe that their actions can produce the outcomes they desire, they have little incentive to act or to persevere in the face of difficulties. Bandura goes on to suggest that these self-perceptions connect every aspect of people's lives - whether they think productively, or optimistically; how well they motivate themselves and persevere in the face of adversities.

Schunk and Pajares (2006) state that self-efficacy is a critical determinant of the self-regulatory practices in which individuals engage as they go about the important task of self-correcting their actions and cognitions. Self-efficacy beliefs should not be confused with outcome expectations, which are people's judgments of the consequences that their behaviour will produce. Furthermore Schunk and Pajares also state that, typically, self-efficacy beliefs help foster the outcome one expects. Confident individuals anticipate successful outcomes. Students confident in their social skills anticipate successful social encounters. Furthermore, those confident in their academic skills expect high marks on exams and expect the quality of their work to reap academic benefits. The opposite is true of those who lack confidence. People who doubt their social skills often envision rejection or ridicule even before they establish social contact. Students who lack confidence in their academic skills envision a low grade even before they begin an exam or enrol in a course. The expected results of these imagined performances will be differently envisioned: social success or greater career options for the former, social isolation or curtailed academic possibilities for the latter. 


\section{Self-efficacy in academic motivation}

Self-efficacy beliefs are also influenced by the verbal messages and social persuasions individuals receive from others, whether these are intentional or accidental (Bandura, 1997). These messages can help one to exert the extra effort and persistence required to succeed, resulting in the continued development of skills and of personal efficacy, or they can be powerfully disheartening. Persuaders play an important part in the development of an individual's self-efficacy beliefs.

Bandura (1997) found evidence that students with self-efficacy participate more readily, work harder, persist longer, and have fewer adverse emotional reactions when they encounter difficulties than do those who doubt their capabilities. It was also noted by Bandura that student's beliefs about their efficacy to manage academic task demands can also influence them emotionally by decreasing their stress, anxiety, and depression.

Zimmerman, Bandura and Martinez-Pons (1992) argue that self-efficacy provides students with a sense of agency to motivate their learning through use of such regulatory processes as goal setting, self-monitoring, self-evaluation, and strategy use.

Schunk and Pajares (2006) also agree with the advantages of self-efficacy and make the point that self-efficacy beliefs also influence an individual's thought patterns and emotional reactions. High self-efficacy helps create feelings of serenity when approaching difficult tasks and activities.

Zimmerman (2000) claims that students' self-perceptions of efficacy are distinctive from related motivational constructs because of their specificity and close correspondence to performance tasks (p. 89).

In reviewing the notions of self-efficacy, then, I sensed that it provides many advantages to developing young people to succeed at school and, in particular, at secondary school. 


\section{SUMMARY}

This chapter has explored the literature related to a number of interconnecting threads. Firstly, the literature indicates that it is during the developmental stages of adolescence that young people begin to establish distinct cultural and social identities. Some theorists such as Erikson (1970) have highlighted the different components that influence identity formation. However, as argued by Tupuola's (2004) critique of Erikson's work, from a Pacific perspective these Western ideas of how humans develop a sense of self are not necessarily congruent with the factors that impact on the development and influences of a Pacific adolescent.

The literature also indicates that when a student feels a personal connection to a school and perceives that their contribution is valued, this plays a significant part in developing a sense of belonging within the school environment. However, although identity formation and belonging are widely recognised as key to student motivation, there is a significant gap in the research literature; that is, there is none that investigates tama Samoa and their experiences and perceptions of belonging in New Zealand mainstream secondary schools.

According to the literature, self-belief and self-regulation are key to young peoples' successful secondary school experiences, as well as enabling them to prepare for the next journey once secondary school is complete. However, I also found that within the literature base on self-efficacy, there is limited investigation of the influences of cultural differences and mismatches in general and, more specifically, of the significant contributing factors for Pacific students' development of self-efficacy within secondary school. Clearly, given the situation outlined in the section "Pacific boys in education", this is an area that requires investigation.

The next chapter, presents the theoretical paradigms used in this thesis along with a description of methods used. It will also provide a description of analysis used to interpretive the data. 


\title{
CHAPTER THREE: METHODOLOGY
}

\author{
Sasa le Niu'afa i le pulu
}

(Beating the husk of the Niu'afa)

\section{INTRODUCTION}

The aim of this study was to identify tama Samoa perceptions of what factors influence their schooling experiences and the impact this has on their decisions. It was anticipated that an analysis of the experiences and perceptions shared by the tama Samoa would reveal ways in which they develop and perform their identities, within secondary school. The study also provides an opportunity to reveal what contributes to their sense of belonging at school, and how these experiences at secondary school influence their aspirations for their future beyond secondary school.

The overarching research question was: In what ways do tama Samoa experiences within a secondary school context contribute to their identity, sense of belonging, and aspirations for the future?

The three sub-questions were;

1. In what ways are tama Samoa identities influenced by their secondary school experiences?

2. What is the nature of the relationship between tama Samoa sense of belonging and their daily experiences within secondary school?

3. What experiences have tama Samoa had during secondary school that have contributed to their aspirations for the future?

This chapter is divided into two parts. Part one is a discussion of the theoretical framework and methodology selected for this study. However, before I discuss this, I take the opportunity to discuss the purpose of theory in an educational 
setting. I then discuss the interpretive paradigm and how this paradigm was deemed to be the most appropriate for this study. I then discuss my position as a researcher within this study. I also discuss Pacific research frameworks and the value of using Pacific research frameworks when working with Pacific participants. Following this I introduce the fa'afaletui framework and justify its use as both a methodology and method for this study.

In part two, I present the methods selected for this study and identify the process used for selecting the tama Samoa participants. The procedures for collecting and analysing the data are also described. The ethical and cultural issues related to this study are taken into consideration and discussed. Issues surrounding credibility and validity are also discussed. The chapter concludes with an overview.

\section{PART ONE: The Role of Theory in Educational Research}

The application of theory to educational research is of great importance and serves many functions. Its purpose and features are variable and can be complex; however, it has a key role to play in educational settings.

Suppes (1974) provides a clear argument about why theory is important and relevant in educational research. In Suppes' (1974) article, "The place of theory in Educational Research", he identifies five key arguments to validate and to justify the need for theory within educational research. The first relates to the idea of building analogies and making universal generalisations. Kettle (2011) elaborates on Suppes' idea by stating how this key idea of building analogies and making universal generalisations has a similar function to the way theoretical advancement underpins the natural science. This is the classical and standard notion of theory. Kettle continues to state that this argument "serves as a reservoir to make predictions on the basis of analogue situations" (p. 5).

The second of Suppes' arguments is the recognition of experience: this places theory as relevant because it can change our perceptions about what is important and what is not. Suppes' third key argument about the role of theory in educational research is that theory nurtures our ability to recognise complexity. Kettle (2011) elaborates on Suppes' third argument, by stating that in matters of 
investigation what appears to be simple on the surface actually turns out to be complex on a deeper level. The fourth key argument is the transformation of a situation. The further argument here is the idea that inquiry or problem solving as a theoretical device can allow for theory to become a potential tool for problem solving by the way theory offers a continually developing perspective on life.

Suppes' final key argument to highlight the importance of theory in educational research is that theory serves as a tool to protect against "triviality empiricism". To avoid the triviality of empiricism is to suggest that theory can be a vehicle of acknowledging the facts and anecdotes being protected and the use of theory can place the data collected to future use. As summed up by Kettle (2011), if the data collected has no theoretical framework it leads nowhere.

Each one of Suppes' (1974) five key arguments is relevant in supporting my own study, particularly in terms of protecting the "facts and anecdotes"; that is, the experiences and perceptions of the tama Samoa in this study. This is because the facts and anecdotes contain the lived experiences of tama Samoa which deserve to be theoretically unpacked and thus preserved through theorisation.

The idea of theory within research complements Kuhn's (1962) notion of paradigmatic thinking. For Kuhn, a paradigm represents the way that the world is seen through people's perceptions, understandings, and interpretations. Associated with this is the notion of paradigmatic shifts. The paradigm is, therefore, a way to model possible patterns and relationships which Barker (1992, p. 32) suggests "establishes or defines boundaries". Thus, paradigms and conceptual frameworks display certain similar dimensional characteristics and roles in doctoral research.

According to Kuhn (1962), paradigms are normative; they determine what the researcher views as important and not important, reasonable and unreasonable, legitimate and illegitimate, possible and impossible, and what to attend to and what to ignore. Paradigms prove to be constitutive of all normal scientific activity, including underlying assumptions made, problem definition, areas of investigation, questions posed and, particularly, data interpretation, conclusions drawn, and policy recommendations made at the end of the research process 
(Kuhn, 1962). Thus all theories as well as the methods generated by them are, ultimately, paradigm based.

Overall Kuhn's idea of paradigm suggests that a paradigm is the set of guiding principles and ontological assumptions functioning within a research study. According to Kuhn's notion, a paradigm shift explains changes in how "something" is perceived and influenced. Further to this, Covey (1989) observed that, "whether they are transitory or developmental paradigm shifts move us away from one way of seeing the world to another" (p. 30). The discussion around the idea of paradigm shifts is important for the following reason: in the past, social activity was conceived as science and therefore science rules were applied to research. This involved proof and prediction. The paradigmatic shift was the move to a position where understanding replaces proof, and appropriate future action based on understanding replaces prediction. In this paradigmatic environment the words of tama Samoa are the data which inform the understanding. However, for a researcher to develop this understanding $s /$ he must first acknowledge that all social life is interpreted; hence the following discussion of the interpretive paradigm and its purpose and suitability for this particular research.

\section{Phenomenology}

In order to understand the experiences and perceptions of the tama Samoa, a qualitative approach was essential. Qualitative researchers focus on the natural world, and assume that an understanding of human experience can be gained by exploring the contexts in which individuals interact. Recording complex and contextualised social interactions helps the researcher to approach an understanding of the meanings that the participants attribute to these interactions (Marshall \& Rossman, 2006; Richards, 2005). Researchers use interpretative skills to understand the data, and results emerge through an iterative and reflective process (Rossman \& Rallis, 2010). "Evidence" and "proof" are generated through this process of exploring and clarifying the meaning of the shared experiences and contributions of participants. 
Specifically, a phenomenological approach was adopted in this study. Phenomenology involves the researcher relating to the experiences which the participants describe and then analysing and interpreting what has been said (Smith, Larkin, \& Flowers, 2009; Smith \& Osborn, 2004). As stated by Thomas (2010), literally, phenomenology is the study of "phenomena": appearances of things, or things as they appear in our experience, or the ways we experience things, thus the meanings things have in our experience. It is the study of structures of consciousness as experienced from the first-person point of view. In its most basic form, phenomenology attempts to create conditions for the objective study of topics usually regarded as subjective: consciousness and the content of conscious experiences such as judgments, perceptions and emotions. Creswell (1998) contends that a phenomenological study describes the meaning of the lived experiences for several individuals about a concept or the phenomenon (p. 51).

This study employed the qualitative techniques of focus group and talanoa through semi-structured interviews in order to gain insight into the meanings behind the tama Samoa experiences. My role as researcher is to move beyond the description of the actual experiences such as the anecdotes and facts. Essentially, this is where I attempt to understand how the tama Samoa make sense of the world. The process of accessing their stories requires a careful approach so that I am able to gain insight into a world where tama Samoa may not necessarily express what they are really thinking (Smith \& Osborn, 2004), or may not be consciously aware of the thought processes which underlie their experiences (Giorgi \& Giorgi, 2004). It is also my role to search initially for significant statements and meanings given by the tama Samoa that relate to the key themes of this study: identity; sense of belonging; and future direction (Johnson \& Christensen, 2004).

Although the data deals with the subjective world of thoughts and feelings, Giorgi and Giorgi (2004) argue that it requires an objective and rational method for collating, organising, and analysing the findings. However, to do this, we must avoid or remove our own assumptions and beliefs in order to break down our observations of the participants until we arrive at the very essence of what the participants are thinking (Heap \& Roth, 1973; Sadala \& Adorno, 2002). This 
concept of obtaining rational findings based on the subjective world of individuals has come under much discussion in the world of research and philosophy.

Finlay (2005) has developed a research practice called "reflexive embodied empathy" which she believes takes the principle of empathy to a heightened level so that it closely knits the thoughts of the participant with that of the investigator. She describes a three-layered approach which the researcher can use, alternating between the different layers in a fluid and subtle manner. On one level, one should put aside personal views and assumptions about the world in order to empathise with and learn the world view of the participant. At another level, one makes an imaginative transposition, temporarily taking on the other's emotions and feelings, to try and relive those same experiences as if they were your own. By reporting back these perceptions of what the tama Samoa may be thinking and feeling, using the fa'afaletui process it is possible to clarify to a degree if these perceptions are aligned with what is shared by tama Samoa . Finally, the third layer suggests such a thorough immersion in the data that, for a brief period, it is not possible to separate the thoughts of "l", the investigator, from those of the "other", the one being investigated.

Finlay (2005) credits the third layer of her approach to the philosopher, Merleau Ponty, who believed that it is through our body that we experience the world; and as we use our bodily faculties to make sense of something else or someone else (e.g., touch someone's arm), we are also subject to the same process from someone else. This insight is important to this particular research, because as a Samoan woman researcher working alongside tama Samoa, there will be moments of commonality.

In summary, data gathering for this study was undertaken from a phenomenological perspective. The aim was to uncover the thoughts, both conscious and unconscious, of participants, and to produce rich and insightful data. 


\section{Interpretive Research}

The philosophical base of interpretive research is in both hermeneutics and phenomenology (Boland, 1985). The interpretive paradigm is based on the understanding that knowledge does not exist as a set of universal laws, but is created as a construct whereby people derive meaning from the world around them. As described by Price (1992), the process involves "elucidating meaning by constructing new understandings from existing meanings" (p. 66). According to Hyndman (2007), the methods used for interpretive research are "qualitative" because, rather than seeking to measure experiences (as in "quantitative" approaches), they seek to explain them. The interpretive paradigm supports the belief that reality is constructed by subjective perceptions and predictions cannot be made. Principally, interpretative phenomenologists believe it is impossible to rid the mind of preconceptions and to approach something in a completely blank or neutral way. They believe instead that we use our own experiences to interpret those of others.

As stated by Klein and Myers (1999), the underpinning philosophy for interpretive research is that knowledge is gained, or at least filtered, through social constructions such as language, consciousness, and shared meanings. In addition to the emphasis on the socially constructed nature of reality, interpretive research acknowledges the intimate relationship between the researcher and what is being explored, and the situational constraints shaping this process. In terms of methodology, interpretive research does not predefine dependent or independent variables, does not set out to test hypotheses, but aims to produce an understanding of the social context of the phenomenon being investigated and the process whereby the phenomenon influences and is influenced by the social context (Walsham, 2006).

Keeping the above definition of interpretive research in mind, I decided to make it my philosophy that, when accessing knowledge, the people who would work with me would be the source of the knowledge, and it would be for only a slight moment that I would be stepping into the world of tama Samoa who had offered to take part in this research. I was interested in the social construction of meaning, the understanding that participants were studied as active agents. At this point of 
the research the tama Samoa and their anecdotes would be protected through the theorisation of the research. As an interpretive researcher I was aware that my task was to attempt to interpret and understand the tama Samoa's reasons for social actions, the way they construct their lives and attach meanings through theorisation which, according to Guba and Lincoln (1994), is sometimes known as phenomenology.

As identified by Lincoln and Descombe (2005) the entire field of the interpretive paradigm is itself still emerging and being defined. Interpretive research methods are likely to be criticized by those of a positivist persuasion because they uphold variations of a relativistic ontology of multiple, individually constructed but socially and culturally constrained realities. Pragmatic and moral concerns are important considerations when evaluating interpretive research. Fostering a dialogue between researchers and respondents is critical. It is through this dialectical process that a more informed and sophisticated understanding of the social world can be created. Such understanding is the aim of interpretive research.

The interpretive paradigm permitted me to assume that tama Samoa would make their decisions and act in accordance with their subjective understandings of the situations in which they found themselves. I was particularly interested in the notion that tama Samoa understood their experiences through the meanings found in their everyday lives through the relationships they had built. This was an opportunity to look through the eyes of tama Samoa. It was through an interpretive approach that I was able to build rich local understandings of the lifeworld experiences the tama Samoa had within.

However, it is important to consider some of the critical views of the interpretive paradigm. By doing so, I am able to reflect and argue that research paradigms developments are ongoing and that there are moments when research topics and research paradigms do not necessarily match. Considering these Bernstein (1974) suggests that subjective reports from participants may be incomplete and misleading. What is overlooked about such negotiated meanings, observes Bernstein, is that the very process by which one interprets and defines a situation is itself a product of the circumstances in which one is placed. One important 
factor in such circumstances that must be considered is the power of others to impose their own definitions of situations upon participants.

Interpretive research methods are also likely to be criticised because they uphold variations of a relativistic ontology of multiple, individually constructed but socially and culturally constrained realities. This may be so in past research, however the value of an interpretive paradigm within this particular study will be carefully monitored by myself as researcher but also through the use of the fa'afaletui framework when collecting the data from tama Samoa, the importance of their voices will be carefully analysed with tama Samoa.

Pragmatic and moral concerns are important considerations when evaluating interpretive research. Fostering a dialogue between researchers and respondents is critical as this is a way of being consistent with acknowledging the tama Samoa and their voices throughout this research. It is through this dialectical process that a more informed and sophisticated understanding of the social world can be created and through the variation and individualism becomes valuable because the key goal for this study was to provide a space to voice the experiences of tama Samoa and how secondary schools cater and support tama Samoa in building their identities, provide a sense of belonging and guide them to future aspirations.

\section{Position as Researcher}

Phenomenology, when viewed from a hermeneutic perspective, accepts that researchers bring personal bias into their work. It acknowledges that researcher and participant come together to produce data which has evolved from a collaborative process of constructing meaning. Researchers need to be aware of their own role in the data-making process; they need to engage in reflexivity where they consider any prejudices and beliefs which might colour their findings (Johnson \& Christensen, 2004). As Richards (2005, p. 42) puts it, "You yourself are part of what you are studying" and as the research journey unfolds, it is not only an understanding of the participants which evolves but a process of selfunderstanding too (Findlay, 2005). 
My position as the researcher within this study is that I hold the view that there exist multiple realities socially constructed by people; that is, I have an interpretive, phenomenological orientation. Consequently, I acknowledge that these constructs impact on people's lives and their interactions with others (Lodico, Spaulding, \& Voegtle, 2006; Patton, 2002). My viewpoint has been influenced by both past and current life experiences: for example, the experiences of sharing stories with my nephews and, interpreting my nephews' experiences of secondary school. I was able to use their stories to contribute to identifying how these experiences related or did not relate to tama Samoa identity formation, sense of belonging, and future aspirations. My own upbringing was moulded through my aiga (family). This does not just include my mother, father, sister, and brother; it also includes my extended family - my aunties, uncles, and first cousins. The foundation of my aiga was influenced through Christian values reinforced by attending the Congregational Church of Samoa (Petone) since birth and as a family which now includes a nephew and two nieces, who continue to attend as serving members. These two major influences within my life, family and church, capture the importance of having trusted relationships with people, which now includes the tama Samoa from this study. As a researcher my position was of someone attempting to co-create and share knowledge. The knowledge generated by this study - knowledge about how better to support and to provide tama Samoa with a more positive space and place within the secondary school context - belongs to the tama Samoa and to their secondary schools.

Acknowledging the role that your own values play in all stages of the research process is of great importance if results are to be credible. Heron (1996) argues that our values are the guiding reason for all human action. Interpretive research is based on interpretations in a particular moment. That is, they are located in a particular context or situation and time. They are open to re-interpretation and negotiation through conversation. By assuming a reality that cannot be separate from our knowledge of it (no separation of subject and object), the interpretive paradigm expects that the researcher's values are inherent in all phases of the research process. Truth is negotiated through dialogue. Findings or knowledge claims are created as an investigation proceeds. That is, findings emerge through 
dialogue in which conflicting interpretations are negotiated among members of a community.

The significance of my gender as a Samoan woman doing research on tama Samoa must also be noted. There are two areas for discussion in this section: a) my gender as a Samoan woman, and b) my culturally informed role within this research.

Firstly, as a Samoan woman the research topic was initiated by the talanoa I had with my nephews; therefore my role as their aunt allowed for them to share and talk with me about their secondary school experiences. The relationship formed with my own nephews is culturally framed and this was also the manner that I approached the tama Samoa within this study. By removing the idea of just being a researcher the relationship between myself and the tama Samoa was built on trust through understanding the va (space) and relationship between myself and the tama Samoa of this study. The distinctive role that I played within this research was an important aspect of building trust between myself and the tama Samoa.

Meeting the tama Samoa for the first time, I was aware that their initial thoughts or perspective of me are of an older woman (my gender). The gender relations in the fa'aSamoa are determined by familial roles, it is not a male or female binary; rather, the roles of being a family member such as daughter, sister, mother or aunt have tremendous significance which are arguably distinctively different than that of Western familial relations. My age was also important, being an older sister, or being the sister of a parent and being sufficiently older to garner respect and trust.

In terms of my culturally informed role, there is mana, a culturally ordained authority, in being a sister of a person's parent. There is a degree of informality in the relationship between a Samoan aunt and her nephews and nieces which it is sometimes not possible to have with one's parents within Samoan culture. In this relationship between an aunt and her nephews or nieces warmth, affection, informality and trust ensue, within which young people confide and share in ways they may not do with their parents, teachers, or other formal authority figures. 
This exploration of who I am as a researcher is an asset in this particular qualitative study. For this particular study, my role as a past classroom practitioner and the experience of working within a secondary school environment contributed to the opportunity to capture the voices of Pacific young men and, in particular, tama Samoa.

For the purpose of this study I uphold certain values that pertain to my own upbringing: these values include compassion, endurance, forgiveness, friendship, honesty, hope, humility, justice, respect, service, thankfulness, and wisdom. Many of these values are common to Pacific peoples - "respect, reciprocity, communalism, collective responsibility, gerontocracy, humility, love, service, and spirituality" (Anae, Coxon, Mara, Wendt-Samu, \& Finau, 2001, p. 14). During the process of collecting the data all these values were at work to develop and maintain a relationship of trust and importance as the study unfolded.

Each of these values also relate and align to the use of the fa'afaletui framework. Most importantly, the research was carried out with the students making the study a collective responsibility. The value of respect was demonstrated by me pronouncing the tama Samoa names correctly, and by listening to their experiences without interruption so giving tama Samoa the time to share their stories. Furthermore, as a researcher, paying attention to the atmosphere of the space where the talanoa took place and ensuring that the sharing included fun and laughter reflected the values of friendship and spirituality.

\section{Pacific Research Paradigms}

For the purpose of this research, I took the opportunity to explore, expand, acknowledge and to celebrate the growing of Pacific research paradigms.

It has been argued that traditionally there has been a lack of cultural appropriateness and sensitivity towards Pacific people in relation to applying research methodologies (see for example Smith, 1999). Tamasese, Peteru and Waldergrave (1997) identify the value of reflecting the needs of participants' knowledge base: 
Constructs of method should emerge from and faithfully reflect the intrinsic source of its participants' needs and knowledge bases. The call for legislative and social relief reflects a community which recognises that it is in crisis. It also raises serious questions for the research community regarding their ability to address their own roles and appropriate process of research within communities in crisis. (p. 301)

As indicated by the authors, the ongoing issue is that a lack of understanding when doing research within communities in crisis - in this case within communities of Pacific people - risks resulting in miscommunication and the misinterpretation of data collected.

Linda Smith (1999) supports communities using their own values and makes the following comment, "Indigenous methodologies tend to approach cultural protocols, values and behaviours as an integral part of methodology. They are 'factors' to be built in to research explicitly, to be thought about reflexively, to be declared openly as part of the research design, to be discussed as part of the final results of a study and to be disseminated back to the people in culturally appropriate ways and in a language that can be understood" (p. 15). Smith continues to state that "research is implicated in the production of theories which have de-humanised Māori and other indigenous peoples and in practices which have continued to privilege Western ways of knowing while denying the validity for Māori of Māori knowledge, language and culture" (p. 17). Smith's reference to "other indigenous peoples" may be applied to diasporic groups such as Samoans in Aotearoa, and even more specifically, to the group that is the focus of this study - tama Samoa in New Zealand secondary schools. As pointed out by Gegeo (2008), Pacific scholars have developed number of appropriate modes to represent the diversity within Pacific indigenous epistemologies, the Pacific cultural world view, and theory of knowledge from a Pacific perspective.

Pacific research broad paradigms embrace the ideas of Pacific research frameworks. As indicated by Anae, Coxon, Mara, Wendt-Samu, and Finau (2001), interest in researching Pacific contexts using Pacific methodologies has grown. The authors explain that the primary role of using a Pacific research framework is to develop a unique Pacific world view that is underpinned by Pacific 
values, belief systems, and ways of structuring knowledge. Identifying the value of Pacific ways of doing things provides empowerment for both the researched and researcher (Anae et al., 2001). Further to this the authors suggest that "if research is to make meaningful contributions to Pacific societies, then its primary purpose is to reclaim Pacific knowledge and values for Pacific peoples" (p. 8). The value of reclaiming Pacific knowledge goes back to the idea of Pacific research by Pacific people for Pacific. This continues to be a strength in building research capacity for Pacific people/

Ta'isi (2009), too, emphasises the importance of blending philosophies and methodologies in policy settings and research. Ta'isi suggests that Pacific people should draw on the strengths, understandings, and meanings of their worlds and have their own role models leading the research. According to Ta'isi, if this approach is adopted, Pacific peoples will offer rich new paradigms, greater diversity and colour in practice, and the warm connections of humanity with land, sea, and spirituality (p. 91).

The following explanation by Crocombe, Slatter, and TupouNiua (1975) captures the value of the "Pacific way" of doing research:

talking things over rather than taking rigid stands, being prepared to negotiate being flexible, adaption and compromise, oratory and verbal negotiation, the value of sharing, universal notions of generosity with time, labours and property, Pacific perceptions of time, leisure, dress, food and dancing and the inseparable dynamics of church, and indigenization of Christianity. (p. 14)

This particular description that Crocombe et al. (1975), suggests to better understand Pacific people and Pacific research was identified four decades ago in the 1970s. It acknowledges the importance of identifying appropriate ways for researching Pacific people in a manner that was acceptable to them and the way Pacific people share their knowledge based understandings. The features included in Crocombe's et al. (1975) description contribute to a better understanding of Pacific people and Pacific research. Conducting my research within Pacific research frameworks provides me with an opportunity to determine 
the purpose and goals (specifically targeting education) for my own communities, based on the visions of my Pacific people, their families, and their children.

However, over time there has been an increase in Pacific researchers identifying the need for Pacific researchers to create their own pedagogy and symbolic orders: examples include Anae et al. (2001), Manu'atu (2000), Nabobo-Baba (2004), Taufe'ulungaki (2003), and Vaioleti (2003).

It is important to acknowledge the Pacific research methodologies that some Pacific researchers have used in generating data and knowledge. Tamasese, Peteru, Waldergrave, and Bush (2005) developed the fa'afaletui framework from Samoa. As identified by Tamasese (2008), fa'afaletui is the critical process of tui (weaving) together all the different levels of knowledge frames from within the houses of collective representation, in order that the Samoan world view is substantially enhanced and added to (pp. 22-23). Fa'afaletui is described in more detail in the following section.

Thaman's (1997) model of Kakala as a metaphor for research is based on the process of making a garland of flowers in Tonga. The process involves three important steps: toli, the gathering of flowers; tui, the making of the garlands; and, finally, luva, or the process of giving away or presenting the kakala. Thaman proposes that the three key processes involved in the making of kakala - toil, tui, and luva - are similar to the processes in the conduct of a research process. As explained by Kalavite (2010), who applied the Kakala metaphor to her own research, Thaman's metaphor of kakala symbolically refers to the researcher selecting and gathering the relevant information needed for the research topic (toli); creating the new knowledge from the collected data (tui); and disseminating the knowledge (luva).

Another example of Pacific frameworks that has become increasingly popular within Pacific research is the model of talanoa. As identified by Otsuka (2005), and Vaioleti (2006), talanoa is widely promoted by Pacific academics and researchers in the New Zealand education sector. In his doctoral thesis, Manueli (2012) explains how talanoa is a culturally appropriate qualitative research method for research involving Pacific people (p. 101). In research contexts, 
talanoa can enable the researcher and participants to connect at a deeper level which facilitates the co-construction of authentic, rich, and inter-related knowledge. (Manueli, 2012, p. 100)

The increase of valid theoretical frameworks for Pacific research based on Pacific values is most appropriate for Pacific peoples. The worthiness of using Pacific research frameworks for Pacific people and Pacific education is in the contribution to the body of Pacific knowledge (Kupa, 2009; Nabobo-Baba, 2006). Otunuku (2011) highlights the relevance of Pacific research frameworks with the observation that Pacific academics' scholarly writings on educational issues aim to deconstruct and reclaim Pacific indigenous education. He claims that Pacific academics are proposing a policy and methodology underpinned by the cultural systems of indigenous peoples (p. 43).

However, as discussed by Tupuola (1993), any researcher who does research with Pacific people needs to have a developing understanding of Pacific knowledge and an awareness of Pacific cultures. Tupuola emphasises that knowing and understanding Pacific culture is one thing, but doing something about it is another (p. 54). Sauni (2011) supports this notion and suggests that for Pasifika research appropriate knowledge and willingness to understand cultural values is necessary in order to create cultural knowledge and social construction of cultural identity. Sauni continues by saying that it is the intent and responsibility of Pacific researchers to continue to address cultural issues and to add to collective wisdom.

The use of the Ethnic Inter-Face Model attributed to Wendt-Samu (2006), is proffered as an effective way to guide the researcher through the process (Airini et al., 2010; Anae, 2010; Coxon et al., 2002). This model encourages the researcher to be aware of the cultural make-up of the participants and note how this affects their interaction with the institution in which the study is contextualised.

As stated by Anae (2010), with this increasing pool of researchers able and motivated to undertake quality research on improving Pacific people's outcomes it is critical that good practice that has enhanced Pacific education research and 
policies linkages is identified and acted upon. Anae also emphasises that it is essential that Pacific education research methodologies are explored and that ideas for and about Pacific education research methodologies are shared amongst those who are interested in doing research with Pacific people and or are interested in Pacific research locally, nationally, and globally (p. 1). This is important because more and more interested researchers are studying Pacific people and having an understanding of the Pacific way of informing one's research is not only beneficial for researcher but also the Pacific groups the research is based on.

For this research, then, I was aware, that when working alongside Pacific communities it was important that I undertook the study having identified and become mindful of key values from my own Samoan culture - in particular the values of fa'aaloalo (respect), alofa (love), and tautua (service). As argued by Sauni (2011), conceptualising the underpinning principles of Samoan culture creates a unique platform for honest, genuine dialogue between researcher and participants, despite differences based on gender, institutional status, and cultural status (p. 58).

\section{Fa'afaletui Framework}

In this study the use of the fa'afaletui framework is considered both a methodology and a method for collecting data. According to Tamasese et al. (2005), the purpose of developing the fa'afaletui research methodology was to provide a rigorous research method that would be "relevant and acceptable in a Samoan cultural context". The fa'afaletui methodology "avoided the danger of Western interpretation and meaning construction and enabled an authentic Samoan-based approach" through an exploration of the experiences of Samoan people and "the meanings they construct around critical mental health issues and definitions" (p. 301).

Fa'afaletui is claimed to be a technique or process well suited to conduct Samoa research (Tamasese, Peteru, Waldergrave, \& Bush, 2005). Tamasese et al. (2005) claim that the fa'afaletui framework facilitates the gathering and validation of important knowledge within the Samoan culture. Originally developed to 
enhance mental health service provision in emigrant Samoan communities in New Zealand, fa'afaletui is considered sensitive and responsive to Samoan cultural norms in that context, and to provide a sound basis for research into health needs and the development of health services consistent with Samoan lifeways (Koloto \& Sharma, 2005; Tamasese, 2008; Tamasese, Peteru, Waldegrave, \& Bush, 2005)

To convey an understanding of the term fa'afaletui, I define the word as used in this study. Tuafuti (2011) defines the term from a linguistic perspective. Fa'a is the causative prefix used with a large number of bases and serving many separate functions, which cause someone or something to have or to do something. Fale means house. The word tui in this concept means to "thread through". Tuafuti's definition interlinks well with the literal translation of fa'afaletui as identified by Goldring (2006) in her Master's thesis: capacity building and knowledge sharing between people in communities of practice such as house building. To ensure successful outcomes, cross-cultural projects should be undertaken by way of concepts indigenous to the culture in question. Fa'afaletui is a research framework that enables the collection, sharing, and validation of all the different levels of knowledge within the Samoan community, and the weaving of these knowledges into consensus about a given problem that reflects the Samoan worldview and is acceptable to those concerned (Tamasese, 2008).

As described by Cowley (2013), as a research tool, "fa'afaletui has often been linked metaphorically to a story which some Samoans tell about the respective views of the fisherman, the tree climber, and the man at the top of the hill" (p.83). Cowley continues to describe each of the perspectives saying; "each perspective provides an important decision from which to view the fish (data); however, to encapsulate the data (fish) in its environment, another view, that of the tree climber, is necessary; and to get the complete picture, one may have to climb even further (to the top of the hill)" (p. 83).

Tupuola (1993) argues that for too long non-Western researchers and peoples have had to adopt and adapt to foreign concepts, structures, and research frameworks. She claims the time had come for the Western world of academia to change their way of thinking and provide opportunities for Samoan and other 
Pacific researchers and research approaches and methods. The fa'afaletui framework underpins an inductive methodology that serves to develop a model of understanding from data in a logical style.

In this particular study fa'afaletui is used both as a verb and as a noun. As a verb it refers to the methodology for collecting the data; in this case, the sharing of lived experiences and perceptions by the tama Samoa, the perceptions of the nominated persons, and the contributions from the literature. Fa'afaletui aims at building close relationships between researcher and participants through collaboration. In this study the building of positive relationships with tama Samoa was achieved through an informal gathering in the beginning to get to meet the tama Samoa with food and drink to allow for this relationship to form. As a noun fa'afaletui refers to the results of actual sharing; that is, what emerged from the various stages of analysis of the data. Fa'afaletui helped me to weave together the collective knowledge and perspectives of the tama Samoa and to reach to a consensus about tama Samoa and their understandings of school life experiences. For all these reasons the fa'afaletui framework was deemed culturally and methodologically appropriate to capture the voices of tama Samoa.

\section{PART TWO: Methods}

\section{School selection and participant recruitment}

When identifying secondary schools from which to select tama Samoa for this study, I decided that I would focus on secondary schools that were situated in the Wellington area, in particular within the Hutt Valley district. This was for two reasons: (i) I am from the Hutt Valley district and was already familiar with the area and surrounding secondary schools, and (ii) I was a part time student, and working full time. These commitments of a full time job while also studying, made the decision to stay local easier due to convenience. The starting point for contact was via initial telephone conversations with school principals followed by an email confirmation of the discussion regarding interest in allowing me to enter their school as a researcher. The schools were chosen because they were culturally diverse. This was important to me as a school's culture and its environment has a major impact on the students. Eight secondary schools were contacted. 
However, only three were interested in continuing with face to face meetings. This had some implications for the study, particularly in terms of the number of participants as explained below.

Three secondary schools took an interest. School One is a co-educational, decile eight state school of 1600 students for Years 9 to 13. It has a 7\% Pacific ethnic composition. School Two is a decile five state integrated Boys Catholic school, of 501 students catering from Year 7 to 13. It has a 27\% Pacific ethnic composition. School Three is a co-educational, decile seven state school of 1105 students for Years 9 to 13. It has a $6 \%$ Pacific ethnic composition.

Reviewing the latest Education Review Office (ERO) reports for each of the schools, a common thread across all schools was that each school highlighted the significance of its Pacific students being at the lower end of NCEA results across the levels (ERO 2010, 2011, 2012). One school ERO report did identify specific programmes that the school was offering to cater for the needs of Pacific students. However, it did not identify the outcomes of such programmes. While ERO reports do not specifically focus on tama Samoa, the reports did provide an overall sense of each school's position in terms of their Pacific students.

Once meeting dates were confirmed with each of the secondary schools, an initial talanoa (conversation) meeting was held with the principal from each of the three schools. These meetings allowed me to discuss my research topic of interest, and to provide a timeframe of study. The principals were given an opportunity to ask questions regarding my research interest. One of the three secondary school principals was hesitant about allowing me to conduct research in her school, and asked the question "What will our school get out it"? Reflecting back now on this I realise that the answer I gave at the time persuaded her to let me in her school. My answer to this question was "You will get an overview on tama Samoa perceptions about how they feel about secondary school. I will also return to your school to provide an overview of this study". This particular principal agreed that this would be of value to their school and allowed me to include the school in my project. 
On receiving a positive response from all three principals, a letter was written to each of them outlining the research and seeking written permission to conduct the research in the school (Appendix 1).

Only Year 12 and Year 13 tama Samoa students were considered for this study. The reason for this decision were these students have been at secondary school longest and therefore have more experiences to reflect on. It was expected that these past experiences could give more insight to the research questions provided. At this point of the initial school selection process, principals were asked to nominate Year 12 and Year 13 tama Samoa who they considered would be appropriate for research study.

To guide school principals in selecting tama Samoa I developed the following criteria - tama Samoa must:

1. be Year 12 and Year 13 at their secondary school

2. be of Samoan descent

3. have achieved endorsed NCEA level One with Merit or Excellence in Year 11 and be taking level Two or Three credits in Year 12 or Year 13

4. be interested in participating in the research.

Table 2: School allocation of student selected.

\begin{tabular}{|c|c|c|}
\hline School & $\begin{array}{c}\text { Original number of } \\
\text { students identified } \\
\text { by each school }\end{array}$ & $\begin{array}{c}\text { Students suited for } \\
\text { the research }\end{array}$ \\
\hline School A & 6 & 4 \\
\hline School B & 8 & 6 \\
\hline School C & 2 & 2 \\
\hline Total & 16 & 12 \\
\hline
\end{tabular}


As noted by Table 2, the original students identified by school principals differs from overall interested students. School A had two students who were not selected because (i) one was not of Samoan ethnicity - the school had the wrong ethnic identification for this student, and (ii) the second student was leaving the school within the next few weeks. School B, also had two that did not continue with the study: (i) one student was not interested in taking part, and (ii) one student was preparing to leave secondary school and apply for a full time job at the time.

The selection criteria for the participants were important to me for two reasons: one, this study was my contribution back to the Samoa community and I wanted to provide insights into the experiences of tama Samoa from a strengths based perspective. Secondly, it was an opportunity to further understand the needs of tama Samoa, to represent their voices and who they were within the secondary school context. As identified by Hamilton (2006), the need for one to listen to student voice is one of the significant enabling factors for the building of caring, empowering relationships within a learning community.

Table 3: Tama Samoa Ethnic composition.

\begin{tabular}{|c|c|c|c|}
\hline Tama Samoa & Full Samoan & Half Samoan/Half... & $\begin{array}{c}\text { Blended ethnicities } \\
\text { Half Samoan// } \\
\text { Part.../Part... }\end{array}$ \\
\hline Tataio & & $\xi_{3}$ Tongan & \\
\hline Mataio & $\varphi_{9}$ & & \\
\hline loane & & Cook Island & \\
\hline Toma & & & 鼣Fiji/Māori \\
\hline Filipo & $\xi_{9}^{3}$ & & \\
\hline lese & $\varepsilon$ & & \\
\hline lakopo & $\underbrace{3}_{9}$ & & \\
\hline loane & & & German/Tongan \\
\hline Patolomaio & & $\aleph^{3}$ Palagi (European) & \\
\hline Timoteo & $w_{3}$ & & \\
\hline Aneterea & $\underbrace{3}_{9}$ & & \\
\hline luta & & $\xi_{9}$ & \\
\hline
\end{tabular}


Table 3, displays the ethnic composition of the participants. It also shows that some tama Samoa had a mix of ethnicities which had the potential to influence their identity formations.

In each of the three secondary schools, I arranged a time, through the senior deans, to meet with the tama Samoa. Each school principal had now signed to agree to the research project, and requested that I then worked with senior deans to continue the research process within each school. The initial meet and greet with the tama Samoa in each school was held in their lunch hour. In aligning this research with the fa'afaletui framework the culturally appropriate way of building a relationship is acknowledging the participants and appreciating who they are through informal talanoa over drink and food. This is the beginning of talanoa as identified by Vaioleti (2006): the talanoa will only occur once the tama Samoa feel the time is right and the context appropriate. It is also during this time of building the relationship that the talanoa will establish the expectations that I, as the researcher, and the tama Samoa have of each other, promoting mutual accountability and trustworthiness. In each informal talanoa, tama Samoa were asked to introduce themselves as a way of building a relationship with them. Tama Samoa were given the opportunity to question and think about participation, as well given information to read and sign (Appendix 2).

\section{INTRODUCING THE TAMA SAMOA}

Due to the number of tama Samoa being twelve, for the research each was given the name of one of the twelve disciples from the bible; however, two of the disciples have the same name and therefore I decided to change one of names to lese to limit any confusion for the readers. Below I present each of the twelve tama Samoa brief self-introduction. These introductions were held at our informal lunch gatherings held at each school:

My name is Toma. I play rugby league for Randwick. I enjoy attending this school. I have 2 younger brothers and one sister.

My name is loane. I like to hang out with everyone. I have had a lot of cousins come through this school and I enjoy coming to school to learn. 
Well my name is Tataio, both my older brothers attended this school and my second oldest brother was deputy head boy here in his year. I enjoy PE, Maths, and English.

My name is Timoteo. I was born in Auckland but I was raised here in Wellington.

I am lese. I am 17, my Mum and her siblings moved to New Zealand when she was about five years old.

Well, I am Patolomaio. I am also 17, and I'm a half caste.

Well, my name is lakopo.

Well, my name is luta. I have an older brother in the army, and I live with my parents.

Well, my name is Mataio, my parents are full Samoan.

Well, my name is Filipo. My Dad performs in a band. Thank you.

Well my name is Simona-Peteru. I was born in Lower Hutt and my parents were both born in Samoa

\section{Nominated participants}

Within a research context there are a number of terms used for the process of selecting other participants to be involved in a particular study: chain referral, snowball sampling, friendship pyramiding, or targeted nominations (Magnusson, \& Marecek, 2015). As noted by Magnusson and Marecek (2015), the idea of targeted nominations works well if you are able to find other participants who fit the particular set of characteristics required for the study. In this study, the twelve tama Samoa were each asked to identify one other person that I could meet to have a one on one semi-structured talanoa session. Of course, this was only a request and the tama Samoa were free to decline the suggestion of nominating anyone; however, all twelve participants did take the opportunity to nominate one other participant who was invited to take part in the study. These nominated participants were selected by the tama Samoa as people who knew them well 
and were therefore able to provide further observations and perceptions about factors that contributed to tama Samoa experiences at school. This opportunity allowed for triangulation - the tama Samoa and nominated persons share different perspectives on tama Samoa as individuals, so the tama Samoa perceptions of themselves could be compared with their nominated person's perceptions. Using two different groups of people for the study provides data sets that complement one another. Thus the data from both sources provide a richer detail of tama Samoa and their everyday secondary school experiences.

The individual talanoa sessions with nominated participants were done at a time and place convenient to them. Each nominated person agreed to meet with me for the purpose of this research, and was also provided with research details to read and sign as agreement to be involved in this research study. Table 4 shows the relationship of each tama Samoa to their nominated person. The table shows nominated persons to be a mix of teachers, peers/friends, and family members.

Table 4: Relationship of tama Samoa to their nominated person.

\begin{tabular}{|c|c|}
\hline Tama Samoa & Nominated Person (1) \\
\hline Tataio & Girlfriend \\
\hline Mataio & Teacher \\
\hline loane & Teacher \\
\hline Toma & Friend \\
\hline Filipo & Aunty \\
\hline Simona-Peteru & Mum \\
\hline lakopo & Brother \\
\hline lese & Mum \\
\hline Patolomaio & Girlfriend \\
\hline Timoteo & Sister \\
\hline Aneterea & Brother \\
\hline luta & Friend \\
\hline
\end{tabular}




\section{Data Gathering}

Data for this research was gathered by focus group talanoa and semi -structured one on one talanoa. Both types of data gathering have valuable use in collecting the data. The focus group talanoa was a way to "get to know" the tama Samoa while having other tama Samoa amongst them. The semi-structured talanoa was the one on one talanoa that allowed for me to ask personal detailed questions about their experiences at school.

\section{Focus group}

There were two major benefits to using focus group talanoa as a source of data collection: firstly, a more relaxed and natural discussion can take place than might be found in a one to one interview; and secondly, individuals often find it easier to voice their opinion when they have been listening to others (Marshall \& Rossman, 2011). In order to establish familiarity with the background of the tama Samoa, the tama Samoa were invited to an informal lunch where I got to meet and greet with them at their schools. The purpose of this was to build the relationship so that tama Samoa felt safe to talanoa openly about their perceptions and experiences of secondary school. It was important to allow enough free flow of talanoa since this could lead to more insightful, critical discussion (Vaioleti, 2006).

Furthermore, the talanoa needed to nurture relationships, allowing time for individuals to feel comfortable and know that their opinion was valued. From a talanoa perspective, it was helpful to nurture collaborative discussion, allowing participants to share their experiences and knowledge, as this was an important ingredient in achieving cross-cultural research (Otsuma, 2005).

Focus groups were used when talanoa sessions began with the tama Samoa. Denscombe (2003) identifies distinctive and vital points about focus groups as follows:

The sessions usually revolve around a prompt, a trigger, some stimulus introduced by the moderator in order to 'focus' the discussion; 
There is less emphasis on the need for the moderator to adopt a neutral role in the proceedings than is normally the case with other interview techniques.

They place particular value on the interaction within the group as a means for eliciting information, rather than just collecting each individual's points of view - there is a special value on the collective view, rather than the aggregate view. (p. 169)

An advantage of using focus group talanoa is that this provides the opportunity to explore and discuss topics in a non-threatening way. Conversely, the disadvantage of using focus group interviews, as identified by Descombe (2003), is that it may be difficult to record the discussion that takes place, as participants may interrupt each other and talk simultaneously.

\section{Semi-structured one on one talanoa}

Kvale (1996) states that the qualitative research interview is a construction site for knowledge. In this research a semi-structured interview process was used with both tama Samoa and nominated people. The use of semi-structured interviews offers sufficient flexibility to approach different respondents differently while still covering the same areas of data collection. (Noor, 2008)

Semi-structured interview technique is used to collect qualitative data by setting up a situation (the interview) that allows a respondent the time and scope to talk about their opinions on a particular subject.

The focus of the interview is decided by the researcher and there may be areas the researcher is interested in exploring. As identified earlier, the key themes of this research - identity, sense of belonging and aspirations for the future - were already established, and questions were already set to navigate through each of the themes. In determining the questions for the study, an opportunity to pilot the list of questions with my own nephews allowed for talanoa on how the questions would be suitable or not suitable to use in this study. Once this process was completed further discussion with supervisors identified the final questions for the study. However, during the focus group talanoa and semi -structured talanoa 
with the tama Samoa some questions were refined before interviews with the next round of tama Samoa.

I had already established relationships with tama Samoa during focus group talanoa. However, in semi-structured interviews it was also important to make sure there was good rapport with the tama Samoa and myself and, therefore, the interview was like a conversation embroidered around the themes.

As identified by Mason (2004), the defining characteristic of semi-structured interviews is that they have a flexible and fluid structure. The structure of a semistructured interview is usually organised around an interview guide (see Appendix 3). This contains topics, themes, or areas to be covered during the course of the interview, rather than a sequenced script of standardised questions. The aim is usually to ensure flexibility in how and in what sequence questions are asked, and in whether and how particular areas might be followed up and developed with different interviewees.

\section{Recording data}

In order to secure an accurate account of the conversations and to avoid losing data, it was important for me to take notes as well as record the talanoa sessions using a dictaphone. Although the dictaphone did not allow for non-verbal cues, the use of this tool provided me with extra support in making sure that what was being said by tama Samoa was secured through recording. The non-verbal cues were observed by me as I sat with tama Samoa during focus group talanoa and semi-structured talanoa and written as anecdotal notes. During talanoa focus group sessions each individual used a code to identify himself when speaking. There was careful planning of the questions which were undertaken to ensure adequate coverage of the topic.

\section{Talanoa}

The research method for data gathering in this research was talanoa through semi-structured interviews and focus group. Vaioleti (2006) describes the concept of talanoa as a conversation, a talk, an exchange of ideas or thinking, whether formal or informal. 
Using talanoa for engaging with tama Samoa built confidence amongst the group particularly using the focus group talanoa to build the relationship. The talanoa process is a good example of both a method and a methodology which uses formal or informal discussion in Pacific research. The Talanoa process is a datagathering interviewing method which can be used in one-on-one interviews or focus group discussions, and is also a useful method/methodology to use across disciplines.

Prescott (2008) describes talanoa as the preferred means of communication for Pacific research because it captures the traditions and protocols of the fa'afaletui framework. Manueli (2012) describes talanoa as an opportunity to enable the researcher and participants to connect at a deeper level which facilitates the co-construction of authentic, rich contextual and inter-related knowledge (p. 100). As identified by Vaioleti (2006), talanoa fits well with phenomenological research, and because Talanoa is "flexible, it provides opportunities to probe, challenge, clarify and re-align" (p. 25).

\section{Triangulation and Validation}

The use of the fa'afaletui process of continued revision of talanoa - returning it to tama Samoa to check once transcribing was completed - ensured triangulation of the data. The importance of triangulation is that it can enhance the validity of data. As stated by Descombe (2003), there is an analogy which is often used in this respect. Triangulation involves locating an honest position by referring to two or more other co-ordinates. Using this analogy, researchers like me seeking key findings can use different methods of data collection to provide clear pathways to a topic. In both the semi-structured talanoa interviews and the focus groups, the face-to-face value was the one way of engaging positively with the tama Samoa and selected friends, teachers and family members. 
Table 5: Overview of focus group and semi-structured interviews.

\begin{tabular}{|c|c|c|c|c|c|}
\hline School & $\begin{array}{l}\text { Focus } \\
\text { Group }\end{array}$ & Time & $\begin{array}{c}\text { Semi-Structured } \\
\text { Interviews }\end{array}$ & Time & NP \\
\hline School One & $\begin{array}{l}4 \text { Tama } \\
\text { Samoa }\end{array}$ & $\begin{array}{l}\text { Lunchtime } \\
50 \text { minutes }\end{array}$ & $\begin{array}{c}\text { Simona-Peteru } \\
\text { Timoteo Aneterea } \\
\text { luta }\end{array}$ & $\begin{array}{l}50 \mathrm{~min} \\
40 \mathrm{~min} \\
55 \mathrm{~min} \\
40 \mathrm{~min}\end{array}$ & $\begin{array}{c}1 \mathrm{hr} \\
50 \mathrm{~min} \\
45 \mathrm{~min} \\
50 \mathrm{~min}\end{array}$ \\
\hline School Two & $\begin{array}{l}6 \text { Tama } \\
\text { Samoa }\end{array}$ & $\begin{array}{l}\text { Lunchtime } \\
50 \text { minutes }\end{array}$ & $\begin{array}{c}\text { Tataio Mataio } \\
\text { Ioane Toma Filipo } \\
\text { lakopo }\end{array}$ & $\begin{array}{c}1 \mathrm{hr} \\
50 \mathrm{~min} \\
45 \mathrm{~min} \\
55 \mathrm{~min} \\
40 \mathrm{~min} \\
1 \mathrm{hr}\end{array}$ & $\begin{array}{c}45 \mathrm{~min} \\
50 \mathrm{~min} \\
1 \mathrm{hr} \\
35 \mathrm{~min} \\
35 \mathrm{~min} \\
1 \mathrm{hr}\end{array}$ \\
\hline School Three & $\begin{array}{l}2 \text { Tama } \\
\text { Samoa }\end{array}$ & $\begin{array}{l}\text { Study Period } \\
40 \text { minutes }\end{array}$ & $\begin{array}{c}\text { lese } \\
\text { Patolomaio }\end{array}$ & $\begin{array}{c}1 \mathrm{hr} \\
50 \mathrm{~min}\end{array}$ & $\begin{array}{c}1 \mathrm{hr} \\
45 \mathrm{~min}\end{array}$ \\
\hline
\end{tabular}

\section{Analysis of Data}

Qualitative research can rapidly generate huge amounts of data. As noted by Cohen, Manion, and Morrison (2007) there is no one single or correct way to analyse qualitative data; it is very reliant on interpretation. As with all qualitative data, phenomenological data analysis involves such processes as coding, categorising, and making sense of the essential meanings of the phenomenon. Throughout the data analysis phase of the research I was working with rich descriptive data to identify common sub-themes that arose from the key research question:

In what ways do tama Samoa experiences within a secondary school context contribute to their identity, sense of belonging, and aspirations for the future?

However, it is important to note that the particular questions asked of tama Samoa were centred on the three themes of identity, belonging, and the future. This stage of analysis basically involved total immersion in the data for as long as it was needed in order to ensure a thorough description of the phenomenon.

As pointed out by Kleiman (2004), the structure of phenomena is the major finding of any descriptive phenomenological inquiry. This structure is based upon the essential meanings that are present in the descriptions of the participants and is 
determined both by analysis and also by the researchers (intuitive) insights. When analysing the data provided by the tama Samoa during both focus and semi-structured talanoa sessions I followed the method of analysis as described by Kleiman (2004, p. 9), reading the interview transcript in its entirety in order to get a global sense of the whole.

This process of transcribing each recording from focus group and semi-structured talanoa provided me with a sense of the tama Samoa and their overall idea of what their experiences were during secondary school.

Reading the interview transcript a second time - this time more slowly in order to divide the data into meaningful sections or units.

Through following this process, explained in Chapter Four, each of the main themes was unpacked with its own sub-themes; for example, the Identity theme generate three sub-themes: personal identity, cultural identity, and group identity.

Integrating the sections that you have identified as having a similar focus or content and making sense of them.

At this stage of analysing the data, I began using a mind map of what connections were being made through each sub-theme and tried to identify the relationships between each of the themes.

Subject your integrated meaningful sections/units to a process that is known as free imaginative variation.

During this stage of the analysis, I went through each of the sub-themes from the main themes to identify and highlight any particular variations from tama Samoa experiences that were more essential to this study. This process was quite challenging as a researcher because I wanted to include everything shared by tama Samoa so that their experiences and voices were been included in all parts of this study.

Elaborate on your findings - this includes descriptions of the essential meanings that were discovered through the process of variation. 
Once I was clear in my mind about the themes, sub-themes, and the contributions each of these themes brought to the study, I was now ready to make further connections through the use of literature and theoretical ideas discussed in Chapter Two, to support each of the sub-themes.

Revisit the raw data descriptions again in order to justify your interpretations of both the essential meanings and the general structure. You really do have to prove that you can substantiate the accuracy of all your findings by reference to the raw data.

This process of analysis was ongoing - revisiting the raw data for emerging themes that may have been missed. Creswell (2013) suggests that transcripts should be read several times in order to provide the researcher with general overview of the data.

Once you have completed the analysis of your data, you follow this with a critical analysis of your work within your research study.

This point of the analysis required a review of the data. It was also an opportunity to look at the raw data again and to confirm that the descriptions that I had highlighted throughout this analysis process were relevant to the study and overall aim of the study.

\section{Ethical Considerations}

Throughout this research, every precaution was taken to make sure ethical and cultural issues were considered throughout. It was important that the participants, tama Samoa of Years 12 and 13, understood the process of how the research would proceed and for me, as the researcher, to be completely honest about what their role as participants involved. Ethical considerations are paramount when conducting research of and with young people, and management of these considerations can be very influential on the research that is ultimately completed by young people. Throughout the study, the wellbeing of the participants was a top priority. Ethical issues were carefully considered at the early stages of the study and this consideration was deemed as an on-going process. The ethical issues included gaining informed consent from all participants; ensuring 
participants' privacy, confidentiality, and anonymity; and protection of participants from any form of harm (physical, emotional, or other). This was done by spending time with tama Samoa to build the relationship of trust, to provide an atmosphere where tama Samoa felt they could be open about sharing their experiences and perceptions about secondary school. The opportunity to have food and drink at every focus talanoa and semi-structured talanoa, provided the relaxing setting for both tama Samoa and myself. The building of relationships, and providing of food and drink were all part of the cultural considerations as identified earlier. During this time, to ensure that participants made informed choices, sufficient time was devoted to clarifying the research process with them and complementing this with printed materials.

Tama Samoa's anonymity was high on the list of priorities, therefore, as explained above, tama Samoa were given the names of the twelve disciples from the Bible as pseudonyms. Giving tama Samoa pseudonyms will provide them with privacy and keep their identities confidential, as there is little contact made with the data by persons besides myself.

Human ethics approval was granted by the Victoria University of Wellington's Faculty of Education Human Ethics Committee on January 2011 (TKM2010/121: RM 18204) (Appendix 4). In accordance with the Victoria University of Wellington Human Ethics guidelines, to ensure privacy, confidentiality, and anonymity, data gathered for the study was accessed only by the researcher and two supervisors. All written materials were kept in a locked file and accessed only by the researcher. All electronic information was password protected and accessed only by the researcher. 


\section{SUMMARY}

This chapter has been presented in two parts. Part one describes the research methodology and theoretical framework. It also discusses my position as a researcher, and provides an overview of Pacific research paradigms. In part two, I discuss the method used for participant selection and the data gathering processes. In part two I explain the process of analysing the data collected and present the ethical considerations and limitations to this study.

This research explores the experiences that influenced tama Samoa during secondary school. The study is, therefore, informed by the interpretive paradigm which supports multiple realities that are socially constructed by people. The next chapter of this thesis discusses the findings that derived from the focus group talanoa and semi-structured individual talanoa 


\title{
CHAPTER FOUR:
}

\section{FINDINGS}

\author{
Matofi le Niu'afa i le La \\ (Expose the Niu'afa to the Sun)
}

\section{INTRODUCTION}

To understand who tama Samoa are as individuals, it is necessary to acknowledge that first and foremost these tama Samoa know that they are of Samoan heritage; thus, they identify with an ethnic group. Tama Samoa also have a sense of the multiple identities which they have developed over their time at secondary school; they have a sense of belonging-ness both within and outside the secondary school environment. In the talanoa with the twelve tama Samoa, it also became clear that they do look forward to what the future holds for them.

As identified in the previous chapter the use of the Fa'afaletui framework, gives a multilayered approach to data interpretation using a range of lenses and perspectives. In conducting this research, the combination of Western and Samoan frameworks was appropriate given the stories that would be provided by the tama Samoa.

The tama Samoa brought insightful information about what contributes to their experiences at school. They shared their perceptions and, in most parts of the talanoa, I was able to capture clearly the perceptions tama Samoa had of where they had been and what they hoped to become.

However, there were also complexities in the experiences they shared. Their stories have ambiguous, unspoken messages that are not clearly visible at this point; this is discussed further in Chapter Five where some reasoning behind these messages is developed. Because some of the elements of their stories are visible and easily noticed and other elements are less visible, as I decoded and tried to provide an interpretation of their stories I found experiencing of trying to capture every element of the tama Samoa and their experiences challenging. 
Drawing from the talanoa discussions, Chapter Four illustrates the themes that have been generated by the tama Samoa responses. In order to support the themes, excerpts from the focus group talanoa and from the one-on-one talanoa transcripts are imparted throughout this chapter.

In presenting verbatims from talanoa sessions, the following coding system is used: the contribution of specific tama Samoa is represented by (tama Samoa pseudonym: F), for example, (loane: F); in semi-structured interviews contributions are presented as (tama Samoa pseudonym: SS); and (tama Samoa pseudonym: NP) represents the contribution of specific nominated persons. This coding system is used to keep with the ethical consideration of keeping participants' names confidential.

Each theme has been "unpacked" into sub-themes, and the sub-themes into categories, to provide more insights into the tama Samoa and their stories. It is important to note that quotes from both tama Samoa (primary participants) and from the nominated people (secondary participants) selected by the tama Samoa are provided to illustrate the three themes. The use of quotes from nominated people provides another perspective to the quotes provided by tama Samoa, particularly when these do not necessary align with what has been said by tama Samoa.

The use of the Samoan cultural framework, fa'afaletui, required three different views of the data (Tamasese et al., 1997). Here I drew on the adjectival description of close, closer, closest to the data as explained by Cowley (2013) who applied fa'faletui $n$ her research:

if we can imagine a fisherman in his canoe and the data as the fish (the concept of perceptions becomes more cultural as we triangulate the data and confirm or refute findings. This was especially applicable to the themes which emerged from the data where the constant reviewing of the data, the literature and opinions of cultural advisors were considered. (p.101) 
In my own research, the data was analysed according to the themes (close); each theme was then "unpacked" into sub-themes (closer), and the sub-themes into categories (closest), to provide more insights into the tama Samoa and their stories. It is important to note that quotes from both tama Samoa (primary participants) and from the nominated people (secondary participants) selected by the tama Samoa are provided to illustrate the three themes. The use of quotes from nominated people provides another perspective to those provided by tama Samoa, particularly when these do not necessary align with what has been said by tama Samoa.

\section{THEME 1: IDENTITY}

In psychology and sociology, identity is regarded as a person's interpretation and expression of their and others' individuality or group affiliations (Erickson, 1968; Tajfel, 1981). As identified by Walker (2005), at some point, throughout their adolescence, young people will start to examine their own values, ethics, spirituality, racial and ethnic identity, sexuality, and gender. This supports Gullotta, Adams and Markstrom's (1999) earlier suggestion that adolescents' exploring the different aspects of their identity is part of a very normal desire to understand who they are and where they fit in the world.

As identified by Erikson (1968), as adolescents explore their identity, they learn what makes them unique but this also happens at a time in their lives when they are very keen to "belong", to be part of different groups, to have many friends and to be connected with other people. However, for Pacific adolescents as noted by Tupuola (2004) youth in New Zealand commonly perceives 'New Zealand-born' as a contradictory and ambiguous group with multiple, social cultural, political commitments. Tupuola continues her discussion on the idea that in some studies by Pacific writers on Pacific youth is that this group also imply that they are struggling to forge an identity as 'they are at home neither in their parents' world nor in their country of birth (p. 91).

The data from this study shows that during their time at secondary school tama Samoa ask questions about their own identities as well as exploring the multiple identities they have constructed over time. In this research tama Samoa shared 
their experiences of exploring their identity formation and spoke about their individualism, being Samoan, and the complexity of the multiple identities they grapple with both within and outside the school environment.

Through the use of fa'afaletui it is underpinned by values of respect and honouring the tama Samoa, ensuring that each of the tama Samoa were well represented in this research. Fa'afaletui paid serious attention to their cultural perspectives. The study found tama Samoa to be exploring three different elements of their identity formation: personal identity in terms of their perceptions they have of themselves as students and as a tama, as well as the perceptions they believe others have of them; cultural identity, exploring their Samoa-ness; and, finally, group identity, identifying the influence of peers, as well as their role as a peer amongst friends and within school responsibilities.

\section{Personal identity}

Chapter Three introduces the tama Samoa with their own words to describe themselves in our initial talanoa. During this initial talanoa time, I as the researcher, was aware that I had two contradicting ideas floating in my mind. First, that I was a stranger meeting a group of tama Samoa for the first time; wondering how the tama Samoa would react to my presence in the group. Second, I wondered how confident the tama Samoa would be in their talanoa with me as a Samoan, as a woman, and as a researcher. It was therefore important as a researcher to build a relationship between myself and the tama Samoa, and to make sure that I was able to create a safe environment so that they could feel relaxed and that they could talanoa openly within this study. Later, as I analysed the data, I realised that the richness and depth of the data that was generated from the talanoa indicates that this relationship building was, indeed, successful. During the talanoa sessions the tama Samoa spoke about the perceptions they have about their own personal identity in two ways: i) as students - in terms of how they perform at school and as the key to a better future for their families; and ii) how they believe others perceive them. 


\section{Tama Samoa perceptions of themselves as students}

This section presents a number of perceptions which tama Samoa have of themselves as students and as tama; how they perceive themselves amongst their peers, within their families, and within the school environment.

Steinberg and Morris (2001) note that the way adolescents look at situations, places, and things reflects the way they view the world and influences the conclusions and decisions they make.

These perceptions are presented in their own words, sometimes supplemented and reinforced by quotes from their nominated persons:

For me growing up ... it's just my natural nature... I always like to be competitive. Not verbally but ....in everything I did, my actions. So everything I do I try to be... well, not say the best, but I try and excel at everything I do and that's kind of ... how I was bought up because my real dad he was kind of hard on me about education and stuff and always pushed me to get the highest mark. (Timoteo: SS)

I like to crack jokes. I am one of those funny guys, I pretty much just like to laugh heaps and because most of the boys are funny I just laugh along too. (loane: SS)

I have always been a good student, but I also enjoy my friends. I may not be doing my best at school so I would consider myself a steady achiever at school. I am not a lazy student but I don't want to be a top student because my friends will give me grief about it. (Patolomaio: SS)

All the boys here have potential, but I reckon I have better use of my time. I think my friends look up to me when we have study periods, cos I can study for hours when I have to. (Tataio: SS)

Although tama Samoa were responding to questions about their perceptions of themselves, the above quotes show that they consider the influence of their friends - and in Timoteo's case, his father - also has an important impact on their everyday experiences of identifying who they are as tama Samoa at school. 
Other tama Samoa identified themselves as the key to a better future for their families and, therefore, that they need to do their best at school so that they can have a better future:

I need to do well at school because it is a good foundation for your future. (loane: F)

My parents tell me to work hard so I can get a good job. My older brother is at Massey University, but I am going straight into the work force so I can look after my Mum and Dad. (Mataio: SS)

I want to motivate myself at school because it just means that l'm living up to my family's name. I am an independent worker it's easier for me to, but I have been told I'm a good supporter by my mates and some teachers. (Toma: SS)

I want to have a better future, better life you know. I want to have the best life I can have. I see my parents and my grandparents struggling and I go over to Samoa and I want to be able to give back to the community, have enough money to give back. (Patolomaio: SS)

I just want to give back like to my family and to show them how thankful I am of my parents bringing me up and teaching the basics. That's why I want to do well and give back. (Timoteo: $\mathrm{F}$ )

My family came from the Islands and, trying to find a job, it's like it would be hard for them now. To have kids, they want their kids to do better and that's what makes you determined to do something better. (Mataio: $F$ )

Among the responses above, about family expectations, Mataio, Timoteo, and Patolomaio's comments show a strong sense of giving back to their families. Within a Samoa context, the term "tautua" (service) is identified here, the notion of serving your family. Timoteo also mentions the nurturing support he has received from family, and how this has driven his sense of wanting a better education. 
However, when nominated persons were given the opportunity to share their ideas about the tama Samoa feeling it was important to give back to family, one said:

I am really concerned with the burden that's put on kids when they're told that they're Samoan and that their parents came here to give them a good education and that they've sacrificed their lives and that really troubles me and I often say to kids "you know, that's not your burden. You do not have to accept that at all". (loane: NP)

The contributions illustrate the value of using NP's in this research because it provides the diversity such as the tension or conflicts of influences on tama Samoa perceptions about themselves and from other people in their lives.

While tama Samoa had each been given the opportunity to nominate any person and loane had selected his nominated person because of the positive relationship they had, loane's nominated person was a teacher whose only experience with Samoa families is through the school context. Furthermore, this nominated person is not of Samoan heritage and the comments suggest that they do not clearly understand the concept of "tautua" (service), and what this means for tama Samoa and their Samoan families. This is explored further in the discussion chapter.

Filipo's nominated person (a relative) provided a different perspective than loane's NP, explaining how she saw Filipo's role in terms of tautua in the extended family:

We have always had great expectations of Filipo; he is one of the nephews that you can rely on to make good choices. Filipo has a lot of cousins his age in our family, but he is one I can always rely on to help me out with my own kids. It never seems to bother him when I ask him and he always shows alofa (love) for his Samoan culture. (Filipo: NP)

However, loane's comment, below, shows that he knows that doing his best at school can contribute to finding a good job to support his parents; he describes this as being a motivation tool to get him through secondary school. Like loane, 
other tama Samoa, did not describe doing well at school for the sake of supporting family in terms of being a burden, but the complete opposite:

If I do my best at school and behave at school you can qualify for a good job because your parents struggle and stuff. It's kind of like a selfmotivation, to get further in life and help them as you grow up. (loane: SS)

In terms of Steinberg and Morris's (2001) observation - that the way adolescents look at situations, places, and things reflects the way they view the world and influences the conclusions and decisions they make - tama Samoa highlighted that the perceptions they had of themselves as students are closely related to how they interact and are influenced by friends, peers, family, and the school environment. This perspective was identified by the fa'afaletui process of reading through the transcripts closely, then more closely, and then even more closely Cowley (2013).

\section{Tama Samoa perceptions of how others perceive them}

The perceptions tama Samoa articulated about what others thought of them provides some insight into how tama Samoa perceive themselves amongst others. As identified by Holley and Dobson (2008), students' perceptions of the school environment and people have an impact on their academic attitudes and behaviours.

In reviewing the talanoa I also looked for whether nominated persons' perceptions had similarities and differences with the tama Samoa perceptions of themselves.

I don't know why, but my family say I am probably a chatterbox at school, because of how I am at home, but really I am like shy as, I don't know why. (Aneterea: SS)

Aneterea and I were sort of like bought up together, and we always have each other's back. Even though he has seven brothers he always has my back. Always clowning around and he talks a lot, like a lot. (loane: SS)

I like to crack jokes and be funny and stuff and to have a good laugh, but at school, teachers always ask me if I am ok because I am so quiet and 
focused. I think the teachers think I am disciplined and all that. (SimonaPeteru: SS)

Although Simona-Peteru, above, describes himself in terms of surface features such as being a joker and being funny, his nominated person describes him on a deeper level:

He's got really good relationship with the teachers but I know that the teachers know that they like Simona-Peteru, but depending on the subject, if it's too hard then Simona-Peteru sort of like avoids the teachers, but the teachers know that he's good and they like him. He's very well-liked by his friends. He's like a mentor and a role model. He's very popular. (Simona-Peteru: NP)

Some of the tama Samoa spoke casually about their perceptions of others and their thoughts about them as individuals. However, from their responses to probing questions about these perceptions, it seems that tama Samoa do take into consideration the perceptions of others about themselves:

My mates push me, you always want to do your best because you don't want your peers to think you're the dumb one out of your group. (Mataio: F)

Interestingly enough, Mataio's nominated person provided a very different perception of Mataio:

I've taught two [of Mataio's] older brothers and they have both been bright so I wonder if it's partly my expectation. But Mataio I would have to say is the naughtiest of his brothers. I have to put a lot more time into keeping him in line you know because he can be very lazy doing his school work. (Mataio: NP)

At a first reading, this particular talanoa with Mataio's nominated person suggests that although Mataio had nominated someone he had a positive and strong relationship with, the nominated person's perspective about Mataio and his character within school may not have been as positive. However, when considered with Mataio's comment, above, about feeling the "push" from his 
mates, it may be concluded that his nominated person "keeping him in line" was, in fact, appreciated by Mataio as a positive strategy and therefore he regarded this as a positive aspect of his relationship with his nominated person. As elsewhere, this potential contradiction shows the value of including nominated persons in this study in order to unpack the complexity of tama Samoa experiences and to provide examples of how their perceptions of themselves and of their relationships may differ from those of "mainstream" students.

Other tama Samoa revealed that they feel pressure from others' perceptions of them:

I think - actually, I know - my parents and teachers think I have potential and think I should be up there with the top students, and I feel a bit of pressure because I know I am not doing as good, but I know they have labelled me as a top student. (Simona-Peteru: F)

I have always believed in having a good education, because this is the key to a better future, and I am not shy to let my son know this. Maybe I do put pressure on Simona-Peteru to do well at school, but if I don't who will? (Simona-Peteru: NP)

Simona-Peteru's perception is that others perceive him as a successful or "top" student in secondary school and he acknowledges that he feels some pressure because of these expectations. Simona-Peteru's NP's statement appears to confirm Simona-Peteru's perception that there is pressure for him to do well at school.

Similar perceptions were shared by Timoteo with his selection in a specialty class

You're thinking oh I'm the only Islander there. I've got to like get it, because you know the Asians and Indians they're always smart and stuff, pressure like just to keep up with them and perform at their level, but they look at and you feel like they are thinking "should you really be here"? (Timoteo: F)

In this section, tama Samoa have highlighted their perceptions of how others perceive them. In some examples, tama Samoa are confused about how and why 
people act and think the way they do about them. It was also highlighted that some tama Samoa believe that people they are in contact with have high expectations from them. It was also important to note that, some nominated persons, had different perceptions of individual tama Samoa, and this did not necessarily align with why tama Samoa nominated particular persons. It is therefore important to note that there are a mixture of perceptions that tama Samoa have of what others think of them.

\section{CULTURAL IDENTITY - EXPLORING MY SAMOA-NESS}

The key findings related to cultural identity are divided into three areas: i). Defining my Samoa-ness ii). Characteristics of being Samoan; and iii). Being Samoan amongst others. The elements of this section of identity capture how the tama Samoa identify culturally, and how this experience of identifying as Samoan plays out within the secondary school context.

\section{Defining my Samoa-ness}

The talanoa began with the tama Samoa acknowledging their ethnicity. Interestingly to me as a Samoan, only one of the twelve tama Samoa knew of their parents' village affiliations in Samoa:

My parents are from Samoa. My Mum is from the village of Samusu and

my Dad is from the village of Satitoa. (Simona-Peteru: SS)

Although only one tama Samoa was familiar with the village affiliations their parents had in Samoa, all of them were aware of the connection their parents had to Samoa, with seven of them having been to Samoa in the past for various reasons, such as family holidays, fa'alavelave (unexpected family events), or family reunions.

Because all the primary participants of this study are of Samoan ethnicity, it was obviously relevant and appropriate to ask them if being identified as Samoan was important to them, and what being Samoan meant for them. It was important to ask the tama Samoa these questions to grasp an understanding of what it means for an adolescent secondary school student to be labelled as a Samoan. Their 
responses show that the tama Samoa have a strong sense of being Samoan and identify the central role of culture, family and religion in this. It was therefore important to begin my talanoa with the question - What does it mean to be Samoan?

I think it's important to know your culture, if you don't you're not going to know who you are. (loane: F)

Being Samoan is about knowing your background and your genealogy. (Simona-Peteru: F)

Being Samoan to me means, knowing God, connecting with your family is a big one, just saying it and acknowledging you're Samoan is important too, I guess. (Simona-Peteru: F)

It means being able to be proud, it means to be able to connect with your elders and it means knowing something different from just being a New Zealander. (lakopo: SS)

Aneterea's NP a Samoan family provided an additional perspective, commenting that they were never pressured to show they were Samoan when they were out and about:

Everything about our family was based on our fa'aSamoa and there was never any pressure from our parents to show or demonstrate to others we were Samoa because we just knew who we were and I think Anetere'a just went with it just like I did. (Anetere'a: NP)

There were many aspects tama Samoa recognised as being unique to their Samoan identity such as knowing their genealogy, having strong family connections, and acknowledging their heritage and connection to elders as indicated in the responses, below:

Being Samoan - it's knowing the culture, the traditions like the matai system (chiefly system of Samoa). Also having specific ways of tattoo, the stories and how they are passed down and that's how you find out about the families and your genealogy. (Simona-Peteru: $F$ ) 
Being Samoan is a positive thing, because I think Samoans are more accepting of things and it's cool how you can speak Samoan to others. To me being Samoan is having pride and knowing where you come from. (Mataio: F)

I am a proud Samoan because it's just the way we present ourselves and the way we treat ourselves, it's a lot different from the way Palagi (European) treat each other. (Simona-Peteru: F)

I reckon being Samoan is like, you know, just being as one as a whole, like, you know, culture wise and that you just come together like brothers and sisters, like, you know it's like Samoans, like, they're like a whole family, not like an individual. (Timoteo: F)

Timote's NP provided a further perspective of Timoteo's exploration of his Samoaness:

I don't think Timoteo is really bothered about being Samoan or bothered about showing it off. I mean he speaks Samoan at home like we all do, but I have never known him to show off for being Samoan. (Timoteo's: NP)

These comments, then, indicate the tama Samoa's pride in their cultural identity, their Samoa-ness, and the importance they attach to their Samoan culture. Each one of the tama Samoa commented on being proud that they were of Samoan heritage and that this is something they regard as being theirs to "own". Some of the nominated persons added their perspectives, with one saying it was more to do with how they perceive the tama Samoa as a Samoan by the way they act around other people. Another NP stated that it was not necessary for tama Samoa to "show off" about being Samoan.

This section also shows that, to some extent, the tama Samoa define their Samoa-ness in terms of how they see other ethnicities and cultures around them. 


\section{Characteristics of being Samoan}

When tama Samoa were asked about what makes a person Samoan, the talanoa centred on the characteristics that tama Samoa believed to be unique to Samoa as well as influences that connect them to the Samoan culture. During the focus group talanoa process tama Samoa were asked to list these characteristics and then they shared their ideas with each other as they were recorded. The following is the list of characteristics that tama Samoa identified:

- Siva Samoa (Samoan dance)

- Tatau/Malu (Men's and Women's tattoos)

- Oral language

- $\quad$ Kirikiti (Cricket)

- $\quad$ Lotu (Prayer Meeting)

- $\quad$ Aganu'u (Samoan traditions)

- $\quad$ Umu (Earth oven)

- $\quad$ Gagana (Language)

- $\quad$ Meai (Food)

- Fa'aSamoa (Samoan way of living)

- $\quad$ Tautua (Service)

- $\quad$ Fa'aaloalo (Respect)

- $\quad$ Pese (Song)

- $\quad \mathrm{Va}$ (Relationships between siblings, between parents, between elders)

The characteristics listed above were representative of the everyday experiences most tama Samoa had. The tama Samoa shared learning about the uniqueness of the Samoa culture through family ways of living and their affiliation with a Samoan church. These characteristics were also described by the tama Samoa as being what makes them Samoan. 
Some of the tama Samoa had strong affiliations with a Samoan church, although some of them were members of different churches such as Catholic, Methodist, Assembly of God, and Congregational Christian Church of Samoa. Some of them shared how the church helped with their understanding of Samoan culture. For example:

For me, most of where I learnt about being Samoan is in the church with the others I grew up with, most of it was language through singing and reading the bible in Samoan, as well as the lotu tamaiti (Children's White Sunday). (Tataio: F)

However, being identified as Samoan does not always reflect their daily practices as an individual. lese explained that his experience of being Samoan was only reflected in his home when he had Samoan family visit:

We don't really practice any Samoa customs any more at home. We speak the language sometimes, but it's only when older family members come and visit. (lese: F)

lese's statement was supported by comments made by his NP:

In our family, we always try to remind our kids that they are first and foremost Samoans and that everything they do represents their Samoan culture, but I have to be honest and say the kids speak more English than Samoan at home. (lese's: NP)

Interestingly, both lese and his NP have similar ideas about how both define lese's perspective of Samoan characteristics; especially the use of the Samoan language around the home as noted by lese's NP they acknowledge the importance of being Samoan,

Patolomaio explained that living as a half caste with a Samoan father and Palagi (English) mother meant they did not really grow up with many Samoan customs:

Although, I can say I am very proud to have Samoan heritage, being a half caste, it was not something we would practice at home. We don't speak the language, and we don't go to church. Only now and then my 
Dad would bring home some taro (similar to potato) to cook, but I don't really enjoy eating taro. (Patolomaio: SS)

However, Patolomaio did talk about the stories his father shared about his upbringing in the Samoan village, and mentioned that this made him feel strongly connected to his Samoan heritage.

The tama Samoa expressed their sense of cultural identity within the various ways they experienced being a Samoan. For some of them the church played an important role of contributing to their Samoan heritage, others identified that although Samoan culture was not practiced in the home, this did not reflect negatively on their sense of pride being a tama Samoa.

\section{Being Samoan amongst others at school}

The tama Samoa identified the different characteristics of what it means to be Samoan, and shared what it means for them to be a confident Samoan amongst other people, and how they believe their Samoa-ness is perceived by others:

When you come to school you are accepted by the other Samoans... and it's cool because you can speak Samoan to each other.

Teachers also worry about our education so they set up meetings for Samoan and other Pacific Island parents. (Mataio: SS)

A lot of my mates just joke around with me being Samoan because there are not many Samoans at my school. (Patolomaio: SS) However, although Patolomaio talked about how it was sometimes funny that his mates mocked his Samoa-ness, he also questioned whether it was really important to identify himself as Samoan:

Māori have more chances of getting special admission to tertiary institutions. I don't think that is fair, because I think if the Samoan culture or the Māori culture people work as hard as some of the other people and get in with merits not culture that is how it should be, just be accepted based on their results. Would it make a difference if I went around saying, "but I am Samoan"? (Patolomaio: SS) 
Furthermore, in trying to establish what being a tama Samoa was "like" at secondary school and how they thought the school identified with their Samoaness, loane said:

Our school and most teachers don't really value us as Samoans, but because there are a lot of us here. It is the students that valued our culture including the Samoan teachers, but no one else really (Toma: SS).

Both loane and Patolomaio, identify tensions in their experiences of being Samoan amongst others. These comments indicate the tama Samoa feel tension between their pride in identifying as Samoan, and caution about how others (friends and teachers) may perceive this.

In reviewing the experiences shared the tama Samoa, it is clear that not all tama Samoa have a similar way of thinking about what it means to be Samoan. In most cases, each tama Samoa has his own unique story of being Samoan and this has a strong connection to family and the influence of family has on individual tama Samoa.

Through the talanoa with tama Samoa, it was noted that their everyday perceptions of people around them about themselves as students had a part to play on how tama Samoa thought about school and acted in school. This aligns with Holley and Dobson (2008) notion that the idea that school environments and people within the school setting have an impact on student attitudes and behaviour while attending secondary school. This became clearer, as tama Samoa explored their cultural identity within the secondary school setting, and how the influences and perceptions of others affected their attitudes about their cultural identities. 


\section{GROUP IDENTITY}

In this section of the identity theme, tama Samoa explore their experience of how they adapt in different situations.

When discussing whether or not they adapted their attitudes and behaviours around others or according to different situations, all twelve tama Samoa acknowledged that they felt it was necessary to adapt their identity when surrounded by different people and places.

Tama Samoa described this - how they need to act and behave when in the classroom and how they interact outside the classroom amongst peers and buddies - in terms of using different faces or switching mind frames in different contexts.

There are three categories in this sub-theme: i) Tama Samoa - the adaptive individual; ii) Tama Samoa - adapting roles and responsibilities; and iii) Tama Samoa - Strategising.

\section{Tama Samoa - the adaptive individual}

In this section tama Samoa talk about the experiences of adapting who they are as individuals in order to "fit" the context they are in at the time:

I think I am usually myself in different classes, but it all depends on the boys I am with. If it's all white boys, like in biology, I keep to myself and try and focus really hard. (loane: SS)

When asked why this was, loane responded:

I don't have many friends in biology, so I am not as relaxed around the white boys as I would be if I had my boys in there. (loane: SS)

Mataio made similar comment about why he would change face at school; however, his response was more targeted to who the teacher would be in the class: 
It depends on which class I have, I would adapt my ways [so] the teacher will be more accepting of me. (Mataio: SS)

When asked how he would describe himself, Mataio commented:

I am enthusiastic, run around, love my rugby, always joking around, and laughing with my mates. (Mataio: SS)

Referring back to this comment made by Mataio, through the process of fa'afaletui of weaving and refining perceptions, Mataio reviewed this response with a comment:

If I went into class being enthusiastic and being a joker, they (teachers) wouldn't treat me the same, or they would not be too impressed. (Mataio: SS)

These responses show that how tama Samoa chose to present themselves in class depended, in some cases, on who was in the class, both teachers and students. However, it was also noted that tama Samoa responded differently depending on which subject they were sitting in during class time. The quotes provided show in more detail why it is that their attitudes differ depending on the subject being taught, who was in the class, and their ability to adapt.

I am truly myself in PE, because it is practical and we can clown around - not all the time, but most times - plus most of my mates are this class. I find it quite lucky how we can switch, like we can be like serious in serious classes and be ourselves in other classes. (Tataio: SS)

When I asked Tataio why he found it "lucky" that he could switch, his response was:

because it shows how we Samoans can be flexible and how we can walk in both worlds, being Samoan. (Tataio: SS)

Further to this, some tama Samoa explained why they felt they needed to adapt their identities or their attitudes from home to school: 
When I leave home I know I come into school with a different mind frame. At home I am annoying and I like to bug my brothers and sister big time, but then I come to school and I am, like, different - not hard out different but I know I am different. (Aneterea: SS)

Aneterea mentioned:

Actually once I get to know new people, I started being myself so it's probably more of a confidence thing. (Aneterea: SS)

Timoteo talked about adapting his identities and provided his understanding of why he switches mind frames when at school:

I think as you get older you start to understand, like, the reasons and why you come to school... once you become Year 13 it's over, like you have to step out...you have to start preparing yourself, yeah, and I think when we're at home we're, like, more ourselves but then we come to school we are more controlled...you have to be more controlled, you have to learn to be more self-controlled. (Timoteo: SS)

Similar ideas were identified by lakopo; he too discussed how he would have to use different identities as a way of coping with studies at school:

Only in my early years I would be a different person in class, as I was still getting used to the environment. In the last few years I was able to act the same in class as I would in the playground even though I was around different people. I knew my place and figured out my place in the school and learnt how to cope with the many classes we had. (lakopo: SS)

lakopo's use of the term "cope" indicates that, like other tama Samoa, he understood that he had to find the tools or the skills within himself to support himself while at school. It was therefore noted that tama Samoa, were able to apply themselves in different situations, and be flexible in the various situations tama Samoa were in. 


\section{Tama Samoa - adapting roles and responsibilities}

During the talanoa with tama Samoa they were asked to talanoa about their perceptions of the roles that they had while in the school environment, and the responsibilities that came with these roles. Eight of the twelve tama Samoa revealed that they were in roles that required them to be a leader; some had been asked and some had volunteered to be in these leadership positions, as shown in Table 6 below.

Table 6: Roles taken by tama Samoa in secondary school.

\begin{tabular}{|c|c|c|c|c|}
\hline Responsibility & Role & Asked & Volunteered & $\begin{array}{l}\text { No. of TS in the } \\
\text { role }\end{array}$ \\
\hline First XV & Captain & 8 & & $\xi_{3} \xi^{3}$ \\
\hline Poly Club & Leader & & $\left\{\begin{array}{c}\varepsilon_{3} \\
3\end{array}\right.$ & 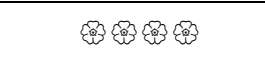 \\
\hline Snr Cricket & Captain & $s_{3}^{3}$ & & $\underbrace{3}_{3}$ \\
\hline School Production & Lead Part & 83 & $\varepsilon$ & 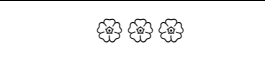 \\
\hline Barbershop & & & 毁 & $\xi_{93}$ \\
\hline Chess Club & Captain & & $\varepsilon^{3}$ & $s_{3}^{3}$ \\
\hline School captain & $\begin{array}{c}\text { Deputy Head } \\
\text { boy }\end{array}$ & $s^{3}$ & & $s_{3}^{3}$ \\
\hline Sports Captain & & 8 & & $\underbrace{}_{3}$ \\
\hline Cultural Captain & & 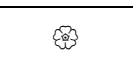 & & $s^{3}$ \\
\hline Board of Trustees & Student rep & & $\left\{\begin{array}{c}y^{3} \\
3\end{array}\right.$ & $\varepsilon^{3}$ \\
\hline
\end{tabular}

Tama Samoa took the opportunity to talanoa about their experiences of participating various groups:

I have always enjoyed my rugby, so when I made it into the first $X V$, and was made captain, I was like "man this is a dream come true". It certainly has been a good year. Also being sports captain. I was a little unsure about that one, but being asked was pretty cool. (Patolomaio: SS)

When I asked Patolomaio how he felt about fulfilling both roles and taking on the responsibilities that went with them he responded: 
Both of the roles were similar, especially both had to do with sport. Only pressure I felt making sure our first XV did well on the field. Didn't quite make it this year, but we played really well. (Patolomaio: SS)

loane and Toma talked about how having extra responsibilities at school seemed to make teachers respect them more in their classes. Taking part in extracurricular activity was encouraged by teachers, as explained by Toma:

I enjoyed the class a lot and so when the teacher asked me to audition and I got offered the lead role, that was pretty cool. It really took me out of my comfort zone. (Toma: SS)

Nominated persons were asked about their perceptions of the roles that tama Samoa had while in the school environment and the responsibilities that came with these roles. NPs had a different perspective about this. Toma's NP stated:

Toma is always involved in a lot of groups, I think he likes it and I think he does a good job in the different groups he joins. (Toma: NP)

loane's NP, however, had a different idea about loane joining different groups:

I think it is good to see loane active and into extra school curricula. He shows good leadership potential, but it is just making sure that he focuses on his school work and the groups are an extra thing that shouldn't take over. (loane: NP)

When it came to roles and responsibilities that required close interaction with school leadership, Tataio and lakopo highlighted the importance of having these roles to show younger Pacific boys the importance of such roles, and how it would make other young men look up to them:

In our school, the principal invites you to apply for the positions of head pupils. I received the letter to apply, and decided to go for it. It was quite a daunting process, but I was happy to be given the role. Being in this role is not only for me, but for my family and especially the boys here at school. (lakopo: SS) 
It is a role I take very serious. We do not have a large Pacific population here, so when you have a Pacific Islander get into one of these roles, it's huge. (Simona-Peteru: SS)

Tama Samoa identified two particular roles that they felt were not very popular amongst other tama Samoa and Pacific students in general. loane and lese talk about why they volunteered for these particular roles:

I took chess out of interest, and found that I really enjoyed it. I got really good at it that I was chosen to be team captain, but I don't play it anymore. (loane: SS)

When I questioned loane about his reasons for not playing chess anymore, he responded with:

I think because it is a brain game and none of the boys want to use their brains. (loane: F)

Tama Samoa, then, provided a number of different reasons for why they chose or accepted the involvement in extra roles and responsibilities. These reasons included: enjoyment and sense of pride of a role, especially the selection to sports teams such as rugby; and the knowledge that being in a role of responsibility meant being a role model to other Pacific students; and that by being in a role of responsibility, tama Samoa gained respect from teachers and other students.

\section{TAMA SAMOA - STRATEGISING}

This section presents the strategies that tama Samoa identified that they use in the school environment in order to be noticed by teachers, to be motivated to attend classes, to support friends, and to get through the school year.

When asked about what strategies tama Samoa used to make sure they were understanding what was learnt in class, Toma responded with the following comment about motivation:

I know I am a Samoan and I have been identified as being successful at school. There are some teachers here that remind us that we've got, like, 
low grades, and ... some boys are like, "oh so what?" But I know if I change the way I think in particular classes this is my motivation to do better and prove them wrong. (Toma: SS)

Toma also mentioned the idea of preparing himself mentally:

I prepare myself like [to be] in the state of mind where I want to learn. You have to prepare yourself mentally so you survive till the end of class. (Toma: SS)

Other tama Samoa reflected back to what it was like being in class with other tama who were not of Samoan heritage:

In the last few years I have watched how the boys act in class, especially the Palagi (European) ones, and they always ask questions and they are never shy about asking others for notes and stuff. Sometimes I think they know it but pretend to act dumb so someone else can do the work for them. Well I am opposite; I try to act smart by asking questions and writing heaps of notes but sometimes I still don't get it. (loane: SS)

It's the people who I hang out with that help me survive. I've got some pretty smart friends and they are pushing me to study. I mean I am not going hang out by myself so l'd rather study with people who know what they are doing and I know they're doing well in subjects because they get good marks in everything. (Patolomaio: SS)

Patolomaio, then, identifies the need to find people that are already successful in certain subjects at school and uses this as a support mechanism to "survive" subjects and succeed at secondary school. loane and Patolomaio were each able to identify a key mechanism, that other tama Samoa also spoke about, to support them as they attend secondary. It is also evident that tama Samoa are aware of and concerned about what other students think of them during class time, and this plays a major part in how they choose to act and respond in class.

Nominated Persons were also asked if they knew of any strategies that their tama Samoa would use to help or support him through his studies. The following 
comments indicate that these Nominated Persons had formed clear ideas about strategies used by "their" tama Samoa at school:

Tataio is quite shy and I know he would rather try and work things out by himself if he is stuck especially when it comes to school work...I think most times if he gives it time he usually figures school work problems out. (Tataio: NP)

I have always had Filipo come over to my house ever since he was young to help him with his school work, and I know when he wants to he would ask for help at school, but I don't think he takes advantage of that help too often - I think sometimes he pretends to show he understands and leaves it at that when he is at school. (Filipo: NP)

What is interesting to identify in the above talanoa with Tataio's close friend NP and Filipo's relative NP. Is that the perceptions from the two tama Samoa and nominated person did align with how each of these two tama Samoa coped with study and doing school work. It was also clear that both tama Samoa had ongoing and continued conversations with their nominated persons about their everyday learning and shared the ways each them dealt with everyday school work.

\section{SUMMARY}

The identity theme and its three sub-themes personal identity, cultural identity, and group identity, have highlighted key factors that contribute to the identity experiences of tama Samoa during their years at secondary school. These factors have provided a clear sense of how tama Samoa interact and socialise within a secondary school setting, and also highlight how tama Samoa create their networks and supporting mechanisms to succeed at school.

In terms of personal identity, the responses show that tama Samoa are confident in knowing who they are and where their heritages come from. Furthermore, the way they talk about their everyday experiences and how they connect with others indicates they have a sense of pride in sharing themselves with others as proud tama Samoa, accepting their Samoan heritage as a key factor in contributing to their development as young men. 
The discussion about group identity highlighted many key factors such as the need to adapt their identities when attending classes in order to survive. Some of the terms provided by the tama Samoa such as 'cope', and 'survive' are strong words indicating negative and challenging experiences for the tama Samoa.

Tama Samoa also highlighted the need to adapt their identities to carry out their leadership roles and to fulfil the responsibilities that go with these. Tama Samoa note that the positive influences of being a good role model in these leadership positions, but also acknowledge the pressure of performing to complete a task well.

\section{Sense of Belonging}

In relation to the second theme, their sense of belonging within the school context, tama Samoa were given the opportunity to talanoa about the factors that contribute to this.

The literature suggests that students must have a sense of belonging within the school context, for reasons such being motivated to learn, for a positive experience and to build tight networks with people (Baumester \& Leary, 1995; Goodenow 1993b; Osterman, 2000). According to Goodenow (1993b) a crucial element which impacts a student's decision to engage themselves in school life is their sense of belonging. When a student feels positive about school, and that their contributions are valued, then engagement is more likely to occur. Goodenow's (1993b) ideas about student feelings towards a school setting support those by Finn (1989), who suggests that it is not only important for students to feel they belonged at school, but also have a connection with others within the school environment. Through the talanoa the tama Samoa identified feelings, bonds, acceptance, and commitment as concepts that intertwine with the notion of belonging.

It is through these concepts that the tama Samoa were able to connect their experiences both positive and negative, and therefore, during the talanoa were able to explore these experiences. 


\section{Defining belonging}

In this section tama Samoa were invited to share their perceptions of belonging through defining what the term belonging meant to them. This gave them the opportunity to talk about their emotions and how they felt about belonging at secondary school and whether their perceptions of belonging aligned with how they were treated at school. To set the scene, tama Samoa spoke about the term "belonging" within the focus group talanoa and explored the meaning of this in terms of their experiences within secondary school as well as their own perspectives of what the term means.

In preparing tama Samoa to share their perceptions of what belonging meant to them, I provided a prompt through the use of a strategy that I would commonly use to develop students' critical thinking when I was a classroom teacher. This strategy involved engaging tama Samoa with three of their senses - looking with their eyes, hearing with their ears, and feeling with their hands - so I was able to capture their Samoa understandings. In applying this strategy, I asked the tama Samoa these questions: "What does belonging look like? What does belonging sound like? What does belonging feel like?"

Below, are the responses of all twelve tama Samoa:

Oh, it's that feeling of like being wanted, happy, and lots of positive words. (Toma: SS)

Being part of a group, feeling comfortable, and chilling out with your mates. (Patolomaio: SS)

It's that feeling of having a bond between you and someone else. Sounds like everyone is having a good time. (loane: SS)

It's about feeling comfortable and bonding with others, and looks like everyone being relaxed. (Mataio: SS)

Belonging is about relationships, and being able to talk to anyone. (Simona-Peteru: SS) 
Being part of different type of groups, and feeling positive, but also lots of laughter. (Tataio: SS)

Belonging for me would be like where you belong for example belonging for me is here, where I am right now, or when I go to church I feel, I have a sense of belonging... or if I go to a Samoan function, I have a sense of belonging there. It's that connection you have with a place. (Timoteo: SS)

It's like being surrounded by, like, people or, like, a place where you feel that you're, like, welcomed and you feel free to, like, share and express yourself. It's a place you feel safe. (Aneterea: SS)

It's a place where you feel you can say anything and do anything. It's being encouraged and being part of a community. (lese: SS)

Belonging where you can take a risk; like here at school, I feel I belong and feel I can push myself. (lakopo: SS)

Belonging is, like, everyone does everything together and everyone knows everyone, and you can laugh a lot. (luta: SS)

For me belonging is about feeling comfortable around others and feeling safe being able to be yourself. (Filipo: SS)

The tama Samoa perceptions of what belonging means to them is evident from these responses. Each one of the tama Samoa have emphasised that belonging is associated with many positive terms such as "comfortable", "encouraged", "happy", "bonding", "safe", and that it is about having positive relationships.

\section{Belonging in school}

The idea of feeling safe and secure in an environment is also related to belonging. Therefore, to follow up their definitions of belonging, tama Samoa were asked to reflect on how it is related to in their experiences within secondary school. This was a challenging task for tama Samoa, as it was asking them to talk about their feelings both in terms of belonging in school as well as describing their feelings towards experiences they have had. 
When I asked them to identify how they felt about their school and belonging and if their school made them feel they belonged at school, their responses show a mixture of feelings. When asked if they had a sense of belonging to their school the responses were varied.

Table 7, below, summarises and shows at a glance whether tama Samoa felt they were made to feel they belonged in their school communities:

Table 7: Tama Samoa sense of belonging at school.

\begin{tabular}{|c|c|c|}
\hline Tama Samoa & Yes & No \\
\hline Tataio & $\checkmark$ & \\
\hline Mataio & $\checkmark$ & $X$ \\
\hline Simona-Peteru & $\checkmark$ & $X$ \\
\hline Toma & & \\
\hline luta & & \\
\hline lakopo & $\checkmark$ & \\
\hline Aneterea & $\checkmark$ & $X$ \\
\hline lese & $\checkmark$ & $X$ \\
\hline Patolomaio & & $X$ \\
\hline Timoteo & & \\
\hline Filipo & $\checkmark$ & \\
\hline loane & & \\
\hline
\end{tabular}

Table 7 shows an almost even split of tama Samoa and their feelings of belonging at their schools. In the next section, tama Samoa reflect on their experiences and although some will have tight connections with friends at school, this did not reflect their sense of belonging at school.

The following talanoa excerpts indicate that some tama Samoa were able to identify in more detail their feelings about their school and their sense of belonging.

lakopo explained belonging as a feeling which gives him the confidence to take a risk; to push himself further. When I asked lakopo if he could give me an example of taking a risk within a school context, he shared the following: 
I took a risk, when I applied for one of the head positions for our school this year. I didn't get head boy or deputy head boy, and one of the reasons the principal gave to me was I was a bit quiet. It didn't quite bother me about not getting the role, but I was a little upset, but all good about it because it was a good mate that did get the role. (lakopo: SS)

The tama Samoa expressed a range of responses about the sense of belonging and the feelings that are attached to it. Some expressed feelings of connection and belonging:

I kind of feel like I belong here. (Toma: SS)

When I asked Toma if he could elaborate on this comment, Toma continued by saying:

Oh, like in drama. Our class is like family. We do everything together with all the boys in the class too. It's like some of us will go down to the drama room during break, some of us will just go because others are there... it's the atmosphere that makes us feel we belong. (Toma: SS)

Toma, then, identified a sense of connection to a particular place within the school environment that he feels he belongs to.

Some tama Samoa were clear that their feeling of belonging at school is because of the people that they interact with each day. Filipo, for example, talked about how it was not the physical school environment that made him feel he belonged, but more the relationship he had with his friends:

Oh I don't reckon the school makes me belong but I reckon the boys make me belong. (Filipo: SS)

Tataio, lakopo, lese, and Timoteo, had similar views about friends and teachers when asked if they felt they belonged at their secondary schools:

Teachers and friends...make me feel I belong to this school, and make me feel that this is my school. (Tataio: SS) 
Yes. Most people including teachers knew the potential and talents that I had. This made me feel comfortable at school. (lakopo: SS)

I have made a lot of friends, and really enjoying my time here at school a lot and felt I belonged to this community. Teachers were encouraging and open minded about things you say and are good with supporting me with my life choices on the way out of Secondary School. (lese: SS)

Like the attitude towards you like when teachers approach you sometimes they will smile and they will talk to you, and have a conversation. Mr Lee he, like, can speak Samoan so like we always have a good conversation with him and he shows us that he is interested and wants to talk about you and how you are doing. (Timoteo: SS)

When nominated persons were asked the question about their perceptions of whether tama Samoa felt a sense of belonging in their school environments, some of the responses were similar answers to those of the tama Samoa. For example:

I think the tama Samoan students feel they belong at this school mainly because of particular teachers like Mr Lee. He does pastoral care for the students but he speaks Samoan, and he's very friendly towards the Samoan students. (Simon-Peteru: NP)

Mataio's and luta's nominated persons responded with:

The boys' feel comfortable here and know the school environment because some of them have had older brothers that have come here so it has been a familiar area for a long time. (Mataio: NP).

He seems to enjoy school, well maybe his mates, but does get himself worked up, when there is a lot of homework and then he cursing the school. (luta: NP)

However, as shown on Table 7, some tama Samoa indicated that they felt no sense of belonging; quite the contrary: 
I felt I belonged at school when I was in Primary and Intermediate, because we did everything together, but I don't feel I belong here, I really hate the school area. (Patolomaio: SS)

All Tama Samoa "define" the term belonging as positive emotions and experiences. While tama Samoa expressed a range of feelings about belonging to their schools, these responses are not associated with particular schools. However, it is clearly evident from the responses that positive feelings of belonging are closely related to tama Samoa's relationships with mates, peers, and teachers both inside and outside the classroom setting. This is explored in more detail in the next section

\section{TAMA SAMOA - THE SOCIAL BEING}

This section describes the tama Samoa and their roles as social beings within their school settings. Tama Samoa talanoa about their reasons for participating in a variety of different groups and why they made the choice to take part in these groups (see Table 8).

Through the talanoa process, tama Samoa identified that their role in these various groups is one of the contributing factors to their sense of belonging within their schools. There are three sub-themes to this theme, presented as i) Tama Samoa belonging to groups; ii) Loyalty from a tama Samoa perspective.

\section{Tama Samoa belonging to groups}

As indicated in the previous section, tama Samoa equate their feelings of belonging within the school strongly with their social relationships. Many of these social contacts are, in turn, associated with their belonging to groups within the school.

When tama Samoa were asked what influenced them to join the groups, their answers indicated that it was due to either individual choice, or to invitation or encouragement by teacher, coach, parents, or peers. As the Table 8 shows, the groups or clubs that tama Samoa were involved in were a mix of sports, drama, religious, culture, and musical groups; subject clubs such Science club; or groups 
organised by school management such as a prefect or student leadership group. What is significant is that the tama Samoa acknowledged that alongside their own decisions to join various groups were often influenced by others such friends, teachers, or school management.

In relation to their membership in groups, tama Samoa were asked what it meant for them to belong to a group. The representative responses, below, show that tama Samoa talanoa about the enjoyment of being in particular groups, about the expectations of being part of a group, and about the positive and negative aspects of being in a group:

Several of the tama Samoa emphasised that they belonged to clubs because of their cultural connections:

I joined Poly club, because it was a place where you could celebrate our identities as Pacific Islanders. You can't be in Poly club until you're in Year 11 in our school, so it's something I know a lot of boys look forward to when they get older, I know I did. (Tataio: SS)

I enjoy performing, so most of the groups I am involved in are performing groups - I am in the Poly club, Drama club, and Pasifika Beats. For me it is about expressing my culture, but I also feel I can be myself in these clubs. (loane: SS).

I joined Poly club because it's a cultural group and it had a lot to do with my Samoan culture. (lese: SS)

Toma mentioned that his motivation for joining the Poly club in his senior year was so that he could be more familiar with his culture:

Oh, because like I wanted to get into my culture more. (Toma: SS)

Aneterea explained that the Polynesian group in his school was the one place that all Polynesian students could get together; a place Pacific students could all connect and see each other. This was of particular importance because in his particular school there were very few Pacific students: 
When you go to Poly group, it's the only place full of Islanders and if you're with all the Islanders you're pumped and ready. We talk in, like, our own language. (Aneterea: SS)

Patolomaio talked about the advantage of belonging to a group and how he believed that belonging to a group, particularly in sports teams, steered you in the right direction for being well placed to be in that sports team for the next year:

Yeah, once you're in you are in, but you still have to trial up to next year.

If you mix with the same people that have the same interests as you, like rugby, you just continue on, and coaches know you and your skills. (Patolomaio: SS)

loane provide a quite different explanation for why he joined the first fifteen, acknowledging simply that it was:

Because I am a really good rugby player. (loane: SS)

Across all five secondary schools, the tama Samoa had commonalities in the groups that they were involved in.

Table 8 displays the number of Tama Samoa involved in each of the different groups or clubs they had identified they belong to:

Table 8: Tama Samoa group/clubs involvement.

\begin{tabular}{|c|c|}
\hline Rugby & $\mathbf{1 1}$ \\
\hline Poly Club & 8 \\
\hline Gateway & 5 \\
\hline Outreach & 5 \\
\hline Drama Club & 4 \\
\hline Prayer Group & 4 \\
\hline Prefects & 4 \\
\hline Freedom Group & 4 \\
\hline Touch Rugby & 3 \\
\hline Choir & 3 \\
\hline A cappella & 3 \\
\hline Cricket & 3 \\
\hline Samoa Club & 3 \\
\hline Pasifika Beats & 2 \\
\hline
\end{tabular}




\begin{tabular}{|c|c|}
\hline Rugby & $\mathbf{1 1}$ \\
\hline (Band). & \\
\hline Orchestra & 2 \\
\hline Japanese Club & 1 \\
\hline Debating Club & 1 \\
\hline Chess Club & 1 \\
\hline
\end{tabular}

The groups were arranged in popularity of how many of tama Samoa were involved in each group which they had highlighted. It is also important to note each tama Samoa was asked which groups they were involved in - this provided the prompt for tama Samoa to discuss why they joined particular groups.

While many of these clubs were popular with the tama Samoa, there were also some groups or clubs that were identified by tama Samoa that involved single individuals from the participant group. These included the chess club, debating club and the Japanese club. These tama Samoa explain why they joined these clubs:

I have been in the chess club for the last three years. It was something I learnt how to play in primary school and I was pretty good. You get to play Palagi/European and Chinese kids. (loane: SS)

I was always a talker and not afraid to speak my mind. It was my Mum that encouraged me to join the debating team. Didn't think much about it, but I enjoyed it, stayed in the team for two years straight. (lese: SS)

I was taking Japanese as my option class since I started secondary school, and because we had a trip to Japan when I was in Year 11, we had to also join Japanese class to help with our oral language. (lakopo: SS)

It can be seen from their responses that lese and lakopo were influenced and encouraged by others to join the debating and Japanese clubs respectively.

On the other hand, although loane attended a school with a large population of Pacific students, he was the only tama Samoa or tama Pacific that had joined the 
chess club during his time. During his talanoa about the chess club, loane noted that he was never teased about joining the chess club by his friends, and stated that there were other tama Samoa that knew how to play chess. loane did not return to chess club in Year 11, due to chess club being held in the lunch hour.

Tama Samoa, then, provided a mixture of reasons for belonging to various groups or clubs. These included that it was sport or activity they had always been interested in or that their friends were part of. It was also noted in their talanoa, that participating in a group or club provided a sense of belonging: feeling that they belonged to particular groups or clubs gave them a sense of pride, a sense of responsibility to do well, and a sense of enjoyment.

\section{Loyalty from a tama Samoa perspective}

Tama Samoa identified the need to be part of the special school character within the school setting. For some tama Samoa, the notion of brotherhood has an immense influence on how they feel about the school environment. Below, tama Samoa share their perspectives on what it means to have loyalty to the school including adults and student body - and also what it means to have loyalty to their friends at school.

For many of the tama Samoa, their sense of loyalty to their schools was evident in their expressions of pride about their schools:

Oh I feel good about my school. Just like a feeling of knowing that I can I say I went to XXX and that. Being at this school makes me very proud. (Filipo: SS)

I am very proud to be a XXX student, because there's like heaps of boys like Pacific Islanders. Everyone's got the same sort of views at school like the same experiences as well. The brothers have the same kind of background that I'm kind of used to. Oh, the same routine and stuff and everyone's got a strong bond here. It's good that the teachers here treat everyone equally. (loane: SS)

I have had two older brothers attend this school, and I have a younger one here with me now. My friends at school will be my friends forever. 
The school does a lot to encourage students to support each other from seniors to juniors. (lakopo: SS)

I am very proud of my school, and I always try to show that by being respectful to teachers and other adults. (Toma: SS)

Some Tama Samoa acknowledge their loyalty to the school has been influenced by their experiences with their teachers:

Simona-Peteru also identified being proud because of teacher support, but also from being identified by school management as being a good role model Teachers, help me feel I can do it here at this school, and this makes me feel proud, but also because the principal is always approaching me about the good things I am doing, and what a good role model I am. (Simona-Peteru: SS)

However, there was a mixture of perspectives in terms of having pride in their schools and the loyalties that align with it. Not all tama Samoa had the same experiences or felt the same pride about their school:

There is nothing about XX College I am proud of. In your senior years it is pretty much a burden - that's what I think. I haven't done so well in NCEA, but I will definitely put my foot down and try harder. It is boring, not particularly interesting. All they do is focus on assessment. They need to involve a curriculum that gets the mind off assessment. At the end of High School we become like robots. It's all hard work. I still want to enjoy school but there is no opportunity, so it makes me dislike it. I don't have any loyalties here, not for the school, that's for sure. (luta: SS)

However, when the talanoa focused on the loyalty tama Samoa towards their peers and friends, all twelve were strongly positive about the importance of this for each of them while at school. The tama Samoa indicated that there is a certain type of loyalty connected with being part of the friends they make at secondary school. Filipo, for example, expresses this as:

Like if everyone's like brothers with each other, like, no one fights and no one hates but respect for each other. (Filipo: SS) 
This idea of brotherhood is more evident in some schools than it is in others: it is particularly more evident in single sex boys' school. This aligns with the findings of Brutsaert \& Bracke (1994) who, when looking at boys attending a Catholic single sex school, found that the boys indicated significantly higher self-esteem than boys in Catholic coeducational elementary schools. They suggested that one possible reason for this finding could be the impactful presence of male faculty in single sex schools. In the single sex school in this study of tama Samoa, the notion of brotherhood for tama Samoa emerged as a key aspect to secondary school life. The importance of being around friends, and being part of the "brotherhood", was one of the fundamental reasons identified for being at school:

I just like to come to school to see the boys sometimes... Oh, I would say this school is like made up of a lot of Samoans. It's just like a big brotherly environment. Brotherhood is very strong in our school. Your brothers make you feel most comfortable, and you can be just yourself. (Toma: SS)

The boys give me a lot of encouragement and influence me heaps. We have much respect for each other, and the boys are like my competition to keep me going. It's rich here...the brotherhood. (Tataio: SS)

One of the positive things about this school for me, is the brotherhood. It's strong and it goes with you even when you finish school. My older brother who left three years ago, still connects strongly to his friends from here. (Mataio: SS)

For tama Samoa in this school the sense of belonging to a brotherhood, and the loyalty contained within their friendships have strong influences on their everyday experiences at school. The strong relationship bonds make these tama Samoa feel connected and loyal to both friends and school.

Furthermore for the tama Samoa in this single sex boys' school, the importance of brotherhood works alongside a feeling of belonging in the school environment. In this school the tama Samoa identified the importance of brotherhood, and were able to identify the code of responsibility that went with being part of the brotherhood. 
Tama Samoa in other secondary schools indicated that a sense of brotherhood was not particularly evident within their school. Timoteo's comment, for example, indicates that, although there is loyalty and close relationships with other students in co-educational schools, there is not the same sense of brotherhood as at a boys only school:

When I moved to this school, there was a different feel. I had come from an all-boys school and now I was in a school with both sexes. It was here that I started to hang out with people I knew like my cousins and other Pacific students. (Timoteo: SS)

\section{SUMMARY}

Tama Samoas' sense of loyalty is developed strongly through their relationships with others. As evident in the comments by tama Samoa, for most of them pride in their school was experienced if they were noticed by other people such as peers, friends, and adults within the school setting. From this pride in their school was generated a sense of loyalty to their school.

For other tama Samoa, although pride in their school was not an important factor for them, being loyal to their friends was of key importance to their experiences in school.

\section{VISUALISING FOR THEIR FUTURES}

This section presents the perceptions of tama Samoa about what they expected from their school environments. Tama Samoa were also given the opportunity to reflect on whether these expectations had been met during their time at secondary school. The talanoa was about Tama Samoas' aspirations for the future, and their plans for once they finish secondary school.

Nichols and Berliner (2007) claim that students who believe in themselves and are competent become more willing to take risks. Tama Samoa were asked if they felt that the opportunities in terms of support, academic and skills development, and self-esteem that they had been given at secondary school had prepared them for the future. Throughout the talanoa sessions the tama Samoa 
spoke about what they perceived school would be like and the expectations they had of how school should support them. They also made connections between what they expected from their secondary school and how this would help them once they completed secondary school.

Thus, there are four sub-themes to this main theme: i) the expectations tama Samoa have of their school; ii) Tama Samoa perceptions of the purpose of academic learning; iii) Tama Samoa and their aspirations for their future when they finish secondary school; and, iv) the final section of this theme, tama Samoa - Perceptions on ways secondary school could do better for tama Pacific.

\section{Tama Samoa expectations of their secondary schools}

Weiner (2005) stated that expectations are linked to students' own beliefs about schooling. Weiner further claims that classic theories of motivation posit that people engage in tasks that provide some expectations of success. This section presents the tama Samoa' responses to questions about the expectations they had of their schools, and whether their expectations were met:

School has a very important part that helps with your future. I expected school to make new friends and now, I have the brothers. I also expected school to help me learn so I can job or maybe get me into Open Polytech in Petone or University - I am still working on that one. (Tataio: F)

I expected school to give me a good foundation for my future. (Mataio: SS)

My parents need the support and that's why I come to school - so I can get better educated and find a good job. That's the important thing. (Filipo: SS)

Basically, I expected school to help me and my future, so that I am ready for anything when I get out of here. (Toma: SS)

You go to school because you have to. But then as you get older and you know more things, I go to school because I expect them to help me get 
skills to find a job and that makes you more determined to study and more determined for teachers to help you too. (Timoteo: SS)

As these quotes by Tataio, Mataio, Filipo, Toma, and Timoteo highlight, the tama Samoa regard the secondary school environment as a place that was to prepare them for a better future, to enable them to support their families, and to open the way for future educational and employment opportunities.

lakopo shared his expectations about school:

When I came to school I expected the teachers to be kind. I knew the boys will really look after each other and I wouldn't see that much bullying. (lakopo: SS)

When asked if the expectations he had had were met, lakopo responded:

Nearly all the teachers are kind. The boys have definitely looked out for each other and apart from the teasing and mocking I haven't seen any bullying during my years here. Everyone knows everyone, and everyone knows what you're like. (lakopo: SS)

As evident from his comments, a key aspect of lakopo's expectations, and one that was met, was having tama look out for each other. This was also noticed by one of the nominated people who commented on what they saw when walking around the school grounds:

I was walking over to my office. I saw one of the European boys walking over with one of the Samoan boys talking about something and [I was] thinking that's what's so great about this school, the natural relationships that everyone gets to have with all these different types of people that we have at our school and they're easy relationships. (Mataio: NP)

Other tama Samoa based their expectations of their secondary school on the relationships they had with others. Patolomaio's expectations of his secondary school were not only based on the relationships he had formed over the years, but also on what he had observed about the media attention his secondary school had received: 
I expected to meet a lot of people at my secondary school because it has a large student population, but then there was also a lot of publicity about the school being a bully school and having a lot of attention on students dealing drugs there. (Patolomaio: SS)

Patolomaio explained, however, that even though the publicity about past events within his secondary school gave the school a bad name, this did not hinder his expectations about what he would get out of his secondary school. He followed this by discussing the positive things he has gained from attending his secondary school:

I expected that I would make some good mates at school. There is quite a few of us that have come through since primary, but as the years have gone on, our group of mates has just got bigger and bigger. (Patolomaio: SS)

luta, shared that his expectations about secondary school were based on what it would be like with the teachers including the principal:

[The] teachers would be cool and the principal would be accessible - is that the right word? (luta: SS)

I noted that when probed about this comment about his expectation, luta paused and took some time to reflect on his comment, and then continued saying:

When I was in my second year at this school, I was thinking about who would be the people that will make this work for me, as in help me get through school, and it was teachers and the principal that came to my mind. (luta: SS)

It can be seen from these comments made by Patolomaio and luta, then that these two tama Samoa had expectations for certain people within the school environment whom they could rely on for support.

luta's, nominated person provided their perceptions of luta, and how luta interacted with certain groups within the school setting, and luta's expectations of his school with the following comment: 
I think luta is quite clever at school, and from what I have heard from other staff, he is not afraid to talk his mind and ask questions. I think luta knows who to talk to for support, he is very familiar with who can help him and who can't (luta: NP).

What was noticeable from this talanoa with tama Samoa was that each one of them was quite clear about having expectations about attending secondary school, and they were easily able to remember and to identify these. The responses reveal that they had a mixture of expectations about their secondary schools these ranged from expectations about support and relationships with staff and other students, to expectations about academic and skills development to prepare them for their futures in terms of educational and employment opportunities.

\section{Perceptions on the purpose of academic learning}

Secondary school is a learning environment. The Ministry of Education (2009) states that the core business of schools is to educate and provide as many opportunities as it can for young people to engage with and learn from.

As highlighted by the comments made by the tama Samoa, by time they reach their last two years of secondary school, their knowledge of the secondary school environment has developed through the experiences they have had and with the people they have met. In this section tama Samoa talanoa about their academic learning experiences, and their perceptions of how relevant this learning has been for them.

I attended X school, because it's a good place. I know I am going to get something for my future here and get a good education here. My favourite subjects are drama, art, maths, and music. I think these subjects are preparing me well for what I want to do when I leave, something in the Arts. (Toma: SS)

I love to learn new things, if it's easy and it's like broken down for me. I am taking Pacific Studies, Statistics, and Drama. I find level three Maths hard, but I know I will need it if I want to go to Uni. I don't want to be an 
actor but I just take Drama because it's different and all the boys are there too. (Aneterea: F)

I attended X school because my older brothers were here. Now that I am in Year 13, I am only taking two NCEA level three subjects - English and PE. For me, I have lasted this long at school because of my mates, it's the boys that are keeping me here but I can't wait to leave school. (Mataio: SS)

Some teachers have helped with my academic learning, and I am thankful for that, but there are other subjects where the teacher just does their own thing and that doesn't help me. (lakopo: SS)

I am not a brainy student, but I enjoy learning and this has helped me get through some of the subjects like English and Biology. (Filipo: SS)

Nominated Persons were also asked about their perceptions of their particular tama Samoa ideas about academic learning:

I know Aneter'a understands how important academic learning is because he hears me talk about all the time - I drum it into my kids more than their dad does. (Anetere'a: NP)

I think Filipo is aware that academic learning is the key to a good future, but I am not sure if that is what Filipo wants - to go the academic way once he finishes secondary school. (Filipo: NP)

I hear Mataio about school and learning, but I am not sure if it is something he considers to be important; he spends a lot of time with his mates (Mataio: NP)

While Simona-Peteru and Filipo's Nominated Persons appear to differ their tama Samoa perspective of academic learning, it seems that Mataio's Nominated Person has a similar notion to what Mataio shared; for Mataio it cames down to the friendships he has built as school not so much the academic learning. 
As noted by some tama Samoa, there were key aspects to their academic learning such as motivation to learn, interaction with teachers, and the influence of friends. Other tama Samoa talk about the opportunities given to them by being at school:

I'm trying my best to make the most of my opportunities in everything I do, not just in school work but extra-curricular stuff, and I just try to be the best I can be in everything I do and I want to achieve the best. I think it's all relevant for my future. (Timoteo, SS)

At Year 11, I was ready for NCEA because of the opportunities I took when I was in Year 10 like lunch time tutoring and going to homework centre. (Simona-Peteru: SS)

Timoteo and Simona-Peteru, describe the opportunities they have been given to support their learning. Making the decisions to attend extra learning support was one opportunity some tama Samoa took to support their academic learning.

lakopo spoke about how relevant the teaching and the learning of skills and knowledge are to his everyday living. As lakopo points out, the relevant learning is not only the learning from different subjects at school, but also the learning of values and how to interact with others.

One of the strong things they teach us here is values. They teach us things we can use like how to respect yourself, how to respect others. It is relevant to our everyday lives and how to be a good person. (lakopo: SS)

The talanoa above from the tama Samoa provides a sense of understanding that secondary school is a learning environment. As some tama Samoa indicated that there are opportunities provided by secondary schools to support their academic learning and for some tama Samoa it is about identifying the opportunities and using these to support their learning. 


\section{Tama Samoa - Aspirations for the future}

Being ready for anything means having the right tools and having the right support throughout secondary school to help young people make the appropriate choices (Hofkins, 2008). Whether you complete the five year journey of secondary school or leave school earlier, there is the hope that young people have gained enough skills and knowledge to guide them on their next journey.

In this section, the tama Samoa were given the opportunity to talanoa about their aspirations for the future, this section therefore began with the question where do you see yourself once you finish secondary school? Their responses to this question were:

Oh I can see myself being like a sports coordinator; my PE [Physical Education] has been the highlight for me. (Tataio: SS)

I want to play touch [touch rugby] for New Zealand. Yeah, I have played for the Wellington representative team, so hopefully l'll get on the New Zealand team for touch rugby. I haven't really thought of what I want to do besides sport but I'm hoping to be something in the trades. I don't know. (lese: SS)

I want to be a rugby player. And, like, when I finish playing rugby I want to be, like, a physiotherapist. (Toma: SS)

I want to be a police officer and have a family. (Mataio: SS)

I hope to get into the Air force and travel the world. (luta: SS)

I hope to go to the Institute of Sport and likely to go into maybe personal training or biomechanics, something like that. (Patolomaio: SS)

I really hope to get into the whole CSI (Criminal Science Investigation) stuff, that's why I am taking Chemistry, Biology, and Physics. (lakopo: SS)

My Dad, he was kind of hard on me with education and stuff and always pushed me to get the highest mark or just to do well. He said it will help 
with my future, and my career in whatever I wanted to do. So at the moment I am not sure what I want to do in the future, but I know I will have a strong work ethic like my Dad. (Timoteo: SS)

My Mum has always pushed us to do well at school. She used to threaten us with do well or else her and my Dad would send us back to Samoa to do the plantation, so I will be going to University after Year 13. Just thinking about it, but teaching might be a possibility, not sure but I know it's definitely University after this, because it is what my Mum expects. (Simona Peteru: SS)

I want to play professional rugby if I can but I am hoping to get into cooking school at Weltech (vocational training institute) or something. I love cooking and my friends say I make a mean fettuccini. (Filipo: SS)

I want to pursue my music career, so I hope to apply for Whitireia Polytech and do their Performing Arts degree. (Aneterea: SS)

I have been fortunate enough to have good teachers at school and they have helped me enjoy my subjects and excel in them. So I hope to apply for a scholarship and attend University. (loane: SS)

The comments made by the tama Samoa about their aspirations for the future show that most of them had a future focus itinerary for themselves. Only one of the twelve was not sure what he wanted to do once he completed secondary school. It was also noted that only one out of the twelve stated that he would attend university, and that the main reason for this was because it is what his mother would expect him to do.

This talanoa about what tama Samoa wanted to do once secondary school was finished is now followed by the tama Samoa's' descriptions about the pathway they need to follow while still at secondary school in order for them to be adequately prepared for these future aspirations.

Stay focused at school, ask questions and study. (Tataio: SS) 
Keep at it, and be prepared for everything. (Toma: SS) Maybe go to Whitireia now and see what I need to [to do to] get into the music programme. (Aneterea: SS)

Pass NCEA (National Certificate of Educational Achievement). (Patolomaio: SS)

Spiritual guidance and family values are also identified:

Sticking to my Mum and prayer. (Simona-Peteru:SS) Continuing to stick to God is a key for me. (lakopo: SS)

My Christian values will be a part of my decisions for the future. (Tataio: SS)

As evidenced by these comments, tama Samoa, were able to identify the importance of having goals for the future, and also show awareness of what pathways they need to take at secondary school in order to reach these goals. Mostly, they realised that achieving these goals depends on personal effort and the need to work hard at school. However, the comments also indicate the significance of the influence of family members, and of values including spiritual guidance that many tama Samoa have grown up having in their families.

\section{Tama Samoa - Perceptions on ways secondary school could do better by tama Pasifika}

In this final section, tama Samoa were given the opportunity to reflect on and to talanoa about their perceptions of what their schools could do to support or do to support younger tama Samoa who are also in their secondary school. Their responses show they have a variety of ideas about this, including suggestions about from use of school resources; strategies for staffing, teaching, and learning; better communication with families; and, perhaps most significantly, ways to celebrate and raise the Samoan and Pacific profiles within the schools:

I reckon probably, like probably, just find some new strategies to engage Samoan boys or taking more time to identify what gaps they have and 
work on those gaps with the boys and maybe their families. Maybe use the space at school better, like, not just the classroom. (Tataio: SS)

I reckon the school needs to acknowledge the different cultures more, also the whole thing about asking questions in class. I know I don't really get it and I have to read it like three or four times over and over. It takes ages for me to take in new stuff, so I think the school needs to find different ways for our Samoan students to get it... we should also have more than Poly club to perform at school events; it needs to be part of our everyday learning. (lese: SS)

Just, like, get the school to have more learning from each other; like, learn from other boys... and, like, instead of focusing on the negative stuff like how the Samoans aren't good at, like, education - like, focus on the positive more. There is a lot we are good at, but not enough teachers focus on that. (Toma: SS)

I think we could do with more Pacific teachers. I think this may make a difference for our tama Samoa. (lese: SS)

A lot of Samoan boys go to church, and this is a big part of their lives outside of school. Maybe this could be more incorporated in our school this is very high among PI (Pacific Island) families and student's spiritual groups could work in this school. (luta: SS)

I think there needs to be more communication [between] schools and families. We need to see more of our Samoan culture around the school, not just on multicultural night. Also in the uniform - [it] might be cool to allow boys to wear the lavalava (wrap around skirt). Other schools allow it. Yeah just seen more around the school. (Patolomaio: SS)

Our school has a small number of PI (Pacific Island) students, but it doesn't mean they should not acknowledge us, so I think this school needs to celebrate our Samoan students more often, through events, and sharing accomplishments. (Simona-Peteru: SS) 
There is a strong brotherhood in our school, and I think there needs to be a lot more working across year groups. Even though there is a lot of work that is done especially when you reach Year 11 and onwards, but more across the levels might be good. (loane: SS)

I liked to see more opportunities for tama Samoa to be in big roles that you don't necessarily have to compete for and don't have to be the brightest for. (lakopo: SS)

These comments by tama Samoa, then, provide a range of ideas about ways to improve the secondary school experience for tama Samoa and other Pacific students. The ideas suggested by tama Samoa - based on their own experiences in the secondary school environment - reinforce aspects of the earlier findings, such as emphasising the importance of the "brotherhood" and strengthening the sense of belonging largely by acknowledging their "Samoan-ess", their identity. The words of one of the tama Samoa best sum this up:

I want my school to make tama Samoa more visible. (Timoteo: SS)

\section{SUMMARY}

This chapter has presented the findings in relation to the three main themes: identity, sense of belonging, and aspirations for the future.

The talanoa reveals that in secondary schools tama Samoa have a variety of experiences that contribute to the identities they formulate, and to the sense of belonging they feel while at secondary school. For most tama Samoa the influence of others within the school setting, such as their mates, peers, teachers, and school management play a large part in the decisions they make and actions they take. The findings highlight the different identities that tama Samoa form in order to maintain their Samoan identity within secondary school. However, it was also important to highlight that the tama Samoa survive secondary school through being confident in their many identities but; they also appear to thrive in their secondary school experiences. 
Tama Samoa also recognised the need to place themselves in certain leadership roles in order to be acknowledged while at secondary school. Related to this, the findings also show that it is important to the tama Samoa that they demonstrate responsibility and show that they can be good role models for other tama Samoa, particularly for their mates. Tama Samoa reveal that while a sense of belonging to their school is important for them, for some of them achieving this is not due to the secondary school they attend, but because of the relationships they have formed with people within the secondary school setting.

In regard to their aspirations for their own futures, each tama Samoa spoke confidently about what they want to do once their secondary schooling is completed, and most were able to identify what they would do while at secondary school to help them reach their particular goal.

It is anticipated that these findings about knowing what counts for tama Samoa during their secondary school experiences will inform educators about how to enhance tama Samoa academic learning and social learning while they attend secondary school.

The Nominated person's perspective throughout the three themes, also provided another layer of understanding who tama Samoa are and the experiences they have during secondary school In most cases both perspectives from tama Samoa and their nominated persons aligned such as the talanoa based on the importance of acknowledging tama Samoa being a Samoa, and the importance of being at school. However there were also comments from nominated persons that did not align with the perceptions of tama Samoa such as; the perceptions of nominated persons who were chosen through the relationships built through school context, these perceptions are further discussed in the next chapter. What is important to note with the perceptions of tama Samoa and their nominated persons is to highlight the importance of accessing other perceptions for tama Samoa to grasp further understanding of who they are.

In the next chapter I will review the research question and sub questions and discuss the tensions and dilemmas I discovered during the data collecting process. 


\title{
CHAPTER FIVE: \\ DISCUSSION
}

\author{
Fa'atafa le Niu'afa
}

(Braiding process of Niu'afa)

\section{INTRODUCTION}

The discussion section of this thesis is an opportunity to align the research questions, literature review, and conceptual framework with the key findings found through the use of the fa'afaletui process. It allows the researcher to reflect on the findings as well as their practical and theoretical implications.

The aim of this study was to identify tama Samoa perceptions of what factors influence their schooling experiences and the impact this has had on their aspirations for the future. The overarching research question - In what ways do tama Samoa experiences within a secondary school context contribute to their identity, sense of belonging, and aspirations for the future - demonstrates that, as a researcher, I had already identified the focus of the study in terms of the three main themes to investigate. The overarching question generated the following sub-questions:

1. In what ways are tama Samoa identities influenced by their secondary school experiences?

2. What is the nature of the relationship between tama Samoa sense of belonging and their daily experiences within secondary school?

3. What experiences have tama Samoa had during secondary school that have contributed to their aspirations for the future?

Trying to capture every experience that the twelve tama Samoa voiced in both focus group and semi-structured talanoa, as well as data generated from the talanoa with nominated persons, was challenging for me as researcher. Trying to capture every essence in the experiences and perceptions given by tama Samoa, 
there was the worry that I could miss important aspects of their experiences that may need to be noted. As suggested by Hammersley and Atkinson (1995), context is important. All accounts must be interpreted in terms of the context in which they are produced...the aim is to not gather "pure data" that are free from potential bias. There is no such thing. Rather, the goal must be to discover the correct manner of interpreting whatever data we have (p. 131).

To understand the relationships and the constructions of individuals' cultural identity, we have to gain insight into their perspectives; it cannot be assumed for instance, that Samoans are all the same (Silipa, 2008). Fa'afaletui is a methodological process that includes determining the relationships between the individuals and the groups, which shape the way of thinking and ways of doing (Tamasese, et al., 1997). As a research tool, Cowley (2013) provides the idea of fa'afaletui been linked metaphorically to a story which some Samoans tell about the respective views of the fisherman, the tree climber, and the man at the top of the hill (refer to Chapter Four for further discussion on fa'afaletui).

In Chapter Four, the findings are presented about the three themes - identity, sense of belonging, and aspirations for the future - and their sub-themes. Chapter Five discusses each of the three main themes in the same order they were introduced in the previous chapter, but explores elements that are common within each set of sub-themes. These include: i) identity - complexities in tama Samoa identity, culture and identity, identity and responsibility, and identities as a tool for survival; ii) sense of belonging - understanding versus experience, participation, and relationships; and iii) The future - expectations, academic achievement, and aspirations for the future.

\section{IDENTITY}

Like other students at secondary school tama Samoa attend with their own aspirations and expectations. However, as discussed in Chapter Two, the secondary school years are also a time for adolescents to develop new identities, to develop new skills, and to form new relationships. As explained by Spano (2003), young people not only undergo physical changes, but they also experience cognitive, social, emotional, and interpersonal changes. In addition, 
outside factors such as families, peers, and community, culture, religion, and world events - including influences from the media - start to become more important to their lives (Fine, 2004; Munro, 2011).

In this study tama Samoa talanoa about the many experiences they have had at secondary school and highlight their different experiences of identity formation. These experiences in terms of identity are based on the relationships and bonds they form with others (teachers and fellow students) and include the need to develop identities to survive within classes and to interact with others while at secondary school. The findings in Chapter Four relating to the identity theme show tama Samoa to be exploring three different aspects of their identity formation: personal identity, cultural identity, and group identity. In this chapter, the elements common to each of these three sub-themes are identified and explored. These are presented as: i) complexities in tama Samoa identity; ii) my culture is my identity; iii) identity and responsibility; and iv) multiple identities as a tool for survival.

\section{Complexities in tama Samoa identities}

In 2008, the New Zealand Ministry of Education funded a research project "Literature review on the experiences of Pasifika learners in the classroom" led by Dr Bruce Ferguson. This project identified the need to address the plural sense of the concept of "identities". The authors noted the importance of acknowledging the many identities taken on by Pacific students:

The plural "identities" has been deliberately selected for use in this review for two reasons. First, to draw attention to the multiple island nations subsumed within the term "Pasifika" and second, because the term may cause readers to reflect in a more focused way on the expectations placed on students whose parents are immigrants, or second or third generation New Zealanders (Ferguson, Gorinski, Wendt-Samu, \& Mara, 2008, p. 25). 
This research, too, focuses on the importance of the concept of "identities"; as shown in Chapter Four the findings indicate the ways in which tama Samoa undertook to grapple with more than one identity during their time at secondary school.

Like any other Pacific Islands student, tama Samoa in New Zealand occupy a number of different worlds (Hawk \& Hill, 1998). They experience connection with their family, their culture or cultures, possibly a connection with their church, the connection with their school, the connection with their peers, and a connection with the Westernised way of living of wider society. All these connections are a reality for them, each connection being valuable and important. Hawk and Hill's findings resonate with the findings about identity in this research: tama Samoa live with multiple identities, and walk within each identity as a part of their everyday lives. It is also noted that that while tama Samoa enter into secondary school already dealing with multiple of identities, during their secondary school years new identities are forming, and through this experience tama Samoa highlight the importance of both their experiences and of those people who influence their identity formation.

The complexity of identity across the development of an individual's life span begins at birth. Sheets (2005) notes that "Identity, knowledge of who we are and what groups we belong to, is a complex, multifaceted developmental process that begins at birth and continues throughout the life span" (p. 50). For this particular research, I explore the identities tama Samoa develop during their secondary school year's experiences.

In most cases, tama Samoa shared enough information about themselves to provide me with a sense of who they are as individuals. What was captured during the talanoa through focus group and semi-structured interviews was that each tama Samoa discussed their identity in relation to their surroundings.

Most studies of identity formation have been grounded in psychology. Erikson's (1968) identity development theory argues that in the early stages of one's life there is a lack of awareness of an individual's identity in relation to a social or cultural group. Developmental psychology's interest in identity development 
stems from Erikson's (1968) early work, "Identity: Youth and Crisis", in which Erikson located the search for and development of one's identity as the critical psychosocial task of adolescence. According to Erikson's theory, the identity crisis of adolescence is resolved by reconciling the identities imposed upon oneself by one's family and society with one's need to assert control and seek out an identity that brings one satisfaction, feelings of industry, and competence. Forming a healthy, developed identity through the process of exploration and commitment was proposed as essential to the mentality of an individual's growth development.

Analysing the data from each tama Samoa, it could be seen that there was no hesitation from tama Samoa about providing perceptions of themselves. However, tama Samoa each presented themselves in different manners and the amount of detail they shared was also varied. It was, however, clear that their perceptions of themselves were connected to certain influences such as the home, and especially their relationships with their friends. It was also clear from the talanoa that the connection tama Samoa have with their peers is a strong influence on their development of who they are as individuals in the secondary school setting. In focus group talanoa, each tama Samoa across all the secondary schools spoke of the need to be an individual that valued friendships, and valued being there for his mates, and being the type of individual who would show responsibility for the sake of his mates. As shown in Chapter Four, tama Samoa emphasise the importance of having quality relationships with others in order to maintain a positive experience during secondary school. These findings resonate with Mila-Schaaf's (2010) PhD study which interrogates second generation Pacific people's conception of their own identity in terms of their relationship with important others. The findings of these studies point to the importance of acknowledging the significance of relationships in the secondary school context. Fine (2004) and Spano (2004) also make connections to the idea shared by tama Samoa and again, highlight the importance and influence of others around them to play a key role to maintaining positive relationships within a school environment. 
In most instances, tama Samoa demonstrated that they felt the need to act a certain way amongst peers and the need to be someone who would meet the expectations of others. This stage of tama Samoa's identity development clearly aligns with Erikson's (1968) theory that states that, during adolescence, reconciling the identities imposed upon oneself by one's family or amongst people of close relationships and seeking an identity brings satisfaction to the individual. Tama Samoa used their identity formation to feel confident amongst others by doing exactly as Erikson describes. They form an identity that will satisfy their perception of how they want others to perceive them.

I have always been a good student, but I also enjoy my friends. I may not be doing my best at school so I would consider myself a steady achiever at school. I am not a lazy student but I don't want to be a top student because my friends will give me grief about it. (Patolomaio: SS)

Barwick (2004) states that, in his view, the stereotyping of the New Zealand male shapes what a New Zealand male would look like, act like, and sound like. He points out that historians and sociologists in the past have identified the New Zealand male to be a "hard man", a decent bloke, and a family man, who is the breadwinner and that this affects males' perceptions of themselves (Mitchell \& Chapman, 2001; Jenson, 2006). However, if we are to go back to the idea of strong social influences, it would be fair to say that times have changed, and that past assumptions of what has been expected of a male to look like and act like have changed dramatically. For example, as shown in Chapter Four, some tama Samoa spoke about their interest in taking drama as a subject for learning. In the past drama would not have been regarded as an ideal subject choice for tama Samoa, however, times have changed and so too have the expectations about and of New Zealand males within a New Zealand secondary school context.

Within the focus group talanoa there were hints of masculinity: for instance, one tama Samoa spoke about how he needed act a certain way when he was amongst friends. 
All twelve tama Samoa who participated in this research are New Zealand born, and thus Barwick's (2004) description of the "New Zealand male" also applies to them. The tama Samoa described others' expectations and perceptions of tama Samoa in terms of "boys being boys". From their experiences during secondary school, there are many influences on how tama Samoa construct their understanding of masculinity through the interaction with their friends, and expected behaviours from families and teachers. It was clear from the talanoa that this complexity for developing who they were as individuals was an ongoing process of negotiating and renegotiating depending on their age, place, and other social factors during their secondary school experience.

The research shows the complexity of the identity formation process for tama Samoa during secondary school. As shown in Chapter Four these many identities include personal identity, cultural identity, and group identity from many influences. The complexity of this identity formation process became clear during the semi-structured talanoa when individual tama Samoa began to talanoa about the emotional effects of having developed many identities. For example, Mataio described the need to develop identities so that he is accepted by the classroom teacher:

It depends on which class I have. I would adapt my ways [so] the teacher will be more accepting of me. (Mataio: SS)

Jackson and Dempster (2009) explain how boys in general construct themselves as having a natural ability that allows them to perform well with little effort in order to be both successful and acceptable in the eyes of their peers. In reviewing what was shared by tama Samoa, it was evident that this is true for many tama Samoa. However, the Samoan secondary student has the added dimension of cultural conflict to deal with; in particular they may challenge their traditional role in, and the expectations of, their family in the light of what they see as the new societal norms. Silipa (2004) describes the conflicts and stresses a Samoan student faces as "wavering" as they move from one situation to another. The tensions of conflict and stresses were identified by most tama Samoa: they indicated that when they attend class it is important that they show they are trying to perform their best in front of their classmates so that they do not seem to be lacking in academic ability. 
Timoteo confirms this by stating his own experience of being in class where he is the only tama Samoa:

You're thinking oh I'm the only Islander there. I've got to like get it, because, you know, the Asians and Indians they're always smart and stuff, pressure like just to keep up with them and perform at their level, but they look at and you feel like they are thinking should you really be here? (Timoteo: $\mathrm{F}$ )

However, this is not necessarily the case when they are amongst their own Samoan friends, where, they feel a responsibility to appear "naturally" bright and confident so that they are seen as somebody that others can approach if they need support or a friend. Some tama Samoa expressed that they feel the pressure of trying to keep up this performance in order to not let down their friends; however, the duel ways in which they present themselves also means that family members and school teachers have high expectations of them.

Linked to this is the need to avoid sharing too much of who you are to your friends. According to Abraham (2008), one way that boys may continue the uncomplicated achievement of communication while still maintaining their relaxed attitude in school is to embrace a counter-school culture in public, but to value learning and academic achievement in private.

In this research tama Samoa, provided examples of how important it is to be who they are in the company of their peers. Within the school environment, tama Samoa develop their identities as tama Samoa, holding on to a surface display of being cool and relaxed amongst peers. However, there is also a hidden side which some tama Samoa feel is unnecessary to share and display with their friends.

loane, for example, in Chapter Four showed that, although he demonstrated an interest and skill in playing chess, he did not want to share his interest in the game with other tama Samoa, for he had made the assumption that other tama Samoa would think differently of him and therefore would rather keep quiet about his interest in playing chess. 
It is clear, then, that identity formation for tama Samoa at secondary school is a complex business.

loane strongly believes in the importance of friends and friendships, but also demonstrates caution of holding back to something he enjoys for the sake of the group identity. As well as navigating the usual influences and expectations from parents, teachers, and peers, for these students there are the added complexities that are associated with cultural considerations.

\section{Culture and identity}

The tama Samoa identities are comprised of a blend of an individual, a cultural, and a group identity. It was evident from the talanoa that all twelve tama Samoa identify themselves strongly, first and foremost, as Samoan. Tama Samoa's cultural identity is defined by a set of preconceived notions about what it means to be Samoan through involvement of being part of a Samoan family, a member of their community, as well experiences of being with other Samoan tama at school. Simona-Peteru defines his cultural identity by stating what being Samoan means to him:

Being Samoan - it's knowing the culture, the traditions like the matai system (chiefly system of Samoa). Also having specific ways of tattoo, the stories and how they are passed down and that's how you find out about the families and your genealogy. (Simona-Peteru: F)

This acknowledgement of being Samoan within the secondary school context was of great importance to most of the tama Samoa. As illustrated in Chapter Four, a big part of the tama Samoa cultural identity experience at secondary school is the influence of other tama Samoa. As identified by Nahkid (2003), for Pacific students, their identity as a Pacific person, rather than their socialeconomic status, plays a more significant role in how they understand their educational experiences. Although Nahkid (2003) discusses Pacific students in general, this argument can also apply to the tama Samoa in this study. Tama Samoa, themselves, noted that identifying as Samoan provided them with a sense of identity amongst their peers and other students within the secondary school environment. Interestingly, this perception was questioned by one 
nominated person who questioned if tama Samoa portray a sense of pride in being Samoan "just for show". This particular nominated person was non-Pacific and a staff member. What is important to note here is that this comment suggests an apparent lack of understanding by this particular staff member about the significance of cultural identity in the secondary school environment. If this lack of understanding is representative of the perceptions of staff in the school, it must be asked how well tama Samoa needs are met in the environment of the secondary school environment.

When tama Samoa shared their perceptions of being identified as Samoan, each stated that he was proud to be identified as Samoan. This solid foundation provided by their Samoan identity and their pride in this was shown through the examples they provided in the talanoa about being able to speak the language, the food they share at home with their families, and the Samoan gatherings they attend. It was also expressed by tama Samoa that they felt that being able to identify with their Samoan heritage was unique because only a small population within the school were of Samoan heritage, and this made it extra special for tama Samoa.

It was also evident from the talanoa with the tama Samoa that their Samoa-ness provided them with a sense of confidence in who they were, and how being identified as Samoan was useful in terms of being able to switch identities. As seen in Chapter Four, Toma expresses his own experiences of switching identities to motivate his learning:

I know I am a Samoan and I have been identified as being successful at school. There are some teachers here that remind us that we've got, like, low grades, and ... some boys are like, "oh so what?" But I know if I change the way I think in particular classes this is my motivation to do better and prove them wrong. (Toma: SS)

Tupuola's (2004) article, "Pasifika Edgewalkers: complicating the achieved identity status in youth research", explores the notion of "edgewalkers" in terms of Pacific. Tupuola's paper refers to Krebs' (1999) concept of edgewalking, a term used to define and interpret through a development and psychological lens the 
transient and shifting roles of "minority" youth of African and Latino descent youth in the United States of America. According to Krebs (1999), an edgewalker is resilient to cultural shifts and able to maintain "continuity wherever he or she goes, walking the edge between ... cultures in the same persona" (cited in Tupuola, 2004, p. 89). Tupuola (2004) goes on to say that this concept of the edgewalker provides an interesting view of identity achievement in that it highlights the resilience of youth of multiple identities, to promote a healthy process of the postmodern world (p. 90).

The Pacific edgewalker concept discussed by Tupuola provides a clear explanation to the everyday experiences had by tama Samoa in secondary school. As shown in Chapter Four, Tataio explained how his identity enables him to be flexible and walk in both worlds: his Samoan world and Palagi (European) world:

because it shows how we Samoans can be flexible and how we can walk in both worlds, being Samoan. (Tataio: SS)

According to tama Samoa in two of the secondary schools, their schools acknowledged and celebrated the various cultural identities of the students within their schools. However, according to tama Samoa attending the other secondary school, their school showed little or no acknowledgement of student cultural identity and these students indicated that this has caused many conflicts between schools and students, as well as between schools and the home:

Our school and most teachers don't really value us as Samoans, but because there are a lot of us here. It is the students that valued our culture including the Samoan teachers, but no one else really. (Toma: SS)

Within this research, tama Samoa expressed a mixture of feelings about how well their schools acknowledge cultural identity and diversity. Some found the experience of their secondary schools doing very little to support their cultural identities to be quite sad, especially considering that some secondary schools, according to tama Samoa, have significant numbers of Pacific students with Samoa being the largest minority student ethnic representation (Manueli \& 
Sibley, 2015). In one particular secondary school, tama Samoa noted that it was only from their participation in Poly club (cultural group) that they felt a sense of acknowledgement, because they heard special mention of Poly club within the school setting. For some tama Samoa the opportunity to take part in Poly club provided a sense of cultural identity and for most tama Samoa involved in Poly club there were many positive reasons for being involved such as developing leadership responsibility, learning about the Samoan (and other Pacific) cultures, and connecting with other tama Samoa. In her article "Pacific Youth Connecting through 'Poly" Peggy (2010) Fairbairn-Dunlop states:

Male students continue to identify strongly with their Pacific ethnicity, however, this may be defined. Further, it has shown that this Samoan identity is one which is being constructed in their New Zealand experience, and that the Polynesian club and related activities are central to this process. (p. 28)

For tama Samoa, then, belonging to poly club provides a sense of pride; however, it was found that it is also important that this sense of pride is acknowledged by their secondary schools.

In a secondary school with smaller numbers of Samoan students, tama Samoa spoke about how it was good that their school acknowledges their cultural identity, and were quite happy with the Polynesian group as an extra activity and having a yearly multicultural dinner. While the tama Samoa in this particular school appeared to not be particularly concerned about what was done or seen around the school, they did note that could be more done to acknowledge the Samoan students within their school.

Conversely, other tama Samoa responded that it is not enough to have token events such as a multicultural dinner once a year to celebrate all cultural heritages. As one tama Samoa said:

You attend the multicultural dinner, you eat multicultural food, and you watch multicultural dances and you go home. (Timoteo: SS) 
Furthermore, tama Samoa who attend a school with a large population of Samoan students claimed that they feel the reason their culture is acknowledged is because of the high number of Samoan students in their school, but not because of anything within the school itself. Clearly, then, schools need to continually review how to acknowledge and involve tama Samoa (and other cultural groups) more, and to consider the purpose and adequacy of "cultural" activities and events for individual students, as well the overall school.

\section{Identity and responsibility}

Tama Samoa indicated that, in most cases, they take it upon themselves to be responsible about who they are in the school environment. They demonstrated that, as tama Samoa, they see that part of their role is to be responsible in representing themselves in a manner that is appropriate for school. They see it as their responsibility to be abiding citizens of the school environment for the sake of their peers, and also for the sake of their families.

Parental expectations were not highlighted within this thesis, however, two nominated persons, both of whom were mothers of tama Samoa, provided some discussion of what their expectations were of their tama Samoa while at secondary school. Both nominated persons expressed their hope for their tama Samoa to do well at secondary school and do the best that they can. However, as highlighted in Chapter Four, tama Samoa expressed their perceptions of being able to do well at school for the sake of their families:

My parents need the support and that's why I come to school - so I can get better educated and find a good job. That's the important thing. (Filipo: SS)

I want to have a better future, better life you know. I want to have the best life I can have. I see my parents and my grandparents struggling and I go over to Samoa and I want to be able to give back to the community, have enough money to give back. (Patolomaio: SS)

This role of responsibility was echoed in the perceptions of several nominated persons. However, this was not always represented as entirely positive. One 
nominated person, for example, suggested that this responsibility is a burden for tama Samoa and questioned whether it is necessary for tama Samoa to have to take on such responsibility for family while at secondary school, suggesting that their focus should be on preparing tama Samoa for learning and that worrying about being responsible for family gets in the way of this. This nominated person was a teacher of tama Samoa. What is important to highlight here is the idea of stereotyping that this particular nominated person has made. It can be concluded there is a negative stereotype here in terms of preconceived assumptions about tama Samoa and negative connotations such as making generalisations about tama Samoa families and expectations they have for their sons. The effects of such stereotyping have been revealed throughout international literature, where it has shown to harm the educational performance of particular groups (Schmader \& Johns, 2003).

It is possible to conclude, then, that the nominated person in question had made an assumption of what tama Samoa parents expect from their tama Samoa. Cook-Sather and Reisinger (2001) state that stereotyping is a particularly insidious factor in the formation of pre- and in-service teachers' images of students. They argue that those who work with young students who rely on stereotypes rather than trying to see the students behind them run the risk of letting cultural and individual biases work to their own disadvantage and to the disadvantage of the next generation of high school students.

Further to this, a study by McClure, Meyer, Garish, Fischer, Weir, and Walkey (2011) identified that Pacific students rated family as a strong factor contributing to their success, rating family as more important than their ability. This quantitative finding is consistent with focus group evidence from Pacific students who cited family support and love as holding primary importance in their academic success (Fletcher, Parkhill, Fa'afoi, Taleni, \& O'Regan, 2009; Graham, Meyer, McKenzie, McClure, \& Weir, 2010). In contrast, according to McClure, Meyer, Garish, Fischer, Weir, and Walkey (2011), students of European ethnicity rate the influence of family significantly lower than both ability and effort. Reyna and Rivers (2008) reported that although most studies show a bias towards making internal attributions that serves to maintain self-esteem, this bias was most pronounced among Westerners. This internal attribution bias may be less 
pervasive among Pacific peoples. As highlighted in Chapter Four, tama Samoa in this study acknowledged the value of family in helping them succeed in secondary school. Furthermore, the tama Samoa themselves did not indicate that this "burden" of responsibility was as a result of parents' expectations. This demonstrates that what was perceived by one nominated person does not reflect what tama Samoa experience within secondary school.

\section{Identity as a tool for survival}

In her study on Pacific students in secondary schools Silipa (2010) notes the use of, and the switching between, multiple identities, saying students constantly manipulate and shift their identity to suit their everyday circumstantial dynamics in the classroom. She goes on to say that these students (Samoan) develop an acute awareness that, no matter what they do or not do, or how well they do or do not it, they are always seen as different. This is in spite of the fact that most of the participants in her research are New Zealand born.

This study, too, shows the importance to tama Samoa of maintaining their multiple identities in order to survive in secondary school.

I know I am a Samoan and I have been identified as being successful at school. There are some teachers here that remind us that we've got, like, low grades, and ... some boys are like, "oh so what?" But I know if I change the way I think in particular classes this is my motivation to do better and prove them wrong. (Toma: SS)

Each tama Samoa spoke of the need to switch identities while at school. Some of the phrases that tama Samoa used to describe this process were "shifting mind frames", "switching identities", "changing face, "adapting identity", "changing mind frames", and "using multiple identities" showing that they are very aware of this process. Furthermore, although the terms above have shades of different meaning in a deeper sense, in this research they all refer to the same thing; in fact, considered together, they add emphasis to the significance of this process. 


\section{SENSE OF BELONGING}

According to Goodenow (1993a), a sense of belonging at school reflects "the extent to which students feel personally accepted, respected, included, and supported by others in the school social environment" (p. 80). During the talanoa tama Samoa were given the opportunity to explore what sense of belonging meant to them as tama Samoa within the school environment. As described in Chapter Four, sense of belonging for tama Samoa captured many positive terms such as "comfortable", "encouraged", "happy", "bonding", "safe", and that it is about having positive relationships.

As with the identity theme, this chapter considers elements that are common to all the sub-themes. Within sense of belonging these sub-themes include: (i) factors contributing to sense of belonging, (ii) participation, and (iii) relationships.

As described in Chapter Four, sense of belonging is defined in many ways, and each person has their own way of how they experience a sense of belonging. However, having a sense of how students feel they belong is a vital part of understanding student ways and may possibly provide further understanding about what works well and what does not work well for students in a school environment. As stated by Osterman (2000), work in psychology tells us that the sense of belonging and the experience of belonging are important factors in understanding student behaviour and performance.

\section{Factors contributing to sense of belonging}

The tama Samoa in this research were given the opportunity to talanoa about many things, including defining what "belonging" means to them, and sharing the experiences they were having at school. The findings show that their definitions about belonging at school do not necessary align with what they experience at secondary school.

The tama Samoa provided a clear understanding of what it meant by sense of belonging, using terms such as "connection", "bonding", "feeling comfortable", "feeling safe", "positive relationships", and "being welcomed". These and other terms highlighted by tama during our talanoa demonstrate that tama Samoa's 
understandings about belonging are similar to those identified in the literature reviewed in Chapter Two.

Goodenow (1993b) describes sense of belonging in educational settings as Students' sense of being accepted, valued, included, and encouraged by others (teacher and peers) in the academic classroom setting and of feeling oneself to be an important part of the life and activity of the class. More than simple perceived liking or warmth, it also involves support and respect for personal autonomy and for the student as an individual. (p. 25)

Eleven of the twelve tama Samoa across the different secondary schools confirmed that they felt they a sense of belonging with the schools they were attending. The key factor that contributed to tama Samoa's sense of belonging was the connection they had with friends and other people who made them feel positive about being at school.

However, one nominated person (school teacher) identified the bond that tama Samoa had with friends and stated that this relationship was sometimes an interruption to them during class time which could have negative effects for the tama Samoa. It was also noted by the nominated person that the bond between tama Samoa and friends did not always allow individual tama Samoa to grow independently to make their own decisions.

Lashbrook (2000) states that adolescents are well aware that they influence each other. She notes that while peer influence can provide many positive elements in an adolescent's life, it is important to remember that peer influence can potentially have a negative impact. Likewise, peer influence can also have both positive and negative effects on an adolescent's academic performance and socialisation. According to Lashbrook (2000), it is also assumed that peer groups may not allow an adolescent to be "themselves" in the truest sense of the word: adolescents sometimes need to put on an act in order to gain acceptance from the specific group with which they would like to be associated.

The comments made by the nominated person, above, resonate with Lashbrook's position. Peers can be identified as impacting and influencing tama Samoa. Clearly, given the degree of influence that tama Samoa themselves say 
their peers have, it is important for schools to understand the nature of peer influence on tama Samoa in order to avoid negative effects. Furthermore, Lashbrook stated that it was assumed that peers, as well as parents, siblings, and teachers, all play a large role in how adolescents function in everyday living.

It was also noted by tama Samoa that their participation in groups provided a clear sense of belonging within their secondary schools. There are many aspects of being part of groups that tama Samoa considered to contribute to this sense of belonging such as responsibilities, leadership, and role modelling.

Only one tama Samoa had very little to say about the sense of belonging. However, his reasons given resonates with Goodenow's (1993a) comment that:

One of the reasons that there is a poor fit between the opportunities provided is the lack of students' need for belonging and support, which leads to a decrease in student academic motivation. (p. 81)

Significantly, this tama Samoa noted that his lack of wanting to succeed in secondary is because of the lack of belonging he felt in school. Therefore, consistent with the findings of Goodenow (1993b) in this specific case the feeling of belonging had a direct and powerful influence on the students' motivation. Conversely, the other tama Samoa, who expressed a strong sense of belonging to their school, were more motivated to succeed.

Key factors that further contributed to tama Samoa sense of belonging are addressed in the next two sections - participation and relationships. As highlighted earlier, tama Samoa define a sense of belonging with concepts that relate to "connection", "bonding", "feeling comfortable", "feeling safe", and "positive relationships. In this research, most tama Samoa shared that the sense of belonging they have in school is primarily because of the relationships individuals have with their peers. They also indicated that their sense of belonging is influenced by their participation in school activities. However, not all tama Samoa felt a strong sense of belonging within their schools and, as identified by one tama Samoa, some of them were just attending secondary school because at this age attending secondary school was just what you had to do. 


\section{Participation}

Many of the tama Samoa in this research spoke about the various and varied groups they participated in. Table 7 (see Chapter Four) lists the various clubs and groups tama Samoa participated in at secondary school, including extracurricular activities. In this section I discuss tama Samoa experiences of participating in these groups.

Previous commentators have noted the range of benefits associated with participation in extracurricular activities. As identified by Massoni (2011), extracurricular activities are found in all levels of our schools in many different forms. They can be sports, culture clubs debating, drama, school publications, student council, and other social events. Finn (1989) notes that although many factors contribute to a student's sense of belonging at school, student participation in extracurricular activities has long been argued as a key factor in which to encourage a greater connection or attachment to school. Furthermore, as stated by Brown and Evans (2002), the school context is a primary social influence in the lives of developing youth and that participation in extracurricular activity is a formalised opportunity for youth to experience active involvement with school.

Within this research the tama Samoa provided the reasons why they chose to join specific groups and what purposes these groups serve for them as individuals: all tama Samoa described their participation in extracurricular activity as being a highlight of their schooling experience. This research found that tama Samoa experience of participating in various groups was positive, and in most cases the outcomes of participating in these group activities has generated a clear sense of belonging to their schools. Participation also provides them with a sense of loyalty to their schools. Linked to this sense of belonging and loyalty, tama Samoa indicated that their participation in such extracurricular group activities has also provided them with a sense of responsibility.

Tama Samoa identified a number of ways in which their participation in group activities involved a sense of responsibility, which they took quite seriously. For most tama Samoa their participation demonstrates that they are in a role of 
leadership, particularly when they are nominated or selected for particular sports teams. For other tama Samoa, being involved in certain groups at Years 12 and 13 can be described as positive role modelling for other tama Samoa at more junior levels. It was also noted by tama Samoa that being involved in various groups, particularly those involving leadership positions, provides the opportunity to be acknowledged by management and senior staff within their secondary school. This was seen as a key element for some tama Samoa who felt that, if it was not for their participation in certain groups or clubs, teachers and senior management such as principal and deans would not have known who tama Samoa were as individuals.

Gerber (1996) concluded that this active participation in extracurricular school activities leads to an increase likelihood of academic achievement. In supporting the idea by Gerber, the tama Samoa in this study were already identified as academic achievers. However, the talanoa from this study indicates that, from the perspective of the tama Samoa, the other benefits of participating in extracurricular group activities outweigh the importance of gaining better academic results: tama Samoa took the opportunity to participate, to take responsibility, and to be leaders primarily for the sake of other tama Samoa with in the secondary school setting.

A further reason given for tama Samoa participation in groups at school was the influence of friends. There was also the perception of some tama Samoa that because they had older siblings who had attended the same secondary school it was, therefore, a tradition that tama Samoa join certain groups or clubs.

According to Eccles, Barber, Stone, and Hunt (2003), the organisation of extra group activities within school setting are a good use of the adolescents' time and the authors identify the following reasons to support their argument:

to acquire and practice specific social, physical, and intellectual skills that may be useful in a wide variety of settings including school; (b) to contribute to the well-being of one's community and to develop a sense of agency as a member of one's community; (c) to belong to a socially recognized and valued group; (d) to establish supportive social networks 
of peers and adults that can help in both the present and the future; and

(e) to experience and deal with challenges. (p. 866)

A study by Brown and Evans (2002) that looked at creating greater school connection among diverse student populations through extracurricular activity found that:

inclusion in extracurricular activities may facilitate inclusion in peer groups, positive school-related experiences, and a sense of belonging, all of which may contribute to greater school connectivity and retention. (p. 50)

This study found that some tama Samoa participated in groups that had minimal numbers of other tama Samoa in them. These tama Samoa noticed quite early in their participation in these groups that they felt they were "alone". Although this did not affect their interest or participation in the group at that time, it did provoke second thoughts about returning to participate in those specific groups. This indicates that, to some extent, tama Samoa are more comfortable being amongst other tama Samoa and amongst their mates.

For whatever reason tama Samoa provided as to why they were participating in extracurricular group activities, it is clear the this participation played a significant role in how tama Samoa felt about being part of the school environment. This suggests that capturing the opportunity to seek and participate in groups that provide new friendships can only improve their sense of pride and belonging within their school.

\section{Relationships}

In this research, the relationship discussion is mainly focused on the nature and quality of tama Samoa key relationships and the impact and influence of these on their experiences within the school environment. These key relationships include (i) relationships with other students/peers, (ii) relationships with teachers, and (iii) relationships with families. These are discussed in order below. 


\section{Relationships with peers}

As explained in Chapter Four, the key factor for tama Samoas' sense of belonging within a school setting is the positive interaction between themselves and their peers. In all talanoa, tama Samoa spoke confidently about the importance of their friends and the need to have their friends around them during school. It was also identified by several of the tama Samoa that it was their relationships with their friends that made them feel they belonged at school.

Furrer, Skinner, and Pitzer (2014) explain the essence of the complex dynamics of relationships through the lens of a "Self-System Model of Development". The model describes how social partners promote development by supporting fundamental human needs for relatedness, competence, and autonomy (Connell \& Wellborn, 1991; Deci \& Ryan, 1985; Skinner, 1995)

Table 9: Adapted from Furrer, Skinner and Pitzer (2014):

Self system model of development.

\begin{tabular}{|c|c|c|}
\hline Relatedness & Competence & Autonomy \\
\hline $\begin{array}{c}\text { The need to be connected to } \\
\text { others or belong to a larger } \\
\text { social group. }\end{array}$ & $\begin{array}{c}\text { The need to feel effective in } \\
\text { interactions with social and } \\
\text { physical environments. }\end{array}$ & $\begin{array}{c}\text { The need to express one's } \\
\text { authentic self and be the } \\
\text { source of action. }\end{array}$ \\
\hline
\end{tabular}

Tama Samoa identified the influence and importance of their mates in their everyday experiences in secondary school. The influence of these relationships were highlighted as a positive impact for tama Samoa for instance.

For some tama Samoa, the need to be in bonding relationships during secondary school was identified as crucial to their experiences. In one particular school, this relationship was formed over the years with friends, and it therefore built a brotherhood that heightened the feeling of belonging within the school setting. In this school, however, the notion of brotherhood was also instilled in the tama Samoa and other boys through the school values.

Like if everyone's like brothers with each other, like, no one fights and no one hates but respect for each other. (Filipo: SS) 
It was therefore taken as accepted that most boys attending this school understood the meaning of brotherhood.

The literature on the impact of brotherhood within the secondary school setting is limited. However, a study by Sanday (2007) based on fraternities in the United States of America is quite helpful in understanding the important role the brotherhood plays in students' lives. Through her research, Sanday discovered that the depth of the emotional bond men feel for their fraternity is explained by the degree to which this bond helps to compensate for feelings of inferiority and powerlessness in a society that privileges male bonding. Fraternity brothers do not become friends or teammates or colleagues; they become brothers. One fraternity Brother Sanday (2007) identified in her study, Sean, "recognized that fraternity life also offered a 'new family' to compensate for the loss he felt at leaving his own family" (p. 150). Further to this, Wyatt (2009) found that involving past black male students to work alongside current young black male students supporting them with their academic learning and pastoral care motivated the "brotherhood" members to increase personal and interpersonal empowerment of self. In some cases for the tama Samoa in my study, it was evident that they valued their friends and being in a brotherhood that would support their future aspirations.

Although Sanday's study is based on a much older group of students and both Sanday and Wyatt's studies were conducted in a context that is different from that of tama Samoa in New Zealand, there are some commonalities with how tama Samoa felt about the need to be part of a brotherhood and how their experiences were built around this need to be within the group. Both projects from Sanday and Wyatt, provide similar experiences of how important it was to have a sense of brotherhood within a school community. Like tama Samoa the relationships with their friends and other boys' within secondary school, was important as it provided a sense of family, that gave support and was a group of friends that would be there for tama Samoa. 


\section{Relationships with teachers}

As shown in Chapter Four, the findings indicate that the quality of relationships between tana Samoa and their teachers and the impact of these relationships is also a key factor which contributes toward tama Samoa sense of belonging within the secondary school environment. The importance of the quality of the relationship between teachers and Pacific students has been documented for some time. The Achievement in Multi-cultural High Schools (AIMHI) project was conducted between 1996 and 2000 in a group of nine low-decile urban secondary schools where a large proportion of the school student population come from Māori and Pacific backgrounds. During this period significant research into ways in which these schools' learning programmes could be improved for Māori and Pacific students was carried out (Hawk and Hill, 1998).

Hill and Hawk's (2000) "Making a Difference in the Classroom" report identifies the fundamental factors that need to be considered for the student and teacher relationship to work as:

- Understanding the worlds of the students

- $\quad$ Respect

- $\quad$ Caring

- $\quad$ Being fair

- $\quad$ Giving of themselves

- Perseverance and patience

(Hawk \& Hill, 1998, pp. 12-13)

It has now been over twenty years since the AIMHI project began; however, the findings from this research indicate that the key attributes required for positive relationships between teachers and students remain current and that Hawk and Hill's findings from past research are still relevant in terms of what is important for having positive and strong student-teacher relationships. As can be seen in Chapter Four, most tama Samoa in this research stated that the relationship with teachers played an important role in building their sense of belonging: 
I think the tama Samoan students feel they belong at this school mainly because of particular teachers like Mr Lee. He does pastoral care for the students but he speaks Samoan, and he's very friendly towards the Samoan students. (Simon-Peteru: NP)

For me it's about the teachers, cos they are the ones that have to engage with you, and they make me feel like this is my school, so there is definitely loyalties here that make me want to come to class. Miss XX, Miss $\mathrm{Y}$, and $\mathrm{Mr} \mathrm{XX}$ and lots of other teachers are good teachers...make me feel proud. (Patolomaio: SS)

The comments made by tama Samoa, show that there continues to be a high need for the teacher-student relationship to work for tama Samoa while attending secondary school.

It must be noted however, that the insights shared by some tama Samoa on teacher and student relationships show that they saw the role of the teacher as being just a teacher. According to these tama Samoa, the teacher was there to do a job and therefore it was not necessary for tama Samoa to build a relationship with the teacher. Further discussion revealed that these tama Samoa felt that the teacher student relationship does not have any effect on their sense of belonging at school, nor did they think it affects their academic studies.

Over time research on the academic effects of positive teacher-student relationships has increased. However, there is limited research on the social outcomes of these relationships between teacher-student. (Averill, 2009; Bishop \& Berryman, 2009; Hawk, Cowley, Hill, \& Sutherland, 2002). Teachers are an important source of social capital for students (Muller, Katz, \& Dance, 1999). Social capital in a classroom setting is defined as caring teacher-student relationships where students feel that they are both cared for and expected to succeed (Muller et al., 1999). Social capital from positive teacher-student relationships can manifest itself in many different ways. Chapter Four highlights the significance of this for tama Samoa and show awareness of this relationship: 
When I came to school I expected the teachers to be kind. I knew the boys will really look after each other and I wouldn't see that much bullying. (lakopo: SS)

Further, it has been found that teacher-student relationships can impact peer relationships in schools. Teacher-student relationships can have a significant effect on the peer acceptance between students. Teachers' interactions with students can affect classmates' perceptions of individual students, in turn affecting which students classmates choose to interact with and accept (Hughes, Gleason, \& Zhang, 2005). Conflicting interactions between teachers and students may convey a lack of acceptance, causing other students to also reject the student involved in the conflict with the teacher (Hughes et al., 2005). In Chapter Four, most tama Samoa indicated that they had a positive relationship with teachers. There was also indication, that there were certain characteristics that tama Samoa described of what made the relationship with teachers work. When teachers showed tama Samoa that they cared through interaction and demonstration of care, tama Samoa responded positively.

\section{Family relationships}

Every tama Samoa in this research highlighted family relationships as a crucial element to their sense of belonging within school. As discussed in the identity section of this chapter, above, tama Samoa described the family component as one of the key contributors to their success within the school environment. Tama Samoa feel a responsibility to family to make something of themselves within the school environment. Other outside influences that tama Samoa acknowledged were those of cousins or girlfriends. Each one had a positive effect on tama Samoa and each outside influence provided tama Samoa with the sense of commitment to "be someone".

The literature supports the assertion that parents' attitudes, behaviours, and actions in relation to their children's education have a substantial impact on student learning and educational attainment. Houtenville and Conway (2008) found that the effort of parents and families to be involved with their young person's learning and school - which included a combination of all types of 
engagement - had a large effect on student achievement. This is in line with the experiences tama Samoa noted in the talanoa. For example tama Samoa highlighted the importance of succeeding at secondary school for their families:

I want to motivate myself at school because it just means that l'm living up to my family's name. I am an independent worker it's easier for me to, but I have been told I'm a good supporter by my mates and some teachers. (Toma: SS)

This relationship between attitudes, behaviours, and actions in relation to their children's education was also highlighted in a study by Cahill (2006) who reviewed the perspectives of Samoan parents and what they expected for their children attending New Zealand secondary schools.

Tama Samoa clearly place relationships in high regard in terms of what is important to them in having a sense of belonging within their secondary schools. For most tama Samoa this means not only gaining from being in positive relationships with "brothers", peers, teachers, and family, but also what tama Samoa could give back in return. A sense of loyalty was highlighted in many talanoa with tama Samoa. For the tama Samoa in this research, the phrase "I got your back" means that relationships with people who show care towards tama Samoa are reciprocated by tama Samoa with a sense of loyalty. Keiningham, Aksoy, and Williams (2009) describe the need for loyalty: "by its very nature [loyalty] demands that we commit ourselves to a person, group or cause" (p. 166). This idea of committing to others is nurtured in talanoa with tama Samoa, where they make personal commitment to supporting others who reflect, care, and show support towards them.

Tama Samoa, then, show clear understanding about what a sense of belonging within the secondary school setting means and what they need in order to have it. It is also very clear from the talanoa with tama Samoa that their sense of belonging with their school is primarily based on the relationships they have with others. Friends, and the support they provide, appear to be the most significant factor; however, relationships with teachers and with families are also key to this sense of belonging. 


\section{Aspirations for the Future}

In Chapter One, it was explained that the tama Samoa selected to participate in this study were of Year 12 and Year 13, and the reasons for this. The tama Samoa in this study have had four or five years of experiences at secondary school. Therefore, over the four or five years, each tama Samoa has had a range of both positive and negative experiences while attending secondary school and these were explored in the talanoa.

During the talanoa about what experiences tama Samoa had at secondary school that they believe to contribute to their aspirations for the future making tama Samoa took the opportunity to reflect and consider where they will go once secondary school was finished.

Tama Samoa talanoa about their academic learning and the implications of this learning for their futures; and about the future and the aspirations they have not only for themselves but also for the younger tama Samoa that would attend the same secondary school.

The following elements that are common to all sub-themes will be presented as follows; (i) expectations; (ii) academic achievement and (iii) aspirations for the future.

\section{Expectations}

As identified Chapter Four, tama Samoa were clear about the expectations they had of their school environments including the expectations they had of others they were connected to while at secondary school. In an article about student, teacher, and parent perceptions, Rubie-Davis, Peterson, Irving, Widdowson, and Dixon (2010) observe that there has been little research into students' expectations, whereas several researchers have shown teachers' expectations having greater effects on students than the opposite (p. 37).

In the talanoa with tama Samoa, the expectations they considered to be important within the school environment varied from expectations about the overall feel of the schools, to what schools should look like, to how they should provide for tama 
Samoa as individuals, and to what programmes could be initiated within school settings.

Rubie-Davis et al. (2010) state that:

It is likely students will have self-expectations and beliefs based on prior achievement, experience and aspirations of parents and teachers. When individuals have a strong belief in their ability to achieve a particular goal they are more likely to design steps towards achieving the goal so ultimately success will be attained. Self-belief is a powerful motivator. (p.39)

Tama Samoa also discussed the importance of what they expected from their teachers. Muller, Katz, and Dance (1999) found that when students perceive their teachers as caring, student self-expectations as well as consequent achievement and behaviour are positively influenced. For tama Samoa, the importance of student and teacher relationship was significant in their sense of purpose within the school environment. As shown elsewhere, for tama Samoa the benefit of having the right connection with certain teachers within the school provided encouragement in all areas of identity development, contributing to their sense of belonging, and setting tama Samoa with high expectations of what the future could hold for them. Thus this expectation about having the right connection with their teachers affects all the areas that have been the key themes for this research.

There was also the expectation from tama Samoa that the school environment would prepare them for the future; that the school environment is a place that would guide and prepare tama Samoa for what was to come. In terms of being successful in their secondary schools, tama Samoa had realistic expectations of what they saw as important in their school life and what they wanted out of their school before completing their final year. As highlighted in Chapter Four, students were very clear about their expectations of school:

School has a very important part that helps with your future. I expected school to make new friends and now, I have the brothers. I also expected 
school to help me learn so I can job or maybe get me into Open Polytech in Petone or University - I am still working on that one. (Tataio: F)

When I was in my second year at this school, I was thinking about who would be the people that will make this work for me, as in help me get through school, and it was teachers and the principal that came to my mind. (luta: SS)

Rudduck (2007) states that the idea of providing students with a voice supports an important shift in the status of students in school. It is also highlighted by Hodgkin (1998) that giving opportunity to students to discuss their school expectations provides them with a voice to express what may need to change in their school environments: thus, moving students from being "passive objects" to being "active players"; as well as moving the school environment that is traditionally hierarchical to one that is more collaborative and allows teacher and student to move beyond conventional roles to develop a stronger sense of partnership. Chapter Four presents clear evidence of tama Samoa provide being able to share ideas for ways in which their schools could do better:

I reckon the school needs to acknowledge the different cultures more, also the whole thing about asking questions in class. I know I don't really get it and I have to read it like three or four times over and over. It takes ages for me to take in new stuff, so I think the school needs to find different ways for our Samoan students to get it... we should also have more than Poly club to perform at school events; it needs to be part of our everyday learning. (lese: SS)

There is a strong brotherhood in our school, and I think there needs to be a lot more working across year groups. Even though there is a lot of work that is done especially when you reach Year 11 and onwards, but more across the levels might be good. (loane: SS)

Brown and Dean (1997) suggest that students themselves need to be a part of the planning of existing extracurricular activities and developing of new opportunities. Hodgkin (1998) explains that the student voice is most successful when it enables students to feel that they are members of a learning community, 
that they matter, and that they have something valuable to offer. As this research shows, tama Samoa are clearly able to articulate their ideas; as suggested by Brown and Dean (1997) and by Hodgkin (1998), the value of student voices could be used to align student needs and school visions.

\section{Academic achievement}

The attitude and behaviour of tama Samoa towards their academic learning provides a sense of what they are thinking in terms of their future direction. In this research, tama Samoa spoke about the importance of what they were learning, the purpose that it would have for them as individuals, and the value of this for their families. The talanoa focus for this section allowed the tama Samoa to identify both the perceived benefits and disadvantages of academic learning, and of ways in which their interaction with peers and teachers supports their academic learning.

In this talanoa, each tama Samoa spoke of what they needed to do in order to make their academic learning work for them; this included motivation to learn, interaction with teachers, and the influence of friends. Zimmerman (1998) reviews the idea of students being self-regulated learners, which he defines as:

Self-regulation is not a mental ability or an academic performance skill; rather it is the self-directive process by which learners transform their mental abilities into academic skills. (p. 74)

Self-regulation refers to self-generated thoughts, feelings, and behaviours that are oriented to attaining goals (Zimmerman, 2000). The self-regulated learner becomes aware of their strengths and limitations and they are guided by set goals and targets. As Zimmerman (2000) observes, self-regulation is important because a major function of education is the development of lifelong learning skills and once students complete secondary school these young adults must learn many important skills informally. It became clear to me during talanoa with tama Samoa, that many of them had gained some of the skills that would identify them as self-regulated learners; examples include being able to adapt their identities to fit into certain classes, involvement in particular groups or clubs that would provide responsibility, and pushing themselves to succeed in academic 
learning. This study has highlighted the importance to tama Samoa of developing an inclusive school environment in order to acknowledge, value, and respect students from diverse backgrounds. Fletcher, Parkhill, and Harris (2011) propose that inclusion provides the learning and support that allows for equal outcomes for all students. Nakhid (2003) suggests that feeling included and identifying with school life is a necessary condition for the success of Pacific students' academic achievement and that non-inclusiveness will lead to a feeling of being undervalued and unwanted. Thus, an inclusive school culture that is welcoming and respectful, supported through the development of positive relationships, empathy, and acceptance will enable tama Samoa to feel connected to the school, resulting in engagement in learning and a positive attitude towards academic achievement.

\section{Aspirations for the future}

Educators have long recognised the value to students of setting ambitious goals, and being inspired in the present to progress toward those goals. It is expected that students who set challenging goals learn to become task-oriented, feel a sense of purpose, and learn more. It is no surprise, then, that raising the aspirations of students is a universal priority (Quaglia \& Cobb, 1996).

As the findings show, tama Samoa reflected on themselves and took time to reflect on "where to" once they finished secondary school. As senior students in their secondary schools, tama Samoa were aware of the expectations for them in the near future in terms of school exams, completing the senior year successfully, and the need to set themselves goals or future aspirations. As stated by Quaglia and Cobb (1996) a definition of aspirations must be contextualised, and further, it should address both present and future perspectives. For these reasons I hypothesis that a student with aspirations is one who is involved in various activities for both their inherent value and enjoyment and their connection to future goals.

Quaglia and Cobb (1996) take the stance that while schools are in a position to help foster aspirations, students must also take the responsibility and be held 
accountable for their present and future situations. In Chapter Four, tama Samoa described the need to be alert about opportunities:

I'm trying my best to make the most of my opportunities in everything I do, not just in school work but extra-curricular stuff, and I just try to be the best I can be in everything I do and I want to achieve the best. I think it's all relevant for my future. (Timoteo, SS)

In the talanoa sessions tama Samoa had no problems sharing their aspirations about the future, and, as explained in detail in Chapter Four, most were also able to identify the pathway required for them to reach their future aspirations. This contrasts with a research project by Rubie-Davies et al. (2010) in which students spoke about aspirations for the future and were able to list a wide range of potential occupations, but did not always seem sure about the qualifications they would need. There was a significant difference between the participants of RubieDavies et al.'s study and the tama Samoa of this study. In the talanoa I had with each tama Samoa, each individual was able to identify both aspirations for the future and the pathway they needed to follow, including qualifications, in order to reach their goals for the future.

As mentioned above, Hodgkin (1998) asserts that students themselves have a huge potential contribution to make - not as passive objects but as active players - to the education system (p. 11). Levin (2000), too, argues that by talking with and listening to students, we can learn more about how classroom and school processes can be made more powerful. This notion sat behind the final talanoa with tama Samoa; about what they predict or believe their schools need to review to better support younger tama Samoa already enrolled in their secondary schools as well as those who will attend there in the future.

All tama Samoa confirmed in their talanoa that in most situations their experiences at secondary school were positive. The influences of others, especially their mates, and the individual decisions they made during their secondary schools have resulted in tama Samoa who are proud and responsible. It was apparent in early talanoa with tama Samoa that, within their particular secondary schools, acknowledgement of their cultural identities is of great 
significance to who they are as individuals. Their ethnic and cultural identities represent a part of tama Samoa that is recognised not only amongst themselves but also amongst their peers; schools must take note of the importance this holds for tama Samoa. "Ua soona mimita le manu o le tava'e i ona fua" - metaphorically speaking, "The tava'e bird is proud of its feathers": this proverb implies that Samoan people should be proud of our individual and collective identities (Rimoni, 2012). The findings show that tama Samoa take their pride in who they are and who they represent:

I am a proud Samoan because it's just the way we present ourselves and the way we treat ourselves, it's a lot different from the way Palagi (European) treat each other. (Simona-Peteru: F)

I am very proud to be a XXX student, because there's like heaps of boys like Pacific Islanders. Everyone's got the same sort of views at school like the same experiences as well. The brothers have the same kind of background that I'm kind of used to. Oh, the same routine and stuff and everyone's got a strong bond here. It's good that the teachers here treat everyone equally. (loane: SS)

Smythe (2006) argues that if schools are serious about having a more realistic regime of accountability that is likely to have a chance of success in making a difference in the lives of those most disadvantaged, then it will have to be one that includes the lives, experiences, cultures, family backgrounds, aspirations, and hopes of young people themselves. The experiences of tama Samoa highlighted by this study, provide key aspects that secondary schools must consider. These will be explored further as recommendations in Chapter Seven.

\section{SUMMARY}

The overarching focus of this research was the opportunity to hear the voices of a group of tama Samoa who were attending New Zealand secondary schools and their experiences/perceptions of being part of a secondary school environment. These experiences and perceptions from tama Samoa were underpinned by three core themes - identity, sense of belonging, and aspirations for the future. 
The findings, presented in Chapter Four, show that there are key aspects to making the experiences of tama Samoa both positive and successful within the secondary school. This chapter has explored the findings in more detail. Identity has been discussed in terms of complexities in tama Samoa identity development, the importance of culture to identity formation, the relationship between identity and responsibility, and the adoption and adapting of multiple identities as a tool for survival. Sense of belonging has been presented in three sub-themes - understanding versus experience, the influence of participation, and the importance of the nature of relationships. The findings from the third theme, aspirations for the future have been presented and discussed as tama Samoa expectations about their secondary schooling, their perceptions of the importance of academic achievement, and their focus on the future.

These include acknowledging tama Samoa and the multiple identities that are formulated while attending secondary school; developing a sense of belonging through everyday interactions with peers, teachers, and others that tama Samoa were surrounded by during their time at secondary school, both in formal classes and also in extracurricular activities; and, finally, the understanding that tama Samoa had an awareness of what purpose secondary school served for each tama Samoa to prepare them for the future once their secondary schooling was completed. 


\title{
CHAPTER SIX: \\ REVIEW OF RESEARCH QUESTION
}

\author{
Fili le Niu'afa
}

(Plaiting commences for the Niu'afa)

\section{INTRODUCTION}

In this chapter, I review the research sub-questions and provide an overview from the findings chapter in relation to the research questions. This is an opportunity to re-examine the purpose of where this thesis began. It is also an opportunity to provide an analysis of tensions and dilemmas that I have identified through the review of the three sub-questions.

In Chapter One, the rationale provided reasons as to why this study focuses on tama Samoa and their everyday experiences in secondary schools was a worthwhile topic for a PhD study. In reviewing the rationale that was provided in Chapter One, I restate the following for the purpose of this chapter:

- The Pacific student population in New Zealand secondary schools has continued to grow in recent years (New Zealand Statistics, 2013).

- One in five Pacific students leaves school without any qualifications at all (Chu, Glasgow, Rimoni, Hodis, \& Meyer, 2013).

- One in five Pacific students leaves with NCEA level 1 only (Chu, Glasgow, Rimoni, Hodis, \& Meyer, 2013).

- $\quad$ One in five leaves with NCEA level 2 (Chu, Glasgow, Rimoni, Hodis, \& Meyer, 2013).

- One in ten will become disengaged from education, employment, or training by the age of seventeen (Chu, Glasgow, Rimoni, Hodis, \& Meyer, 2013).

- Boys tend to be over-represented in the lowest achieving group, and this is particularly true for Māori and Pacific Island male students (Ministry of Education, 2007). 
- Māori and Pasifika males are least likely to leave school with University Entrance or higher qualifications (Ministry of Education, 2007).

While the first five points above are not directed specifically to male students, this does provide an overview of the situation for Pacific students within secondary schools in the New Zealand context.

The aim of this study was to explore the perceptions of tama Samoa about what factors influenced their schooling experiences and the impacts of these on their aspirations for their futures. It was anticipated that these experiences and perceptions would reveal the attitudes that tama Samoa have towards secondary school.

It was also noted that most research done on Pacific students in general was focused on their academic achievement, with no research focusing on tama Samoa and their social experiences with friends, peers, teachers, and school management. Therefore, this was an opportunity to collaborate with tama Samoa to explore their secondary school experiences based on the assumption that this could elicit previously unknown factors that could contribute to enhancing tama Samoa engagement and academic success at the secondary school level. As noted by the Scott (2014), "engagement encompasses attendance, a sense of belonging and wellbeing and enjoyment. Student disengagement leads to higher risks of negative youth behaviour" (p. 19). Taken together with the bullet points above, based on previous research, the implication is that tama Samoa do not do well because they are disengaged and lack a sense of belonging and wellbeing at secondary school. However, in this study it was found that most of the experiences the tama Samoa participants had of secondary school were in fact positive; most of the tama Samoa reported that their secondary school was a place where they did have a sense of belonging through the interaction with others, particularly friends, and through their roles and responsibilities in the groups and clubs they were involved in. This study, therefore, provides a fresh new perspective - focused on tama Samoa perceptions of identity, sense of belonging, and aspirations for the future - which can contribute to existing knowledge to inform policy and practice. 


\section{Question One:}

In what ways are tama Samoa's identities influenced by their secondary school experiences?

Through the talanoa process with tama Samoa, it became clear that most of the tama Samoa identity development were influenced by their secondary school experience. As highlighted in Chapter Four, tama Samoa noted the need to have multiple identities for different purposes: these included awareness of other's perceptions of them, to access teacher attention, as a survival strategy to be applied in different learning environments, and for the purposes of being amongst and relating to mates and peers.

The study identified that tama Samoa do develop identities during their secondary school experiences. In the one to one talanoa with each tama Samoa, they described and explained why it was important and necessary to formulate multiple identities during their time at secondary school.

The first of three common threads that were highlighted by tama Samoa was selfidentity. Tama Samoa discussed the importance of being confident in knowing who they were, so that peers, teachers, and close friends were able to identify who a tama Samoa was in relation to the circle of friends and others that tama Samoa connected and communicated with during secondary school. As described by Nahkid (2003):

In constructing our identity, we build (with what we know of our past and our historical experiences), using the present to shape how we see who we are. That is not all that forms our identity. It is hollow unless we fill within it visions of what we hold for ourselves in the future, and how we see ourselves being. It is not only the state of being who we are, but who we are to become. (p. 303)

Nahkid (2003) found that the perceptions held by both the schools and the teachers of Pacific students adversely affected their educational opportunities and outcomes. In this research, too most of the tama Samoa participants were aware of the stereotypes that some school teachers and school management had 
of tama Samoa, and of the need to build an identity to represent tama Samoa within the school setting.

The second common explanation highlighted from tama Samoa talanoa was the need to develop a cultural identity within the secondary school setting. As identified in Chapter Four, all twelve tama Samoa demonstrated a sense of their cultural background, and acknowledgment of their Samoan heritage. Fletcher and her colleagues found that Pacific students and their families held a strong desire to succeed in all aspects of mainstream culture as well as in maintaining their own cultural identity (Fletcher, et al., 2005; 2006; 2009). As pointed out in Chapter Three, not all tama Samoa were of full Samoan heritage. However, this did not influence the value and emotion tama Samoa attached to being a Samoan. Across all four secondary schools, tama Samoa described how necessary it was to demonstrate within their school environments their cultural identity. The importance tama Samoa attached to this demonstrates their sense of pride in their Samoan heritage.

Tama Samoa also identified the need to highlight their cultural identity so that they could connect with other tama Samoa. Tama Samoa highlighted the importance of having a cultural identity because of the link that it had back to their family roots, and acknowledges the ethnicities of their parents. For tama Samoa being able to identify their Samoan heritage within the school environment provided other important information about each tama Samoa.

The third common thread highlighted by tama Samoa, is that they formulated multiple identities as a strategy in order to feel that they were to fit into the different schooling situations as well when engaging with different groups of people. For example; there was an identity that was adopted for engaging with the group of friends each tama Samoa spent their social time with while at school. There was also the identity that belonged in the classroom setting; however, the identity adopted during class time, also depended on which group of friends that were also in the class. Within this context some tama Samoa described the need to make sure they were not seen as less capable than their peers and therefore made the effort to have an identity that demonstrated they were a focused student. 
Overall, tama Samoa identities are influenced by many of their secondary school experiences. The development of their self-identity is through the connections they have with others such as peers, and close friends. Their multiple identities are used as a tool to adapt in different contexts and most importantly their cultural identity, again, is based on the group they choose to surround themselves as well as the knowledge that tama Samoa have from their family backgrounds. These many identity formations all connect to what makes a tama Samoa, learning to build many different identities is a major part to their secondary school experience.

\section{Question Two:}

\section{What is the nature of the relationship between tama Samoa sense of belonging and their daily experiences within secondary school?}

Most tama Samoa identified that through their everyday experiences at secondary school, there was a sense of belonging primarily through the relationships they had with others, and through their participation in group activities. Glynn and Berryman (2005) state that the desire for "a sense of belonging is a basic human need" (p. 310) and that students who saw school as positive environments and who had a sense of ownership there go on to do well in society.

Through the talanoa sessions each tama Samoa reviewed the everyday experiences they had at school and how each one the different experiences either connected or not connect them to having a sense of belonging at schools. This provided different perceptions and views, as the school environment played a huge part in the experiences had by tama Samoa. There were two key aspects that were highlighted by tama Samoa which contributed to their sense of belonging.

First, it was through their relationships with their friends, peers and other people within the school environment. Baumeister and Leary (1995) suggest that the need to belong is characterised by a need for regular contact and the perception that the interpersonal relationship has stability, affective concern, and is ongoing. In their seminal article on the importance of sense of belonging to wellbeing, they 
proposed the "belongingness hypothesis", suggesting that "human beings have a pervasive drive to form and maintain at least a minimum quantity of lasting, positive, and significant interpersonal relationships" (p. 497).

As highlighted in Chapter Five, relationships amongst different people within the school setting, influenced how tama Samoa interacted and influenced their decision making with the school environment. This strong influence of others was also a key part to how tama Samoa participated in extracurricular activity.

The second key aspect was the tama Samoa involvement in extra-curricular group activities whether it be a club of their own choosing or a nomination to be involved in school groups. Phinney (1993) points out that the development of adolescents is influenced by their identification with social groups. He notes that for adolescents, the choices involving group identities are constrained by the norms and values of a particular group. On the other hand, the influence of certain behaviour and interactions with their peers and social groups reflect on individual developments of an adolescent. Furthermore, Phinney's statement about the influence of peer groups was strongly highlighted in the interaction and attitudes of tama Samoa. For most tama Samoa, the involvement in various school groups provided them with the feeling that they belonged to a particular secondary school, and this sense of belonging, in turn, generated a sense of pride and provide loyalty towards their secondary schools. Tama Samoa, took on the responsibility of group or club involvement quite seriously, and the outcome for most tama Samoa was that it was not only interest that lead them to participate in group or club activities, but also being able to identify certain acknowledgements such as, leader of particular groups or clubs, and taking ownership for particular groups and clubs.

The overall nature of the relationship between tama Samoa sense of belonging and daily experiences within secondary school, suggests that tama Samoa, like to be involved, and take part in various group settings, while in secondary school, there are many reasons for this such as; demonstrating responsibility, being interested, loyalty to their school or taking part because of friends. The importance of this particular relationship for tama Samoa indicates that in most experiences, tama Samoa are social individuals who like to belong through 
various activities and take enjoyment in these experiences, as well demonstrating that within some of these involvements with various groups comes leadership and responsibility.

\section{Question Three:}

\section{What experiences have tama Samoa had during secondary school that have contributed to their aspirations for the future?}

The findings in Chapter Four highlight the many experiences tama Samoa have had at secondary school, and also provide their perceptions and expectations of secondary school. Tama Samoa were also able to identify what aspects of their experiences during their time in secondary school have contributed to their aspirations for the future. Each tama Samoa was able to express where they hope to be once they had completed secondary school. However, even though there were times in their talanoa that tama Samoa did not directly connect their secondary school experiences and their aspirations about the future, it was clear from the descriptions made by tama Samoa, that various experiences and choices made at secondary school are likely to have an impact on their futures:

\footnotetext{
At Year 11, I was ready for NCEA because of the opportunities I took when I was in Year 10 like lunch time tutoring and going to homework centre. (Simona-Peteru: SS)
}

The above example provides evidence that tama Samoa were already using skills that can support their decisions about what the future could look like for them when secondary school is finished. As indicated by Simona-Peteru, he was aware that there are opportunities provided by secondary schools to support his academic learning, and that once they identify the opportunities they can use these, thus increasing their self-efficacy.

Self-efficacy is a phrase originating from Bandura's (1977) social cognitive theory and refers to an individual's perceptions of their abilities in a given domain. Further to this, self-efficacy enables people to control their thoughts, feelings, and actions (Hall, 1991). It is widely accepted that self-efficacy influences an individual's choice of engagement in any given domain, how well they perform, 
how long they persevere, how they cope and respond to adverse scenarios (Cretchley, 2007; Johnson, 2005).

Tama Samoa were aware that they did not have much time left at secondary school, and the opportunities to seek guidance and advice on what to do once secondary school was finished was highlighted in the talanoa sessions. It was also important to note that some tama Samoa were planning to wait on their results from NCEA level two and three to make final decisions about future pathways, according to some tama Samoa this left the future open for choices.

At this stage of the tama Samoa experiences, tama Samoa have explored the options available to them, they have also considered their roles within their own families, and how the impact of their decisions for once secondary school was finished had on their families. The opportunity to be directed and advised by key people in secondary school is important for tama Samoa. The future aspirations of their friends were also important to tama Samoa, for some this also had an influence on what they could do once secondary school was completed.

\section{TENSIONS AND DILEMMAS}

The analysis of the findings, the discussion chapter (Chapter Five), and this review have revealed a number of tensions and dilemmas related to tama Samoa secondary school experiences. It is significant to note that these were not all identified by the tama Samoa as tensions and dilemmas, but by the researcher during the analysis of the data. This is fa'afaletui: the view of the researcher who is less close to the data.

Detailed talanoa with tama Samoa highlight that while they were able to acknowledge that it was important to attend secondary school, the school organisation and management itself did not make it easy for tama Samoa to enjoy school. One result of this was that they developed the skills to formulate different identities in order to fit into the different school contexts. Although tama Samoa did not express this experience as a tension or dilemma in their everyday experiences, the question remains why it was that tama Samoa had to develop certain identities in order to fit into school structures rather than the other way 
around whereby the schools are structured to fit around tama Samoa needs. Through the use of fa'afaletui (see Chapter Three for further explanation of fa'afaletui), the importance of reviewing tama Samoa stories from the perspective of the tree climber, accessing the complete picture from tama Samoa experiences and asking the question what is happening here?

As identified in Chapter Four, one out of the twelve tama Samoa indicated that he did not feel a sense of belonging within his secondary school or that having a sense of belonging was an important aspect of attending secondary school. During the talanoa this tama Samoa revealed that he had his mates, he had his sports, and he was also academically achieving well; and therefore felt that was enough to keep him at secondary school. This tama Samoa has highlighted many factors that he believes to be enough to make the schooling experience positive with not necessarily having a sense of belonging to the school. In Chapter Three, I have provided a description of how tama Samoa were selected for this study, each one was nominated by their school principals this was shared with this particular tama Samoa. Interestingly, following through with the fa'afaletui process, this tama Samoa was given his transcript to review, he indicated that he was not aware of his achievements noted on school records. Therefore the dilemma highlighted here is the lack of acknowledgement for when tama Samoa do well at school from school leadership, and therefore this particular tama Samoa had gone through school feeling unnoticed by school leadership.

Two tensions were identified through analysis of talanoa with tama Samoa's nominated persons; in both cases these are associated with the nominated persons' perceptions conflicting with those of the tama Samoa. Fletcher et al. (2009) suggest that cultural values played a key role in building Pacific students' confidence. In support of this notion, Tuafuti and McCaffery (2005) claim that raising Pacific students' self-esteem, self-discipline, and self-identity requires the inclusion of Pacific and cultural considerations in all aspects of Pacific students' education. The findings presented in Chapter Four clearly demonstrate the importance to tama Samoa of being Samoan within the secondary school setting. Tama Samoa talanoa emphasises their pride in being Samoan, and what it means to be Samoan. Although this was also identified and acknowledged by some nominated persons as being important to the identities of tama Samoa, one 
questioned whether this cultural identity was necessary or relevant while attending school. This nominated person felt that these descriptions made by tama Samoa were not reflected in the everyday experiences of tama Samoa. It was pointed out by this nominated person that most tama Samoa have not been to Samoa and, according to the nominated person, do not fully understand Samoan cultural practices; based on this they questioned how tama Samoa could have this sense of pride in their Samoan culture. Clearly, the difference in perception shows a lack of understanding between tama Samoa and this nominated person. In this particular case a classroom teacher and suggests that some teachers do not understand the significance of how significant it is for tama Samoa to identify with being Samoan, within a school context.

The second tension I have highlighted is the differences in the perceptions of tama Samoa and nominated persons relating to the nature of the relationship between tama Samoa and their mates. In some cases nominated persons suggested that the bonds between tama Samoa and their mates impacted negatively on attitudes and decisions made by tama Samoa. As identified in Chapters Four and Five, the relationships between tama Samoa and their mates was close to the point where, sometimes, the closeness of this relationship formulated a brotherhood that did not allow for individual tama Samoa to build independent identities. Some nominated persons suggested that this resulted in some tama Samoa showing a lack of independence and could be described as followers, or demonstrating negative attitudes towards their learning for the sake of keeping cool amongst friends. For this particular tension, the nominated persons were school affiliated as teachers or in senior management positions, and therefore have observed and worked with different tama Samoa in different situations during their times at secondary school. The experiences and perceptions made by these nominated persons is also captured in what some tama Samoa have said about being part of the group and not wanting to explore an independent identity for the sake of how friends might react. What is highlighted from both nominated persons and tama Samoa is the lack of developing individual identities. The question can be asked: what opportunities can be developed to allow tama Samoa to be individuals within a group identity? 
Both nominated persons and tama Samoa highlight the issue; what needs to be reviewed is how this can be further developed within a school environment.

\section{SUMMARY}

This study focuses specifically on tama Samoa own perceptions of their experiences at secondary school. While previous research, largely focused on Pacific academic (under)achievement, has suggested links between (lack of) achievement, (dis)engagement, (weak) sense of belonging and wellbeing at school, the participants of this study reported that most of their secondary school experiences were positive. Tama Samoa were able to describe a strong sense of belonging to their schools, particularly in terms of their relationships. They also recognised and acknowledged the importance of their involvement in a range of extra-curricular activities and the roles and responsibilities that these provided. They were also all able to discuss their aspirations for the future and to identify what aspects of their experiences during their time in secondary school have contributed to these.

The study also uncovers a number of tensions and dilemmas experienced by tama Samoa at secondary school, particularly in relation to how they adopt and manage multiple identities, and negotiate relationships.

This study, therefore, provides a fresh new perspective - focused on tama Samoa perceptions of identity, sense of belonging, and aspirations for the future - which can contribute to existing knowledge to inform policy and practice. The next chapter presents a series of recommendations which are based on the study's findings and are intended to begin to address some of the tensions and dilemmas identified above. 


\section{CHAPTER SEVEN: \\ CONCLUSION}

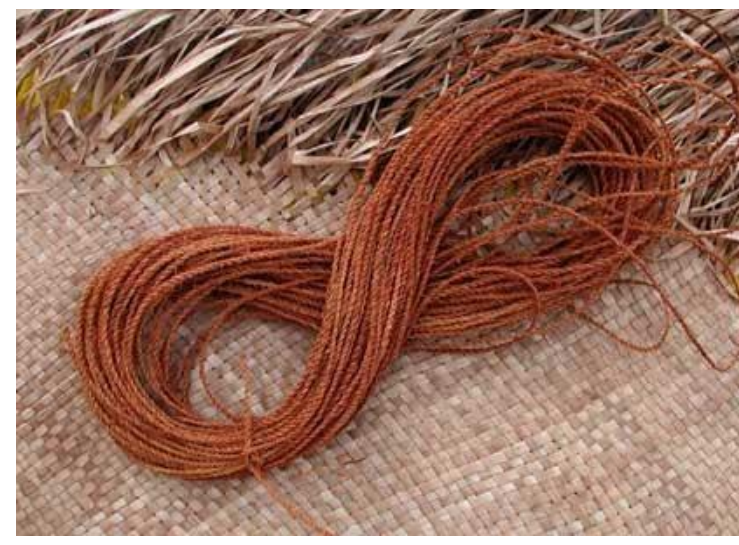

Sooga o le Niu'afa

(Joining the strands)

As I come near to the end of this thesis, I return to my 'afa metaphor; this, too, near ready for its purpose in binding, joining the poles of the traditional fale Samoa. In Chapter One I describe the use of the Samoan 'afa (braided coconut fibre rope) as a metaphor to provide a sense of who I am as a Samoan researcher. It is also significant as a metaphor as it symbolises both unity and endurance because the various strands of the 'afa are plaited and pulled together so that it is strong enough to bind the central poles of the fale Samoa so that the people are sheltered. In preparing the 'afa, each strand from the coconut husk has its role to play in strengthening the cord before it can be used. In Chapter One, we are introduced to the visual image of a coconut husk, in its rough and rugged form. As I go through each of the seven chapters, each chapter has been introduced with a process of preparing the Samoan 'afa.

In this final chapter, we are visually directed to the coconut sennet, in its strong and beautifully braided form. This shows the 'afa ready to be used in its purposeful way. In this thesis, the tama Samoa represent the individual strands of the coconut husk; their stories have been processed through the use of the fa'afaletui framework, and each strand has been twisted, braided, and intertwined 
with the others. Tama Samoa experiences have now been collated and refined in a manner that represents their voices and presents their experiences. This, however, does not complete the journey of the 'afa Samoa. It is now ready for another purpose - to connect, to strengthen, and to support a structure that will signify yet another purpose. Similarly, the tama Samoa in this study are ready for their futures and purposes.

This final chapter signifies the arrival of the journey of this thesis. It reflects on the significance of the study. It will also highlight key conclusions identified in this study, and makes recommendations for policy, practice and research which will support tama Samoa in the secondary school context. This chapter also acknowledges limitations of the research. The chapter concludes with the researcher's final words reflecting on the overarching themes highlighted in this study, as well as providing a reflection of being a Samoan researcher during this study.

\section{SIGNIFICANCE OF THE STUDY}

The study is significant for a number of reasons. First, as highlighted in Chapter One, previous studies exploring the classroom experiences of Pacific students in New Zealand involved tama Samoa merely as part of a bigger collective of Samoan students (Goldring, 2006; Lipine, 2010; Siope, 2010). In other cases, tama Samoa were part of a collective group of Pacific students in studies that were focused on the barriers that prevented them achieving in secondary school (Atkinson, 2013; Macdonald 2004; Siope, 2010). This study allows for the opportunity to focus on one particular group that represents the highest growing population within Pacific groupings in New Zealand secondary schools. (Scott, 2014).

Second, the opportunity identified for this study was to build upon the findings from previous studies by taking it one step further and identifying key factors in the experiences and perceptions of tama Samoa about secondary school life. It is anticipated that from this research, the factors that are highlighted by tama Samoa can contribute to identifying the key attributes that support them while attending secondary school. Samoan students make up $47 \%$ of the Pacific 
population in secondary schools (Scott, 2014). It was therefore considered to be imperative that this research was undertaken to better understand the situation for tama Samoa within the secondary school environment. This research was an opportunity to explore the schooling experiences of tama Samoa, with particular focus on exploring their identity formation, their sense of belonging, and how their experiences of secondary school support their aspirations for the future.

Third, as highlighted in Chapter One, the tama Samoa who participated in this study are a group of twelve strong, articulate, and thoughtful young men, who are clear about their self-identities, their cultural identity, and their group identity. Tama Samoa employ a variety of strategies that have both worked and not worked to demonstrate their identity formations, their experiences of belonging at school, and how they perceive these experiences will support their future directions. Their stories capture important ways that they negotiate and make sense of the experiences of being a tama Samoa in a New Zealand secondary school, which Griffin (1997) describes aptly as a "complex series of intersecting moments" (p. 6). The tama Samoa in this study have shown themselves to be communicative, imaginative, and reflective of their lived experiences.

Four, like all other Pacific cultures, the Samoan culture has its core concepts that are unique to its people. As identified by Lui (2003), central to these Samoan concepts are kinship and family. Samoan people have a very strong sense of identity and belonging. In this research, I argue that tama Samoa are a significant group to understand: their experiences and perceptions through secondary school can highlight deeper cultural issues of ways that tama Samoa manage their identities and certain roles within a secondary school setting. Further to this, becoming familiar with tama Samoa experiences has the potential to contribute to further understanding the impacts and influences of their environment outside of the school setting - particularly the expectations and assumptions of family and other outside influences - on tama Samoa 


\section{Conclusions}

The following are the key conclusions that have emerged from my research. Tama Samoa made it clear in their talanoa that their identity formation was an important aspect of their secondary school experience. First, tama Samoa revealed their ability to switch identities to enable them to settle into an individual that would be comfortable to participate and contribute depending on the context. This was a significant tool or mechanism that tama Samoa appeared able to employ naturally or effortlessly as was required to fit into different situations such as when amongst mates, taking on responsibility, or attending classes. Tajfel (1974) states that this idea of switching identities can be understood as a person having not one "personal self", but rather several selves that correspond to widening circles of group membership. Different social contexts may trigger an individual to think, feel, and act on the basis of his personal, family, or national "level of self. Tama Samoa were well aware of when there was a need to change identities; they explained how, depending on the situation, they would consciously switch identities to accommodate how they were perceived amongst their friends, peers, teachers, or school management. The need to formulate different identities was seen as a necessary mechanism or skill each tama Samoa developed in order to survive in secondary school.

Second, tama Samoa emphasised the importance of their Samoa-ness. Their cultural identity was their way of celebrating their Samoan culture and family heritage. Anae (1998) uses the term "Secured Identity" which, she explains, is marked by a persistent Samoan self-concept where one finds resolution between internal and external conflicts in what it means personally to be a New Zealandborn Samoan. The tama Samoa construction and enactment of their multiple and often ambiguous identities involves complex negotiations such as contemplating which identities to switch when experiencing varied contexts within school and amongst people, or considering which groups to participate in by questioning "which group I would benefit more from?" It was clear from the talanoa that these complex negotiations were ongoing for tama Samoa as they interacted with people within their secondary school settings and people within their families 
Third, tama Samoa positioned themselves in relation to their peers, in order to demonstrate different ways they understand interaction and expectations. At school they experience the demands of competing for social status and prestige with their male peers, especially in academic and sporting domains, yet they also understand that they can empower themselves by using aspects of their skills such as adapting identities to fit different contexts.

Four, tama Samoa placed huge importance on the value of their relationships with their friends; the impact of these relationships essentially determined how they felt about school. The everyday interactions and relationships with their friends explored by tama Samoa reveals how they position themselves amongst friends. According to Hartnett (2007), peers possibly play an increasingly critical role in forming identity as family dynamics change, society changes, and young peoples' futures seem more unpredictable than ever. Harris (1996) asserts that peers have more influence on each other than their parents do in shaping values. Chapter Six also reveals that tama Samoa encounter some dilemmas as they try to fit in among their male peers, whilst also attempting to define, express, and maintain their individuality. However, tama Samoa consistently reflected on the importance of friends and other people who showed care towards them during secondary school.

Fifth, tama Samoa place a high value of having close bonds with their family members, especially their parents, and highlight the key to having a positive experience at school, which included academic achievements, was attributed to their families and the ongoing support given by their families to their learning and participation in extra curriculum activities.

In keeping with the school environment, student and teacher relationships, were identified as key to aligning with tama Samoa identity formation, and sense of belonging. What is important to note here is the influence of teachers can have on tama Samoa and their schooling experiences. It is important to identify tama Samoa are well aware of what makes their experiences positive and student and teacher relationships was highlighted by tama Samoa throughout Chapter Four. 
The sixth key idea is that tama Samoa identified the importance to succeed at secondary school, and felt it was within their responsibility to support their families once school was finished. As explained by Siope (2011), many Pacific families have migrated to New Zealand for a better life and, similar to international findings, families perceive education as an important tool for gaining economic prosperity. So too do Samoa families; the idea of New Zealand providing a better life for Pacific families resonates with tama Samoa, who reflected back on stories they had heard and been told by family members about leaving the homeland. Taking this into consideration, tama Samoa highlighted that this was why doing well at school was important. For tama Samoa, it was very clear that their sense of belonging with their school is primarily based on the relationships they have with others. Friends, and the support they provide, appear to be the most significant factor; however, relationships with teachers and with families are also key to this sense of belonging.

The seventh key idea notes the how tama Samoa expressed an awareness of why they attended Secondary school. Quaglia and Cobb (1996) argue that while schools are in a position to help foster aspirations, students must also take the responsibility and be held accountable for their present and future situations. They, too, have to speak out and work with educators to create an environment that promotes empowerment, a sense of belonging, sensible risk-taking opportunities, and engaging activities. As noted earlier tama Samoa are familiar with school routines and the purpose of school. Quaglia and Cobb's stance on fostering aspirations reaffirms that tama Samoa are capable of taking a stance about what could work in a secondary school context. Zimmerman (2000) claims that students' self-perceptions of efficacy are distinct from related motivational constructs because of their specificity and close correspondence to performance tasks (p. 89). In reviewing the notions of self-efficacy, the advantages to developing young people such as tama Samoa to succeed at secondary school is providing them with opportunities to develop self-efficacy within the everyday learning and experiences tama Samoa have. 
Tama Samoa construct possible future selves through a process of reflection about who they are, how others see them, and what they believe is expected of them. In this study, tama Samoa experiences and perceptions were embedded in educational talanoa.

\section{Limitations of the Research}

This qualitative research has provided some significant insights into some tama Samoa experiences and perceptions while attending secondary school in New Zealand. However, the research has a few limitations, particularly in relation to the generalisability of the findings. Although qualitative research in general does not aim to focus on breadth, but on depth, I see this as a limitation for this study. Firstly, because the sample of tama Samoa was taken solely from secondary schools across the Wellington region there is some difficulty in being able to generalise across the general population of tama Samoa secondary school students in New Zealand, the majority of whom live in the Auckland region. Added to this, the sample size of twelve participants is only a diminutive representation of tama Samoa thus the wider experiences, perceptions and views of tama Samoa could have been overlooked and again generalisation may not be applicable. Furthermore, all the tama Samoa were born and raised in New Zealand and identified that English was their first language; that is, none of the tama Samoa were born and raised in Samoa before migrating to New Zealand. The experiences of tama Samoa born and raised in Samoa another significant group of tama Samoa in New Zealand secondary schools may have captured a different set of experiences and perceptions to the tama Samoa in this study. However, despite these limitations, the study does provide a set of common trends and patterns of tama Samoa voices that are current and that have existed for a number of years, and which seem to align with existing literature about Pacific education in New Zealand. The limitations also identify opportunities for the focus of future related research. 


\section{RECOMMENDATIONS}

The findings of this research are useful for guidelines, programmes, and policy that will achieve better outcomes for tama Samoa in secondary schools. Furthermore this data will be useful to develop culturally appropriate theories and models which could be used as frameworks to investigate the links between students at school and in the home for other ethnic groups in New Zealand with similar values and worldviews. The following are recommendations of how these findings could be used to improve and further understand the experiences of tama Samoa in secondary school. The recommendations are presented under the subheadings policy, practice, and research.

\section{Policy}

As explained elsewhere, there is limited research that focuses primarily on understanding the experiences of tama Samoa in New Zealand secondary schools from the tama perspectives The Pasifika Education Plan (2001) was designed to close the gap between Pacific and non-Pacific students in 20 years (Ministry of Education, 2002). While changes and slight improvements have been made, Pacific students still remain at the lower end of the tail academically compared to their non-Pacific counterparts, with Pacific boys achieving at the lowest rates. For these reasons policies must pay particular attention to Pacific students including tama Samoa; policy makers can be more responsive to the unique experiences of tama Samoa and tama Pacific, not only academically, but also in terms of their social experiences in secondary school. The findings from this thesis can be used to inform policy makers about how to support tama Samoa in secondary school environments and to support and develop Teacher Education programmes for future teachers. Based on the findings of the study it is recommended that:

- Existing policies and guidelines review how to highlight successful strategies to support tama Samoa in secondary schools such as the opportunities to represent leadership qualities, and responsibilities. 
- Policy documents be updated on a regular basis so that they continue to address the needs of tama Samoa and tama Pacific within secondary school settings.

- Updated documents such as curriculum, Education reports and Pacific Education Plans continued to be shared with the community and school management through talanoa.

- $\quad$ Appropriate and sufficient support - such as funding and teacher support be provided to secondary school environments in order that they can action policies that will support tama Samoa and tama Pacific.

\section{Practice}

Tama Samoa are young men who are able to facilitate and identify key tools that will support their learning and engagement within the secondary school system. Based on the finding of the study it is recommended that:

- There is a need for school-wide programmes to allow for consideration of cultural processes within classroom settings.

- Schools provide space for tama Samoa to showcase their skills, it is likely that they will formulate identities that align well with core school values.

- School management and all teachers give greater attention to the acknowledgement of student cultural identity. Through providing teachers with professional development and opportunities to share teaching and learning with Pacific communities.

Schools provide teachers with appropriate professional development to immediately remove negative assumptions about tama Samoa and use strategies that allow teachers to strengthen their understandings of tama Samoa and become very familiar with tama Samoa way of working and thinking within a school system. 
- Schools build the relationship between tama Samoa and families by nurturing tama Samoa and their time at school through review of what it means to have open policy within school systems. In practice this could involve open evenings and varied times for families to attend school activities and take part.

\section{Research}

Above, are a number of limitations relating to the generalisability of this study were acknowledged. It was also pointed out that these provide the opportunity for further research to extend the body of data. Based on the findings of this study it is recommended that:

- The perspectives of a more diverse group of tama Pacific would provide further valuable data to add to that generated by this research.

- Future research could seek the perspectives of Samoan or Island born tama.

- Similar studies could be conducted in other regions of New Zealand with significant numbers of Pacific students. Together these studies would contribute to the body of knowledge and provide comparative study across New Zealand.

- There is a gap in understanding tama Samoa and their perceptions of masculinity and sexuality within their identity formation. It is possible that it is because these topics are tapu (sacred) in the wider Pacific context little research has been done regarding the perceptions of tama Samoa in this area.

- A comparative study of tama Samoa and teine Samoa (Samoan girls) could identify key issues within secondary school context.

This thesis has generated data about the three main themes: identity, sense of belonging, and decisions and aspirations about directions for the future. Each one of these themes could be further investigated as individual research topics as many sub themes were highlighted within each of the three themes; for example, complexity in identity or multiple identities. 


\section{Final Thoughts}

The findings of this study show that the contemporary tama Samoa is a fluid mixture of traditional and newly formulated identities developed through their lived experiences and through the influences of both people and place. I found the Tama Samoa to be confident young men, who demonstrate the ability to blend their traditional role of being a Samoan young man with a contemporary role of being a secondary school student. This traditional role has provided tama Samoa with the ability to develop new identity formations within secondary school, as well as building skills to maintain an appreciation of school experiences to access a sense of belonging, and direction for future aspirations.

It is anticipated that this study has achieved its aim of providing a space to give voice to tama Samoa experiences and perceptions as a way of gaining a more in-depth understanding of what they experience during their secondary education. I hope that this research contributes to a wider understanding of tama Samoa identity formations, how they manoeuvre through secondary school to maintain a sense of belonging, and how they identify key experiences of secondary that contribute to their future directions in the negotiation of their everyday social encounters. I am hopeful that these new understandings may be usefully applied in future educational settings.

I finish my thesis with a quote that signifies my place in this world and is my tribute to tama Samoa:

I am not an individual; I am an integral part of the cosmos. I share divinity with my ancestors, the land, the seas and the skies. I am not an individual, because I share my tofi (an inheritance) with my family, my village and my nation. I belong to my family and my family belongs to me. I belong to my village and my village belongs to me. I belong to my nation and my nation belongs to me. This is the essence of my belonging.

Tui Atua Tupua Tamasese Ta'isi Efi (2009).

Fa'afetai Tele Lava 


\section{REFERENCES}

Abdelal, R., Herrera, Y. M., Johnston, A. I., \& McDermott, R. (2006). Identity as a variable. Perspectives on Politics, 4(04), 695-711.

Abraham, J. (2008, January). Back to the future on gender and anti-school boys: A response to Jeffrey Smith. Gender and Education, 20(1), 89-94.

AIMHI. (2013). Achievement in Multicultural High Schools. Retrieved from http://www.aimhi.ac.nz/

Airini, Anae, M., Mila-Schaaf, K., with Coxon, E., Mara, D., \& Sanga, K. (2010). Teu le va: Relationships across research and policy: A collective approach to knowledge generation and policy development for action towards Pasifika education success. Wellington: Ministry of Education.

Alton-Lee, A. (2003). Quality teaching for diverse students in schooling: Best evidence synthesis. Wellington, New Zealand: Ministry of Education. Available at https://www.educationcounts.govt.nz/publications/series/2515/5959

Alton-Lee, A., \& Pratt, A. (2000). Explaining and addressing gender differences in the New Zealand compulsory school sector. Wellington: Ministry of Education.

Anae, M. (1997). Towards a NZ-born Samoan identity: Some reflections on "labels". Pacific Health Dialog, 4(2), 128-137.

Anae, M. (1998). Fofoa-i-vao-'ese: The identity journeys of NZ-born Samoans (Doctoral thesis, University of Auckland, Auckland, New Zealand). Retrieved from https://researchspace.auckland.ac.nz/docs/uoa-docs/rights.htm

Anae, M. (2001). The new Vikings of the sunrise: New Zealand-borns in the information age. In C. Macpherson, P. Spoonley, \& M. Anae (Eds.), Tangata o Te Moana Nui: The evolving identities of Pacific peoples in Aotearoal New Zealand (pp. 101-121). Palmerston North, New Zealand: Dunmore Press.

Anae, M. (2010). Research for better Pacific schooling in New Zealand: Teu le va-a Samoan perspective. MAl review, 1. Retrieved from http://www.review.mai.ac.nz.

Anae, M. (2012). All power to the people: Overstayers, dawn raids and the Polynesian Panthers. In S. Mallon, K. Mahina-Tuai, \& D. Salesa (Eds.), Tangata o Le Moana: New Zealand and the people of the pacific. Wellington, New Zealand: Te Papa Press. 
Anae, M., Coxon, E., Mara, D., Wendt-Samu, T., \& Finau, C. (2001). Pasifika education research guidelines. Wellington: Ministry of Education.

Atkinson, M. (2013). Leaders' perceptions of the practices and challenges that influence Pasifika achievement in New Zealand secondary schools (Doctoral dissertation). Unitec Institute of Technology, Auckland, New Zealand.

Averill, R. (2009). Teacher-student relationships in diverse New Zealand year 10 mathematics classrooms: Teacher care (Unpublished doctoral thesis Victoria University of Wellington, Wellington, New Zealand). Retrieved from http://hdl.handle.net/10063/1033

Babad, E. Y., Birnbaum, M., \& Benne, K. D. (1983). The social self: Group influences on personal influences. Beverly Hills, CA: Sage.

Bandura, A. (1977, March). Self-efficacy: Toward a unifying theory of behavioural change. Psychological Review, 84(2), 191-215.

Bandura, A. (1986). Social foundations of thought and action: A social cognitive theory. Prentice-Hall, Inc.

Bandura, A. (1997). Self-efficacy: The exercise of control. New York, NY: W. H. Freeman.

Barker, J. A. (1992). Paradigms: The business of discovering the future. New York, NY: Harper Collins.

Barwick, H. (2004). Young males: Strengths-based and male-focused approaches: $A$ review of research and best evidence. Wellington, New Zealand: Ministry of Youth Development.

Battistich, V., Solomon, D., Watson, M., \& Schaps, E. (1997). Caring school communities. Educational Psychologist, 32, 137-151.

Baumeister, R. F., \& Leary, M. R. (1995). The need to belong: Desire for interpersonal attachments as a fundamental human motivation. Psychological Bulletin, 117, 497-529.

Becker, B. E., \& Luthar, S. S. (2002). Social-emotional factors affecting achievement outcomes among disadvantaged students: Closing the achievement gap. Educational Psychologist, 37(4), 197-214.

Bernstein, B. (1974). Sociology and the sociology of education: A brief account. In J. Rex (Ed.), Approaches to sociology (pp. 145-159). London, England: Routledge \& Kegan Paul. 
Bishop, R. (2003). Changing power relations in education: Kaupapa Māori messages for 'mainstream' education in Aotearoa/New Zealand. Comparative Education, 39(2), 221-238.

Bishop, R., \& Berryman, M. (2009). The Te Kotahitanga effective teaching profile. Set: Research Information for Teachers, 2, 27-34.

Bishop, R., Berryman, M., Tiakiwai, S., \& Richards, C. (2003). Te kotahitanga: The experiences of year 9 and 10 Māori students in mainstream classrooms. Hamilton, New Zealand: Māori Education Research Institute (MERI), School of Education, University of Waikato.

Bishop, R., \& Glynn, T. (1999). Researching in Māori contexts: An interpretation of participatory consciousness. Journal of Intercultural Studies, 20(2), 167-182.

Boekaerts, M. (1993). Being concerned with well-being and with learning. Educational Psychologist, 28, 149-167.

Bonne, L. (2012). The effects of primary students' mathematics self-efficacy and beliefs about intelligence on their mathematics achievement: A mixed-methods intervention study (Unpublished PhD thesis). Victoria University of Wellington, Wellington, New Zealand.

Bosma, H. A., \& Kunnen, E. S. (2001). Determinants and mechanisms in ego identity development: A review and synthesis. Developmental Review, 21(1), 39-66.

Boland, R. (1985). Phenomenology: A preferred approach to research in information systems. In E. Mumford, R. A. Hirschheim, G. Fitzgerald, \& T. WoodHarper (Eds.), Research methods in information systems (pp. 193-201). Amsterdam, Netherlands: North-Holland.

Brayboy, B. M., \& Deyhle, D. (2010). Insider-outsider: Researchers in American Indian communities. Theory into Practice, 39(3), 163-169. doi: 10.1207/s15430421tip3903_7

Brown, R., \& Dean, L. (1997). What do youth want? Journal of Extension, 36.

Brown, R., \& Evans, W. P. (2002). Extracurricular activity and ethnicity: Creating greater school connection among diverse student populations. Urban Education, $37,41-58$.

Brownlee, J., Boulton-Lewis, G., \& Berthelsen, D. (2008). Epistemological beliefs in child care. British Journal of Educational Psychology, 78, 457-471. 
Bruner, J. S. (1996). The culture of education. Cambridge, MA: Harvard University Press.

Brutsaert, H., \& Bracke, P. (1994). Gender context of the elementary school: Sex differences in affective outcomes. Educational Studies, 20(1), 3-11.

Carpenter, V. (2001). Curriculum and the (re)production of education. In V. Carpenter, H. Dixon, E. Rata, \& C. Rawlinson (Eds.), Theory in practice for educators (Chapter 5, pp.109-136). Palmerston North, New Zealand: Dunmore Press Ltd.

Cahill, F. (2006). Crossing the road from home to secondary school: A conversation with Samoan parents. Waikato Journal of Education, 12, 57-71.

Callister, P., \& Didham, R. (2008). Emerging demographics and socioeconomic features of the Pacific population in New Zealand (pp. 13-40). In A. Bisley (Ed.), Pacific interactions: Pacific in New Zealand: New Zealand in Pacific. Wellington, New Zealand: Institute of Policy Studies, Victoria University of Wellington.

Chan, E., \& Elevitch, C. R. (2006). Cocos nucifera (coconut). Species Profiles for Pacific Island Agroforestry, 2, 1-27.

Chu, C., Glasgow, A., Rimoni, F., Hodis, M., \& Meyer, L. (2013). An analysis of recent Pasifika education research literature to inform improved outcomes for Pasifika learners (Report to the Ministry of Education). Wellington, New Zealand: Ministry of Education.

Clarke, S. (2008). Culture and identity. In T. Bennett \& J. Frow (Eds.), The SAGE handbook of cultural analysis (pp. 510-530). London, England: Sage. http://dx.doi.org/10.4135/9781848608443.n25

Cohen, L., Manion L., \& Morrison K. (2007). Research Methods in Education. London, England: Routledge.

Combs, A. W. (1962). Perceiving, behaving, becoming: A new focus for education. Washington, DC: National Education Association.

Connell, J. P., \& Wellborn, J. G. (1991). Competence, autonomy, and relatedness: A motivational analysis of self-system processes. The Minnesota Symposia on Child Development: Self-Processes and Development, 23, 43-77.

Cook-Sather, A., \& Reisinger, O. (2001). Seeing the students behind the stereotypes: The perspectives of three preservice teachers. The Teacher Educator, 37(1), 1626. 
Cowley-Malcolm, E. (2013). Perceptions of Samoan parents from a small town in New Zealand on parenting, childhood aggression, and the CD-ROM 'Play Nicely' (Unpublished PhD thesis). Victoria University of Wellington, Wellington, New Zealand.

Covey, S. R. (1989). The 7 habits of highly effective people. New York, NY: Simon and Shuster.

Coxon, D. E., Anae, M., Mara, D., Wendt-Samu, T., \& Finau, C. (2002). Literature Review on Pacific Education issues (Final report). Wellington, New Zealand: Ministry of Education.

Creswell, J. W. (2013). Research design: Qualitative, quantitative, and mixed methods approaches (4th ed.). Los Angeles, CA: SAGE.

Cretchley, P. (2007). Does computer confidence relate to levels of achievement in ICT-enriched learning models? Education and Information Technologies, 12(1), 29-39.

Crocombe, R. G., Slatter, C., \& Tupouniua, S. (Eds.). (1975). The Pacific way: Social issues in national development. Suva, Fiji: South Pacific Social Sciences Association.

Deci, E. L., \& Ryan, R. M. (1985). Intrinsic motivation and self-determination in human behavior. New York, NY: Plenum.

Deci, E. L., \& Ryan, R. M. (1991). A motivational approach to self: Integration in personality. Nebraska Symposium on Motivation: Perspectives on Motivation, 38, 237-288.

Descombe, M. (2003). The good research guide: For small-scale research projects (2nd ed.). Maidenhead, England: Open University Press.

Dorman, J. P., \& Ferguson, J. M. (2004). Associations between students' perceptions of mathematics classroom environment and self-handicapping in Australian and Canadian high schools. McGill Journal of Education, 39(1), 69-86.

DuBois, D. L., Burk-Braxton, C., Swenson, L. P., Tevendale, H. D., \& Hardesty, J. L. (2002). Race and gender influences on adjustment in early adolescence: Investigation of an integrative model. Child Development, 73(5), 1573-1592.

Eccles, J. S., Barber, B. L., Stone, M., \& Hunt, J. (2003). Extracurricular activities and adolescent development. Journal of social issues, 59(4), 865-889. 
Education Counts. (2014). Student numbers. Retrieved from https://www.educationcounts.govt.nz/statistics/schooling/student-numbers

Education Review Office. (2008). Boys' education: Good practice in secondary schools. Retrieved from http://www.ero.govt.nz/publications/boys-educationgood-practice-in-secondary-schools/

Education Review Office. (2010). Promoting Pacific student achievement schools' progress. Retrieved from http://ero.govt.nz/content/download/139781/2329475/version/31/file/Promoti $\underline{\text { ng+Pacific+Student+Achievement++Schools++Progress+June+2010.pdf }}$

Education Review Office. (2011). Secondary schools and alternative education. Retrieved from http://www.ero.govt.nz/National- Reports/Secondary-Schoolsand-Alternative-Education-April-2011

Education Review Office. (2012). Improving education outcomes for Pacific learners. Wellington, New Zealand: Author.

Education Review Office. (2013). Making connections for Pacific learners' success, November 2013. Retrieved from http://www.ero.govt.nz/National$\underline{\text { Reports/Making-Connections-for-Pacific-Learners-Success-November-2013 }}$

Efi, T. T. T., \& Suaalii, T. M. (2009). Su'esu'e manogi - In search of fragrance: Tui Atua Tupua Tamasese Ta'isi and the Samoan indigenous reference. Samoa: Centre for Samoan Studies, National University of Samoa.

Elliot, R. (1984). "Metaphor, imagination and conceptions of education". In K. Sanga, \& K. Thaman (Eds.), Metaphors of education. Victoria University of Wellington, New Zealand.

Erikson, E. H. (1959). Identity and the life cycle: Selected papers. Psychological Issues, 1-4.

Erikson, E. H. (Ed.). (1963). Youth: Change and challenge. New York, NY: Basic Books.

Erikson, E. H. (1968). Identity: Youth, and crisis (No. 7). New York, NY: W.W. Norton \& Company.

Erikson, E. H. (1970). Reflections on the dissent of contemporary youth. Daedalus: Journal of the American Academy of Arts and Sciences, 99(1), 154-176. 
Evans, B. F. (2011). Teaching practices that support high achievement in the education of pacific boys (Master's thesis, Unitec Institute of Technology, Auckland, New Zealand). Retrieved from http://unitec.researchbank.ac.nz/handle/10652/1734

Fairbairn-Dunlop, P. (2013). Pacific identities and well-being: Cross-cultural perspectives. Journal of the Polynesian Society, 122(4), 393-395.

Fairbairn-Dunlop, T. P. (2010). "He's won, but he's lost it". AlterNative: An International Journal of Indigenous Peoples, 6(2), 143-154.

Fairbairn-Dunlop, T. P. (2010). Pacific youth connecting through polly. In C. Ward, J. Liu, P. Fairbairn-Dunlop, \& A. Henderson (Eds.), Youth voices, youth choices: Identity, integration and social cohesion in culturally diverse Aotearoa/ New Zealand. Wellington, New Zealand: Centre for Applied Cross-Cultural Research \& Va'aomanu Pasifika, Victoria University of Wellington.

Fearon, J. D. (1999). What is identity (As we now use the word)? Unpublished manuscript, Department of Political Science, Stanford University, Stanford, CA.

Ferguson, P., Gorinski, R., Wendt-Samu, T., \& Mara, D. (2008). Literature review on the experiences of Pasifika learners in the classroom. Wellington, New Zealand: Ministry of Education.

Fine, G. A. (2004). Adolescence as cultural toolkit: High school debate and the repertoires of childhood and adulthood. The Sociological Quarterly, 45(1), 1-20.

Finlay, L. (2005). Reflexive embodied empathy: A phenomenology of participant researcher intersubjectivity. The Humanistic Psychologist, 33(4), 271-292.

Finn, J. D. (1989). Withdrawing from school. Review of Educational Research, 59, 117-142.

Fletcher, J., Parkhill, F., \& Fa'afoi, A. (2005). What factors promote and support Pasifika students in reading and writing. Teaching and Learning, 2.

Fletcher, J., Parkhill, F., \& Harris, C. (2011). Supporting young adolescent students from minority cultural groups who are underachieving in learning. Support for Learning, 26(3), 122-126.

Fletcher, J., Parkhill, F., Fa'afoi, A., \& O'Regan, B. (2009). Pasifika students: Teachers and parents voice their perceptions of what provides supports and barriers to Pasifika students' achievement in literacy and learning. Teaching and Teacher Education, 25(1), 24-33. 
Fresno-Calleja, P. (2016). Between marginality and marketability: Contesting representations of diasporic Pacific identities. Nordic Journal of English Studies, 15(1), 25-45.

Friedman, J. (2000). Americans again, or the new age of imperial reason? Global elite formation, its identity and ideological discourses. Theory, Culture \& Society, $17(1), 139-146$.

Furrer, C. J., Skinner, E. A., \& Pitzer, J. R. (2014). The influence of teacher and peer relationships on students' classroom engagement and everyday motivational resilience. National Society for the Study of Education, 113(1), 101-123.

Furrer, C., \& Skinner, E. (2003). Sense of relatedness as a factor in children's academic engagement and performance. Journal of Educational Psychology, 95(1), 148-162.

Furrer, C. J., Skinner, E. A., Pitzer, J. R. (2014). The influence of teacher and peer relationships on students' classroom engagement and everyday resilience. National Society for the Study of Education, 113(1), 101-123.

Gegeo, D. W. (2008, April). Shifting paradigms in Pacific scholarship: Towards islandbased methodologies, epistemologies and pedagogies. Paper presented at Building Pacific Research Capacity and Scholarship Fono 2008, Fale Pasifika, University of Auckland, New Zealand.

Gerber, S. B. (1996). Extracurricular activities and academic achievement. Journal of Research \& Development in Education, 30(1), 42-50.

Gibbs, L. (2007). Applying research to making life-affecting judgments and decisions. Research on Social Work Practice, 17(1), 143-150.

Giorgi, A., \& Giorgi, B. (2004). Phenomenology. In J. Smith (Ed.), Qualitative psychology: A practical guide to research methods (pp. 25-50). London, England: Sage.

Glynn, T., \& Berryman, M. (2005). Understanding and responding to students' behaviour difficulties. Learners with special needs in Aotearoa New Zealand, 3, 294-315.

Goldring, M. (2006). Weaving language with identity; The story of Samoan secondary students: Letoga: A precious thing (Master's thesis, Christchurch College of Education, Christchurch, New Zealand). Retrieved from http://ir.canterbury.ac.nz/bitstream/10092/1053/1/thesis fulltext.pdf 
Good, T. L., \& Weinstein, R. S. (1986). Schools make a difference: Evidence, criticism, and new directions. American Psychologist, 41(10), 1090.

Goodenow, C. (1992). Strengthening the links between educational psychology and the study of social contexts. Educational Psychologist, 27(2), 177-196.

Goodenow, C. (1993a). Classroom belonging among early adolescent students: Relationships to motivation and achievement. Journal of Early Adolescence, 13, 21-43.

Goodenow, C. (1993b). The psychological sense of school membership among adolescents: Scale development and educational correlates. Psychology in the Schools, 30, 70-90.

Gorinski, R., \& Fraser, C. (2006). Literature review on the effective engagement of Pasifika parents and communities in education. Wellington, New Zealand: Research Division, Ministry of Education.

Graham, J., Meyer, L. H., McKenzie, L., McClure, J., \& Weir, K. F. (2010). Māori and Pacific secondary student and parent perspectives on achievement, motivation and NCEA. Assessment Matters 2, 132-157.

Griffin, S. (1997). Trouble teens: Managing disorders of transition and consumption. Feminist Review, 55, 4-21.

Guba, E. G., \& Lincoln, Y. S. (1994). Competing paradigms in qualitative research. In N. K. Denzin \& Y. S. Lincoln (Eds.), Handbook of qualitative research (pp. 105117). Thousand Oaks, CA: Sage.

Gullotta, T. P., Adams, G. R., \& Markstrom, C. A. (1999). The adolescent experience (4th ed.). New York, NY: Academic Press.

Hall, S. (1990). Cultural identity and diaspora. In J. Rutherford (Ed.), Identity, community culture (pp. 222-237). London, England: Lawrence and Wishart.

Hall, S. (1991). Ethnicity: Identity and difference. Radical America, 23(4), 9-20.

Hamilton, M. (2006). Listening to student voice. Curriculum Matters, 2, 128.

Hammersley, M., \& Atkinson, P. (1995). Ethnography: Principles in practice (2nd ed.). London, England: Routledge.

Harkess, C., Murray, S., Parkin, M., \& Dalgety, J. (2005). Pasifika achievement: Engagement and choice. Retrieved from Education Counts website: http://www.educationcounts.govt.nz/ data/assets/pdf file/0019/6373/pasifika a chievement engagement and choice.pdf 
Harris, H. W., Blue, H. C., \& Griffith, E. E. H. (1995). Racial and ethnic identity: psychological development and creative expression. New York, NY: Routledge.

Harris, J. (1996). The nurture assumption. New York, NY: The Free Press.

Hartnett, S. (2007). Does peer group identity influence absenteeism in high school students? The High School Journal, 91(2), 35-44.

Hattie, J. (1992). Measuring the effects of schooling. Australian Journal of Education, 36(1), 5-13.

Hattie, J. (2003). Teachers make a difference: What is the research evidence? Melbourne, VIC, Australia: Australian Council for Educational Research.

Hawk, K., Cowley, E. T., Hill, J., \& Sutherland, S. (2002). The importance of the teacher/student relationship for Māori and Pasifika students. Set: Research Information for Teachers, 3, 44-49.

Hawk, K., \& Hill, J. (1998, December). Teaching students under stress: Implications for schools and teachers in multi-cultural schools. A paper presented to NZARE Conference, Dunedin, New Zealand.

Hill, J., \& Hawk, K. (2000). Making a difference in the classroom: Effective teaching practice in low decile, multicultural schools (AIMHI report to the Ministry of Education). Wellington, New Zealand: Ministry of Education, Research Division.

Hawk, K., Hill, J., \& Seabourne, T. (1996). Towards making achieving cool: Achievement in Multi Cultural High Schools (AIMHI) (Report). Wellington, New Zealand: The Ministry of Education.

Heap, J. L., \& Roth, P. A. (1973). On Phenomenological Sociology. American Sociological Review, 38(3), 354-367.

Heron, J. (1996). Co-operative inquiry: Research into the human condition. London, England: Sage.

Hodgkin, R. (1998). Children's voices in the corridors of power: The case for a minister for children. In D. Utting (Ed.), Children's services now and in the future. London, England: National Children's Bureau.

Hoffman, R. (1983). Recent research on metaphor. Semiotic Inquiry, 3, 35-62.

Hofkins, D. (2008). Enriching the experience of schooling: A commentary by the teaching and learning research programme. Retrieved from http://docplayer.net/7295759-Enriching-the-experience-of-schooling-acommentary-by-the-teaching-and-learning-research-programme.html 
Hogg, M. A. (2006). Social identity theory. In P. J. Burke (Ed.), Contemporary social psychological theories (pp. 111-1369). Stanford, California, CA: Stanford University Press.

Hogg, M. A., \& Abrams, D. (1988). Social identifications: A social psychology of intergroup relations and group processes. London, England: Routledge.

Holley, D., \& Dobson, C. (2008). Encouraging student engagement in a blended learning environment: The use of contemporary learning spaces. Learning, Media and Technology, 33(2), 139-150.

Houtenville, A. J., \& Conway, K. S. (2008). Parental effort, school resources, and student achievement. Journal of Human resources, 43(2), 437-453.

Hughes, J. N., Gleason, K. A., \& Zhang, D. (2005). Relationship influences on teachers' perceptions of academic competence in academically at-risk minority and majority first grade students. Journal of School Psychology, 43(4), 303-320.

Hunkin-Tuiletufuga, G. (2001). Pasefika languages and pasefika identities: Contemporary and future challenges. In C. Macpherson, P. Spoonley, \& M. Anae (Eds.), Tangata o te moana nui: The evolving identities of pacific peoples in Aotearoa/New Zealand (pp.196-211). Palmerston North, New Zealand: Dunmore Press.

Hurtado, S., \& Carter, D. F. (1997). Effects of college transition and perceptions of the campus racial climate on Latino college students' sense of belonging. Sociology of Education, 70, 324-345.

Hyndman, R. M. (2007). Connecting school culture to boys' learning: An investigation into how school culture affects boys' learning in one New Zealand primary school (Doctoral dissertation, The University of Waikato, Hamilton, New Zealand). Retrieved from http://researchcommons.waikato.ac.nz/handle/10289/2322

Irwin, M. (2007). Hear our boys' voices: What hinders and enhances their academic success (Unpublished doctoral dissertation). Massey University, Palmerston North, New Zealand.

Irwin, M. (2009). Educating boys: Helping Kiwi boys to succeed at school. Auckland, New Zealand: HarperCollins. 
Jackson, C., \& Dempster, S. (2009). 'I sat back on my computer... with a bottle of whisky next to me': Constructing 'cool' masculinity through 'effortless' achievement in secondary and higher education. Journal of Gender Studies, 18(4), 341-356.

James, A. N. (2007). Gender differences and the teaching of mathematics. Inquiry, 12(1), 14-25.

Jenkins, R. (1996). Social identity. London, England: Routledge.

Jenson, J. (2006). The LEGO paradigm and new social risks: Consequences for children. In J. Lewis (Ed.), Children, changing families and welfare states (pp. 27-50). Northampton, MA: Edward Elgar.

Johansson-Fua, S., Ruru, D., Sanga, K., Walker, K., \& Ralph, E. (2012). Creating mentorship metaphors: Pacific Island perspectives. Learning Landscapes, 6(1), 241-259.

Johnson, R. D. (2005). An empirical investigation of sources of application-specific computer-self-efficacy and mediators of the efficacy-performance relationship. International Journal of Human-Computer Studies, 62(6), 737-758.

Johnson, R. B., \& Christensen, L. B. (2004). Educational research: Quantitative, qualitative, and mixed approaches. Boston, MA: Allyn \& Bacon.

Jones, A. (1991). "At school I've got a chance": Culture/privilege: Pacific Islands and pakeha girls at school. Palmerston North, New Zealand: Dunmore Press.

Kalavite, T. (2010). Fononga 'A fakahalafononga: Tongan students' journey to academic achievement in New Zealand tertiary education (Doctoral dissertation, University of Waikato, Hamilton, New Zealand). Retrieved from http://researchcommons.waikato.ac.nz/handle/10289/4159

Keiningham, T., Aksoy, L., \& Williams, L. (2009). Why loyalty matters. Dallas, TX: Benbella Books Inc.

Kelly, K. M. (2001). Individual differences in reactions to rejection. In M. R. Leary (Ed.), Interpersonal rejection (pp. 291-315). New York, NY: Oxford University Press.

Kettle, M. (2011). Academic practice as explanatory framework: Reconceptualising international student academic engagement and university teaching. Discourse: Studies in the cultural politics of education, 32(1), 1-14. 
Kleiman, S. (2004). Phenomenology: to wonder and search for meanings. Nurse Researcher, 11(4), 7-19.

Klein, H. K., \& Myers, M. D. (1999). A set of principles for conducting and evaluating interpretive field studies in information systems. MIS quarterly, 23(1), 67-93.

Koloto, 'A. H., \& Sharma, S. V. (2005). Pasifika women's economic wellbeing study: Final Report. Auckland, New Zealand: Koloto \& Associates.

Krebs, C. J. (1999). Ecological methodology (Vol. 620). Menlo Park, California, CA: Benjamin/Cummings.

Kuhn, T. S. (1962). Logic of discovery or psychology of research. In I. Lakatos \& A. E. Musgrade (Eds.), Criticism and the growth of knowledge (pp. 1-23). London, England: Cambridge University Press.

Kupa, K. (2009). Te Vaka Atafaga: A Tokelau assessment model for supporting holistic mental health practice with Tokelau people in Aotearoa, New Zealand. Pacific Health Dialog, 15(1), 156-163.

Kvale, S. (1996) Interviews: An introduction to qualitative research interviewing. Thousand Oaks, CA: Sage.

Lashbrook, J. T. (2000). Fitting in: Exploring the emotional dimension of adolescent peer pressure. Adolescence-San Diego, 35, 747-758.

Lashlie, C. (2005). He'll be ok: Growing gorgeous boys into good men. Auckland, New Zealand: HarperCollins.

Lerner, R. M. (2002). Concepts and theories of human development (3rd ed.). Mahwah, NJ: Lawrence Erlbaum.

Levin, B. (2000). Putting students at the centre in education reform. Journal of Educational Change, 1(2), 155-172.

Lichtman, M. (2006). Qualitative research in education: A user's guide. London, England: Sage.

Lincoln, Y. S., \& Denzin, N. K. (2005). Epilogue: The eighth and ninth moments: Qualitative research in/and the fractured future. Handbook of Qualitative Research, 3, 1103-114.

Lipine, T. (2010). Education of secondary Samoan students in New Zealand: The road to success (Doctoral thesis). Victoria University of Wellington, Wellington, New Zealand. 
Lodico, M. G., Spaulding, D. T., \& Voegtle, K.H. (2006). Methods in educational research: From theory to practice. San Francisco, CA: Jossey-Bass.

Lui, D. (2003). Family-a Samoan perspective. Mental Health Commission.

Marecek. J., \& Magnusson, E. (2015). Doing interview-based qualitative research: $A$ learner's guide. Cambridge, England: Cambridge University Press.

MacDonald, D. (2004). Collaborating with students' spirituality. Professional School Counseling, 7(5), 293-300.

Maestas, R., Vaquera, G. S., \& Munoz Zehr, L. (2007). Factors impacting sense of belonging at a hispanic-serving institution. Journal of Hispanic Higher Education, 6, 237-256.

Manu'atu, L. (2000). Tuli Ke Ma'u Hono Ngaahi Mālie: Pedagogical possibilities for Tongan students in New Zealand secondary schooling (Doctoral thesis, The University of Auckland, New Zealand). Retrieved from ttp://hdl.handle.net/2292/715

Manueli, K. T. (2012). Pasifika tertiary students' use of information and communication technologies (Doctoral thesis, Victoria University of Wellington, New Zealand). Retrieved from http://researcharchive.vuw.ac.nz/xmlui/handle/10063/2480

Manuela, S., \& Sibley, C. G. (2015). Why do Pacific people with multiple ethnic affiliations have poorer subjective wellbeing? Negative ingroup affect mediates the identity tension effect. Social Indicators Research, 115(1), 319-336.

Marcia, J. E. (1980). Identity in adolescence. In J. Edelson (Eds.), Handbook of adolescent psychology (pp. 159-187). New York, NY: Wiley.

Marcia, J. E. (1993). The ego identity status approach to ego identity. In J. E. Marcia, A. S. Waterman, D. R. Matteson, S. L. Archer, \& J. L. Orlofsky (Eds.), Ego identity: A handbook for psychosocial research (pp. 3-21). New York, NY: Springer. doi: 10.1007/978-1-4613-8330-7_1

Marshall, C., \& Rossman, G. B. (2006). Designing qualitative research (4th ed.). Los Angeles, LA: Sage Publications.

Marshall, C., \& Rossman, G. B. (2011). Designing qualitative research (5th ed.). Los Angeles, LA: Sage Publications.

Maslow, A. (1954). Motivation and personality. New York, NY: Harper \& Row.

Maslow, A. (1968). Toward a psychology of being. New York, NY: Van Nostrand Reinhold Company. 
Massoni, E. (2011). Positive effects of extra-curricular activities on students. ESSAI, 9(1), 27.

McClelland, D. C. (1987). Human Motivation. Cambridge, England: Cambridge University Press.

McClure, J., Meyer, L. H., Garisch, J., Fischer, R., Weir, K. F., \& Walkey, F. H. (2011). Students' attributions for their best and worst marks: Do they relate to achievement? Contemporary Educational Psychology, 36(2), 71-81.

McCrae, R. R., \& Costa Jr, P. T. (1997). Personality trait structure as a human universal. American Psychologist, 52(5), 509.

Ministry of Education. (2000). Pasifika education plan 2001-2005. Wellington, New Zealand: Author.

Mitchell, D., \& Chapman, P. (2001). Researching with men: Ideas and strategies for doing better. NZ Research in Early Childhood Education, 4, 165-175.

McMillan, A. (2012). Exploring the role of the rock and water programme in the improvement of Māori and Pacifika boys' engagement with school (Master's thesis, Victoria University of Wellington, Wellington, New Zealand). Retrieved from http://hdl.handle.net/10063/2520

Mila-Schaaf, K. (2010). Polycultural capital and the Pasifika second generation: negotiating identities in diasporic spaces (Doctoral thesis, Massey University, Albany, New Zealand). Retrieved from http://mro.massey.ac.nz/bitstream/handle/10179/1713/02 whole.pdf?sequence= 1\&isAllowed $=y$

Ministry of Education. (2003). Education statistics of New Zealand for 2003. Wellington: New Zealand: Author.

Ministry of Education. (2007). Pasifika education plan monitoring report. Wellington: New Zealand: Author.

Ministry of Education. (2008). A study of students' transition from primary to secondary schooling. Wellington: New Zealand: Author.

Ministry of Education. (2009). Pasifika education plan 2009-2012. Wellington: New Zealand: Author.

Ministry of Education. (2012). Pasifika education research priorities: Using research to realise our vision for Pasifika learners. Wellington, New Zealand: Author. 
Ministry of Education. (2015). Regulatory impact statements (RIS). Retrieved from http://www.education.govt.nz/ministry-of-education/regulatory-impactstatements/

Ministry of Education. (2015a). Pasifika education. Retrieved from http://www.education.govt.nz/quick-links/pasifika/

Ministry of Women's Affairs. (1996). The full picture. Te tirohanga whanui: Guidelines for gender analysis. Wellington, New Zealand: Ministry of Women's Affairs.

Mulitalo-Lauta, P. T. (2001). Pacific peoples' identities and social services in New Zealand: Creating new options. Tangata o te moana nui: The evolvingidentities of Pacific peoples in Aotearoa/New Zealand. Palmerston North, New Zealand: Dunmore Press Ltd.

Mitchell, D., \& Chapman, P. (2001). Researching with men: Ideas and strategies for doing better. NZ Research in Early Childhood Education, 4, 165-174.

Muller, C., Katz, S. R., \& Dance, L. J. (1999). Investing in teaching and learning dynamics of the teacher-student relationship from each actor's perspective. Urban Education, 34(3), 292-337.

Munro, R. L. (2011). Narratives of teenage boys: Constructing selfhood and enacting identities (Doctoral thesis (Clinical Psychology)). Massey University, Albany, New Zealand.

Murray, H. A. (1938). Explorations in personality: A clinical and experimental study of fifty men of college age. New York. NY: Oxford University Press.

Nabobo-Baba, U. (2004). Research and Pacific indigenous peoples: Silenced pasts and challenged futures. In T. Baba, O. Mahina, N. Williams, \& U. Nabobo-Baba (Eds.), Researching the Pacific and indigenous peoples: Issues and perspectives (pp. 17-32). Auckland, New Zealand: Centre for Pacific Studies, The University of Auckland.

Nakhid, C. (2003). "Intercultural" perceptions, academic achievement, and the identifying process of Pacific Islands students in New Zealand schools. The Journal of Negro Education, 72(3), 297-318.

Newman, D. (2003). On borders and power: A theoretical framework. Journal of Borderlands Studies, 18(1), 13-25. 
New Zealand Qualifications Authority. (2015c). Secondary school statistics. Retrieved from http://www.nzqa.govt.nz/studying-in-new-zealand/secondary-schooland-ncea/find-information-about-a-school/secondary-school-statistics/

Noor, K. B. (2008). Case study: A strategic research methodology. American journal of Applied Sciences, 5(11), 1602-1604.

OECD. (2001). Knowledge and skills for life: First results from PISA 2000. Programme for International Student Assessment. Retrieved from http://www.oecdilibrary.org/education/knowledge-and-skills-for-life 9789264195905-en

OECD. (2002). Education at a glance. OECD indicators 2002. Retrieved from http://www.oecd-ilibrary.org/education/education-at-a-glance-2002 eag-2002-en

Ormond, A. (2001) 'Voice of Maori youth: The other side of silence'. International Journal of Critical Psychology, 4(2), 49-60.

Osterman, K. F. (2000). Students' need for belonging in the school community. Review of Educational Research, 70, 323-367.

Otsuka, S. (2005). Talanoa research: Culturally appropriate design in Fiji. Proceedings of the Australian Association for Research in Education (AARE) 2005, International Education Research Conference: Creative Dissent- Constructive Solutions. Melbourne, Australia. Retrieved from www.aare.edu.au/05pap/ots05506.Pdf.

Otunuku, M. A. (2011). How can talanoa be used effectively in an indigenous research methodology with Tongan people? Pacific-Asian Education, 23(2), 43-52.

Pajares, F., \& Urdan, T. C. (2006). Self-efficacy beliefs of adolescents. Greenwich, Connecticut, CT: IAP.

Para, E. A. (2008). The role of social support in identity formation: A literature review. Graduate Journal of Counseling Psychology, 1(1), 9.

Patton, M. Q. (2002). Qualitative research and evaluation methods (3rd ed.). London, England: Sage.

Peterson, C. (1989). Looking forward through the lifespan - developmental psychology. New York, NY: Prentice Hall.

Phinney, J. S. (1989). Stages of ethnic identity development in minority group adolescents. The Journal of Early Adolescence, 9(1-2), 34-49. 
Phinney, J. S. (1990). Ethnic identity in adolescents and adults: Review of research. Psychological Bulletin, 108(3), 499-514.

Phinney, J. S. (1993). A three-stage model of ethnic identity development in adolescence. Ethnic identity: Formation and transmission among Hispanics and other minorities, 61, 79.

Prescott, S. M. (2008). Using talanoa in Pacific business research in New Zealand: Experiences with Tongan entrepreneurs. AlterNative: An International Journal of Indigenous Scholarship, 4(1), 127-148.

Price, G. G. (1992). Using quantitative methods to explore multicultural education. In C. A. Grant (Ed.), Research and Multicultural Education: From the margins to the mainstream (pp. 58-70). Washington, DC: The Falmer Press.

Pulotu-Endemann, F. K. (2001). Fonofale: Model of Health. Retrieved from http://www.hauora.co.nz/resources/Fonofalemodelexplanation.pdf

Pulotu-Endemann, F. K., Crawley, L., \& Stanley-Findley, R. T. U. (1995). Strategic directions for the mental health services of Pacific islands people. Wellington, New Zealand: Ministry of Health.

Quaglia, R. J., \& Cobb, C. D. (1996). Toward a theory of student aspirations. Journal of Research in Rural Education, 12(3), 127-132.

Reyna, V. F., \& Rivers, S. E. (2008). Current theories of risk and rational decision making. Developmental review: $D R, 28(1), 1$.

Richards, L. (2005). Handling qualitative data. London, England: Sage.

Rimoni, F. (2012). Identity and its relationship to place. Available at SSRN: http://ssrn.com/abstract $=1971462$

Roeser, R. W., Eccles, J. S., \& Sameroff, A. J. (1998). Academic and emotional functioning in early adolescence: Longitudinal relations, patterns, and prediction by experience in middle school. Development and Psychopathology, 10, 321352.

Roeser, R. W., Midgley, C., \& Urdan, T. C. (1996). Perceptions of the school psychological environment and early adolescents' psychological and behavioral functioning in school: The mediating role of goals and belonging. Journal of Educational Psychology, 88, 408-422.

Rogers, C. R. (1951). Client-centered therapy: Its current practice, implications, and theory. Boston, MA: Houghton Mifflin. 
Rossman, G. B., \& Rallis, S. F. (2010). Everyday ethics: Reflections on practice. International Journal of Qualitative Studies in Education, 23(4), 379-391.

Rubie-Davies, C. M., Peterson, E., Irving, E., Widdowson, D., \& Dixon, R. (2010). Expectations of achievement: Student, teacher and parent perceptions. Research in Education, 83, 36-53.

Rudduck, J. (2007). Student voice, student engagement, and school reform. In D. Thiessen \& A. Cook-Sather (Eds.), International handbook of student experience in elementary and secondary school (pp. 587-610). Dordrecht, Netherlands: Springer.

Ryan, R. M. (1993). Agency and organization: Intrinsic motivation, autonomy and the self in psychological development. In J. E. Jacobs (Ed.), Nebraska symposium on motivation, 1992: Developmental perspectives on motivation (Vol. 40, pp. 1 56). Lincoln, NE, US: University of Nebraska Press.

Sadala, M. L. A., \& Adorno, R. D. C. F. (2002). Phenomenology as a method to investigate the experience lived: A perspective from Husserl and Merleau Ponty's thought. Journal of Advanced Nursing, 37(3), 282-293.

Sanday, P. R. (2007). Fraternity gang rape: Sex, brotherhood, and privilege on campus. New York, NY: NYU Press.

Sanga, K. (2013). Indigenous Pacific emerging educational metaphors. The International Journal of Diversity in Education, 12(4).

Sauni, S. L. (2011). Samoan research methodology: The ula-a new paradigm. PacificAsian Education, 23(2), 53-64.

Schmader, T., \& Johns, M. (2003). Converging evidence that stereotype threat reduces working memory capacity. Journal of Personality and Social Psychology, 85(3), 440.

Schunk, D. H., \& Pajares, F. (2009). Self-efficacy theory. In K. R. Wentzel \& A. Wigfield (Eds.), Handbook of motivation at school (pp. 35-53). New York, NY: Routledge.

Scott, D. (2014). How does New Zealand's education system compare? OECD's Education at a Glance 2014 (Report to Ministry of Education). Wellington, New Zealand: Ministry of Education.

Shah, S. (2003). The researcher/interviewer in intercultural context: A social intruder! British Educational Research Journal, 30(4), 549-575. 
Sheets, R. (2005). Ethnic identity and its relationship with school achievement. Multicultural Education, 13(4), 58-60.

Shields, C. M., Bishop, R., \& Mazawi, A. E. (2005). Pathologizing practices: The impact of deficit thinking of education. New York, NY: Peter Lang.

Shortcliff, A. (2014). Sabbatical report: Strategies for improving Maori and Pacifica student outcomes. Retrieved from http://www.educationalleaders.govt.nz/content/download/64663/533778/file/Andr ew\%20Shortcliffe\%20Sabbatical\%20Report\%202014\%20\%20Improving\%20Maori\%20and\%20Pasifica\%200utcomes.pdf.

Silipa, S. (2008). Fanaafi o fa'amalama: A light within the light: Nurturing coolness and dignity in Samoan students' secondary school learning in Aotearoa/New Zealand (Doctoral thesis, College of Education, University of Canterbury, Christchurch, New Zealand). Retrieved from http://hdl.handle.net/10092/2886

Siope, A. (2011). The schooling experiences of Pasifika students. Teaching and Learning 10(3), 11-15.

Siope, S. A. M. (2010). Children of the migrant dreamers: Comparing the experiences of Pasifika students in two secondary schools attempting to be culturally responsive to mine from a generation ago (Master's thesis, University of Waikato, Waikato, New Zealand). Retrieved from http://hdl.handle.net/10289/5003

Skinner, E. A. (1995). Perceived control, motivation, \& coping (Vol. 8). London, England: Sage.

Smith, A., \& Osborn, M. (2004). Phenomenology. In J. Smith (Ed.), Qualitative psychology: A practical guide to research methods (pp. 25-50). London, England: Sage.

Smith, J. A., Larkin, M., \& Flowers, P. (2009). Interpretative phenomenological analysis: Theory, method and research. Los Angeles, LA: Sage.

Smith, L. T. (1999). Decolonising methodologies: Research and indigenous people. London, England: Zed Books.

Smyth, J. (2006). 'When students have power': Student engagement, student voice, and the possibilities for school reform around 'dropping out' of school. International Journal of Leadership in Education, 9(4), 285-298.

Spano, S. (2003). Adolescent brain development. Youth Studies Australia, 22(1), 36. 
Spano, S. (2004). Research facts and findings. Retrieved from http://libvolume4.xyz/homescience/bsc/semester5/humandevelopment2hdfs4/ad olescence/adolescencetutorial1.pdf.

Statistics New Zealand and Ministry of Pacific Island Affairs. (2010). Demographics of New Zealand's Pacific population. Wellington: Author.

Statistics New Zealand. (2013). Census QuickStats about culture and identity. Retrieved from http://www.stats.govt.nz/Census/2013-census/profile-andsummary-reports/quickstats-culture-identity.aspx

Statistics New Zealand. (2014). National population estimates: At 30 June 2014. Retrieved from http://www.stats.govt.nz/browse for stats/population/estimates and projections Inational-population-estimates-info-releases.aspx

Statistics New Zealand. (2015). 2013 Census of population and dwellings. Retrieved from http://www.stats.govt.nz/Census.aspx

Statistics New Zealand. (2008). Pacific profiles: 2006. Retrieved from http://www.stats.govt.nz/Census/about-2006-census/pacific-profiles-2006.aspx

Steele, C. M. (1997). A threat in the air: How stereotypes shape intellectual identity and performance. American Psychologist, 52(6), 613.

Steinberg, L., \& Morris, A. S. (2001). Adolescent development. Journal of Cognitive Education and Psychology, 2(1), 55-87.

Suppes, P. (1974). The place of theory in educational research. Educational Researcher, 3(6), 3-10.

Sutton, A., Airini, Pinara, R. (2011, July). Auckland Pasifika education landscape: A snapshot in 2011. Report prepared for and presented at the Raise Pasifika Fono, Auckland, New Zealand.

Tajfel, H. (1974, April). Social identity and intergroup behaviour. Social Science Information/sur les sciences sociales, 13(2), 65-93.

doi: $10.1177 / 053901847401300204$

Tajfel, H. (1981). Human groups and social categories: Studies in social psychology. Cambridge, England: Cambridge University Press.

Tajfel, H., \& Turner, J. C. (1979). An integrative theory of intergroup conflict. The Social Psychology of Intergroup Relations, 33(47), 74. 
Tajfel, H., \& Turner, J. C. (1986). The social identity theory of intergroup behaviour. In S. Worchel \& W.G. Austin (Eds.), Psychology of intergroup relations (pp. 7-24). Chicago, Illinois, IL: Nelson-Hall Publishers.

Tamasese, T. K. (2008, September). Achieving wellbeing with Pacific peoples, families and communities: Considerations of gender, culture and socio-economic contexts. Paper presented at Creating Futures Conference, Cairns, QLD, Australia.

Tamasese, K., Peteru, C., \& Waldegrave, C. (1997). Ole taeao Afua:A qualitative investigation into Samoan perspectives on mental health and culturally appropriate services. Report for the Health Research Council of New Zealand. Wellington, New Zealand: The Family Centre.

Tamasese, K., Peteru, C., Waldegrave, C., \& Bush, A. (2005). Ole Taeao Afua, the new morning: A qualitative investigation into Samoan perspectives on mental health and culturally appropriate services. Australian and New Zealand Journal of Psychiatry, 39(4), 300-309.

Taufe'ulungaki, A. M. (2003). The role of research: A Pacific perspective. In E. Coxon (Ed.), Global/local intersections researching the delivery of aid to Pacific education (pp. 19-40). Auckland, New Zealand: Research Unit of Pacific Education (RUPE), The University of Auckland.

Taylor, J. (2011). The intimate insider: Negotiating the ethics of friendship when doing insider research. Qualitative Research, 11(1), 3-22.

Taylor, R. D., \& Oskay, G. (1995). Identity formation in Turkish and American late adolescents. Journal of Cross-Cultural Psychology, 26(1), 8-22

Teaiwa, T., \& Mallon, S. (2005). Ambivalent kinship Pacific people in New Zealand. In J. H. Liu, T. McCreanor, T. McIntosh, \& T. Teaiwa (Eds.), New Zealand Identities: Departures and destinations (pp. 207-229). Wellington, New Zealand: Victoria University of Press.

Thaman, K. H. (1997, September). Kakala: A Pacific concept of teaching and learning. Keynote address, Australian Colleges of Education Annual Conference, Cairns, QLD, Australia.

Thomas, G. (2010). Doing case study: Abduction not induction, phronesis not theory. Qualitative Inquiry, 16(7), 575-582. doi: 10.1177/1077800410372601.

Tiatia, J. (1998). Caught between cultures: A New Zealand-born Pacific Island perspective. Auckland, New Zealand: Christian Research Association. 
Timperley, H. S. (2007). The leadership of the improvement of teaching and learning: Lessons from initiatives with positive outcomes. Australian Journal of Education, 51(3), 247-262.

Tuafuti, P. (2011). Multiple challenges in research within the fa'asamoa context. Pacific-Asian Education, 23(2), 33-42.

Tuafuti, P., \& McCaffery, J. (2005). Family and community empowerment through bilingual education. International Journal of Bilingual Education and Bilingualism, 8(5), 480-503.

Tajfel, H. (1974, April). Social identity and intergroup behaviour. Social Science Information/sur les sciences sociales. 13(2), 65-93.

Tukuitonga, C. (2013). Pacific people in New Zealand. In I. St. George (Ed.), Cole's medical practice in New Zealand (Chapter 6, 12th ed., pp. 65-71). Wellington, New Zealand: Medical Council of New Zealand.

Tupuola, A. M. (1993). Raising research consciousness the Fa'a Samoa way. New Zealand Annual Review of Education, 3, 169-190.

Tupuola, A. M. (1998). 'Adolescence': Myth or reality for Samoan women? Beyond the stage-like toward shifting boundaries and identities (Unpublished doctoral thesis). Victoria University of Wellington, Wellington, New Zealand.

Tupuola, A. M. (2000). Pacific cultures in the teacher education curriculum. Module four: Making sense of human development, beyond western concepts and universal assumptions (pp. 1-19). Suva, Fiji: Institute of Education, University of the South Pacific.

Tupuola, A. M. (2004). Pasifika edgewalkers: Complicating the achieved identity status in youth research. Journal of Intercultural Studies, 25(1), 87-100.

Vaioleti, T. M. (2003, April). Talanoa research methodology: A perspective on Pacific research. Paper presented at the Power, Politics and Practise- Pasifika Educators Conference, Auckland, New Zealand.

Vaioleti, T. M. (2006). Talanoa research methodology: A developing position on Pacific research. Waikato Journal of Education, 12, 21-34.

Vallerand, R. J. (1997). Toward a hierarchical model of intrinsic and extrinsic motivation. In M. P. Zanna (Ed.), Advances in experimental social psychology (pp. 271-360). New York, NY: Academic Press. 
Walker, S. (2005). Culturally competent therapy: Working with children and young people. New York, NY: Palgrave Macmillan.

Walsham, G. (2006). Doing interpretive research. European journal of information systems, 15(3), 320-330

Waterman, A. S. (1985). Identity in the context of adolescent psychology. New Directions for Child and Adolescent Development, 1985(30), 5-24.

Weber, L. (1998). A conceptual framework for understanding race, class, gender, and sexuality. Psychology of Women Quarterly, 22(1), 3-22.

Weiner, B. (2005). Motivation from an attribution perspective and the social psychology of perceived competence. In A. J. Elliot, \& C. S. Dweck (Eds.), Handbook of competence and motivation (pp. 73-84). New York, NY: The Guilford Press.

Willmott, B. (1989). Introduction: Culture and national identity. In D. Novitz \& B. Willmott (Eds.), Culture and identity in New Zealand (pp. 1-20). Wellington, New Zealand: GP Books.

Wilson, S. (2010). Le Tofi ne'i Vale Tuulima: Perceptions of Samoan students, teachers and parents on the place of the Samoan language in New Zealand today (Master's thesis, Victoria University of Wellington, Wellington, New Zealand). Retrieved from http://researcharchive.vuw.ac.nz/handle/10063/9/browse?value=Wilson\%2C+Sal ainaoloa+Lisa-Maree\&type=author

Wyatt, S. (2009). The brotherhood: Empowering adolescent African-American males toward excellence. Professional School Counseling, 12(6), 463-470.

Zimmerman, B. J. (1998). Developing self-fulfilling cycles of academic regulation: An analysis of exemplary instructional models. In D. H. Schunk \& B. J. Zimmerman (Eds.), Self-regulated learning: From teaching to self-reflective practice (pp. 119). New York, NY: Guilford Publications.

Zimmerman, B. J. (2000). Self-efficacy: An essential motive to learn. Contemporary Educational Psychology, 25(1), 82-91.

Zimmerman, B. J., Bandura, A., \& Martinez-Pons, M. (1992). Self-motivation for academic attainment: The role of self-efficacy beliefs and personal goal setting. American Educational Research Journal, 29(3), 663-676. 


\section{APPENDIX 1}

February 2011

Dear Principal

\section{RE: PERMISSION TO RESEARCH YEAR 12 AND 13 SAMOAN BOYS' IN YOUR SCHOOL}

Talofa lava, my name is Fuapepe Rimoni and I am a doctoral student at Victoria University of Wellington conducting research on Year 12 and 13 Samoan boys in secondary schools. I am writing to ask your permission to conduct some of my research at your school during Terms 3 and 4 of the 2011 school year.

Currently school performance and achievement of male Pacific students in secondary schools is of concern. As a Samoan researcher and community member, I am particularly concerned about the possible effects of focusing on the "underachievement problem". Despite this, there are groups of Pacific students who do achieve and are highly successful academically and socially in New Zealand secondary schools.

The essence of this research is to capture the voice of Pacific students in particular the voices of high academic achieving Samoan boys within secondary school. The research on Pacific people and Pacific education is gradually increasing, however, the gap in identifying the needs of specific Pacific ethnic groups, is limited and therefore this study will contribute positively to the gap of research on Pacific people in education.

In order to conduct this research I am approaching secondary schools to take part in the study. The research will involve the principal to nominate three high academic Year 12 or 13 Samoan boys. I will also be asking the nominated Samoan boys to select other people to participate in semi-structured interviews and focus group interviews.

If you agree to allow students and teachers to take part in the study, the expected impact on your students and teachers will be minimal. I plan to interview selected boys' individually, teachers' in a focus group setting and use digital video diaries for peers. Each interview and focus group session will be negotiated on the available time slots of both selected boys' and teachers during class time and will take up two hours. 
Throughout the project, all attempts will be made to minimise the disruptive on your students' learning. Once the study is complete, your school will be provided with a summary of the research findings and any publications that result from the study. All those involved in the study will sign confidentiality forms. Your school will not be identified in any work generated from this study. All files generated from this study will be securely stored on a password-protected computer, and hard copies will be kept in secure storage for five years after the conclusion of the research before being deleted or destroyed. This project has been approved by the Victoria University of Wellington Faculty of Education Ethics committee.

If you agree to participate in this study please complete the consent form included with this letter and return it in the stamped and addressed envelope provided. If you do not wish to take part in the study your school's relationship with Victoria University of Wellington will not be affected in any way.

I would like to thank you for taking the time to read this overview of the project and hope you will agree to allow your school to take part in the study. If you have any questions about the study now or at any time in the future, please feel free to contact me using the following contact information: Fuapepe Rimoni, Te Kura Māori, Faculty of Education, Victoria University of Wellington, PO Box 17-310, Karori, Wellington, NZ or my supervisors Associate Professor Kabini Sanga, Te Kura Māori, Faculty of Education, Victoria University of Wellington, PO Box 17-310, Karori, Wellington, NZ, or Dr Anne Hynds, School of Educational Psychology and Pedagogy, Faculty of Education, Victoria University of Wellington, PO Box 17-310, Karori, Wellington, NZ.

Yours sincerely

F Rimoni

Fuapepe Rimoni

PhD student

Victoria University of Wellington

Faculty of Education 


\section{APPENDIX 2}

January 2011

Dear student

Talofa lava, my name is Fuapepe Rimoni and I am a doctoral student at Victoria University of Wellington doing research on Year 12 and 13 Samoan boys in secondary schools. I have taught in both Primary and Secondary school in the Hutt Valley for over 5 years and I am very interested in listening to the experiences of Year 12 and 13 Samoan boys' identified as high academic achievers in secondary school.

I am writing to ask if you would be willing to participate in my research. I want to understand what Year 12 and 13 Samoan boys' perceptions are of 'what contributes to their sense of belonging' in secondary school. I will be organising a time to have an interview with you, and ask you questions about your experiences.

If you decide to participate, you, your peer, teacher and caregiver, or school will not be identified in any way.

Thank you very much for taking the time to read about my project. If you would to participate in the study please complete the consent form with your parents and return it to your form teacher.

Yours sincerely

Fuapepe Rimoni

PhD student

Victoria University of Wellington

Faculty of Education

Te Kura Māori 


\section{APPENDIX 3}

\section{Research Questions}

The overall research question is: In what ways do tama Samoa experiences within a secondary school context contribute to their identity, sense of belonging, and future decisions?

\section{Sub-Questions}

1. In what ways are tama Samoa's identities influenced by their secondary school experiences?

2. What is the nature of the relationship between tama Samoa sense of belonging and their daily experiences within secondary school

3. What experiences have tama Samoa had during secondary school that have contributed to their aspirations for the future?

4. What is one positive experience you have had at this school?

5. What is it about your school that has helped/assisted/supported/guided you to get where you are today?

6. Who at this school has made the most influence on you?

7. What motivates you come to school/to do well at school?

8. How do you feel about your secondary school?

9. What are the highlights of being Samoan at your school?

10. What challenges have you had being Samoan at your school?

11. Is it important to identify with your Samoan culture at school? Why?

12. Does your school show that they value your Samoan ethnicity? How?

13. Do you consider yourself being Samoan at school?

14. How is this reflected when you're with your friends/classes/teachers? 
15. What do you consider to be your academic achievements at school?

16. Have you always been motivated to be successful at school?

17. What does being successful at school mean for you?

18. Do you believe you possess any special qualities that make you different from other Samoan students?

19. In what ways is being successful at school related to being Samoan? Can you be both if so how?

20. What does the word 'relationships' mean to you?

21. What do you believe a Snr. Samoa male student needs to succeed at school?

22. What groups do you belong in and why do you belong to those groups?

23. How do you interact within different groups you belong to at school?

24. What are your families' expectations of you being at school?

25. What support systems do you have at home?

26. What do you think your school could improve to support Snr Samoan male students?

27. Complete this sentence at the end of Year $13 \mathrm{I}$ will........

28. What are your aspirations for the future?

29. Who do wish to nominate so that I am able to interview about you? (names and contact details) 


\title{
APPENDIX 4
}

\author{
Fuapepe Rimoni \\ Lecturer \\ Victoria University of Wellington Faculty of Education \\ $\mathrm{C} /$ - Te Kura Māori \\ Donald Street \\ Wellington
}

Dear Fuapepe

\section{RE: Ethics Application TKM/2010/121: RM 18204}

I am pleased to advise you that your ethics application 'Samoan Boys' stories: Identity, achievement and belonging at school.' with the requested amendments, has been approved by the Victoria University of Wellington Faculty of Education Ethics Committee. Please note that the approval for your research to commence is from the date of this letter.

Best wishes for your research.

Yours Sincerely

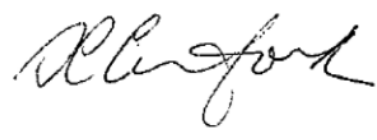

Dr Sue Cornforth

Co-Convener

Victoria University of Wellington Faculty of Education Ethics Committee 